\title{
ADUBAÇÃO NPK AFETANDO O DESENVOLVIMENTO DO CAULE DA SERINGUEIRA E PARÂMETROS FISIOLÓGICOS DO LÁTEX
}

\author{
Newton Paulo de Souza Falcão
}

Engenheiro Agrônomo

Orientador: Prof. Dr. Takashi Muraoka

Tese apresentada à Escola Superior de Agricultura "Luiz de Queiroz", da Universidade de São Paulo, para obtenção do título de Doutor em Agronomia, Área de Concentração: Solos e Nutrição de Plantas.

P I R A C I C A B A

Estado de São Paulo - Brasil

Maio de 1996 


\section{Dados Internacionais de Catalogação na Publicação (CIP) DIVISĀO DE BIBLIOTECA E DOCUMENTAÇẤO - Campus "Luiz de Queiroz"/USP}

Falcão, Newton Paulo de Souza

Adubação NPK afetando o desenvolvimento do caule da seringueira e

parâmetros do látex / Newton Paulo de Souza Falcão. - - Piracicaba, 1996.

$134 p$.

Tese (doutorado) - - Escola Superior de Agricultura Luiz de Queiroz, 1996.

Bibliografia.

1. Caule - Desenvolvimento 2. Látex - Parâmetros fisiológicos 3. Seringueira Adubação NPK - Efeito I. Título

CDD $\quad 633.895$ 


\section{ADUBAÇÃO NPK AFETANDO O DESENVOLVIMENTO dO CAULE dA SERINGUEIRA E PARÂMETROS FISIOLÓGICOS DO LÁTEX}

\section{NEWTON PAULO dE SOUZA FALCÃO}

Aprovada em: 23.08.1996

\section{Comissão Julgadora:}

Prof. Dr. Takashi Muraoka

CENA / USP

Prof. Dr. José Dias Costa

ESALQ / USP

Prof. Dr. Quirino A. de C. Carmello

ESALQ / USP

Profa Dra Maria A. P. da Cruz Centurion

UNESP/JABOTICABAL

Dr. Newton Bueno

EMBRAPA / CPAA

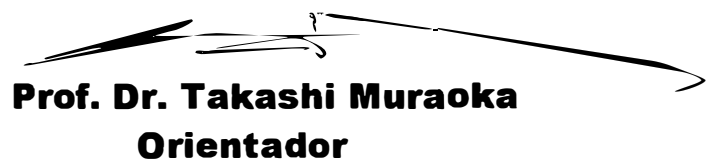


A Deus pela força espiritual.

"É preciso saber segui-lo para reconhecer o Senhor. Certa como a aurora é a sua vinda, ele virá até nós como as primeiras chuvas, como as chuvas tardias que regam o solo."

Livro do profeta Oséias (Os. 6, 3-6).

Aos meus pais

Nilson \& Cleonice Falcão

Ao meu sogro Carlos S. Filho

Minha eterna gratidão

A minha esposa Noélia

e as minhas filhas Nádia e Nivea

Ofereço este trabalho em reconhecimento a incansável paciência e compreensão nos momentos dificeis, e a tudo que representam para mim. 


\section{AGRADECIMENTOS}

- Ao Instituto Nacional de Pesquisas da Amazônia (INPA), à Escola Superior de Agricultura "Luiz de Queiroz" (ESALQ/USP) e ao Centro de Energia Nuclear na Agricultura (CENA) pela oportunidade de realizar este curso.

- Ao ex-diretor do Instituto Nacional de Pesquisas da Amazônia (INPA), Prof. Dr. Seixas Lourenço e ao ex-chefe de gabinete, Sr. José Edil Benedito, pela oportunidade.

- Ao IBAMA e a FAPESP pelo apoio financeiro.

- Ao Prof. Dr. Takashi Muraoka, pela orientação, compreensão, amizade e confiança depositada em minha pessoa.

- Ao Prof. Dr. Ronaldo Ivan Silveira, pela colaboração.

- Ao Prof. Dr. Antonio Enedi Boaretto, pelo incentivo e pela colaboração do laboratório de Nutrição Mineral de Plantas do CENA/USP.

- Ao Prof.Dr. Geraldo Victorino de França, ex-coordenador do Curso de Pós-Graduação em Solos e Nutrição de Plantas, pelo tratamento dispensado durante o curso de PósGraduação.

- Ao Prof. Dr. Dilermano Perecin pela proveitosa assessoria nas análises estatísticas.

- Ao Engenheiro Agrícola Luiz Roberto Takitane, gerente da Fazenda Mundo Novo, ao Sr. Hissashi e ao Grupo Sasazaki, pelo apoio logístico na execução do presente trabalho.

- Aos técnicos de laboratório: Marileuza A.B. Elias, Sandra T.Pereira, João O.Salvador, Henriqueta M.G.Fernandes.

- Ao técnico Agrícola do Departamento de Ciência do Solo da ESALQ, Sr. Dorival Grisotto pela colaboração nos trabalhos de campo.

- A amiga Maria A.Calegaro pela amizade, paciência e dedicação na digitação da tese.

- Aos Colegas de Pós-Graduação: Marcos F. Camargo, Adonias de Castro Virgens Filho e Marcos Murback, pela parceria ao longo da condução desta pesquisa.

- Aos demais companheiros de curso: Cassio Hamilton Abreu Junior, Edilson Brasil, Eduardo J. Maklouf Carvalho, Amarindo Fausto Soares, Rivaldo Vital dos Santos, Raffaella Rossetto,

A todos que direta ou indiretamente contribuiram para a realização do presente trabalho, externo meus sinceros agradecimentos. 


\section{SUMÁRIO}

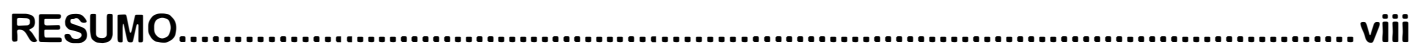

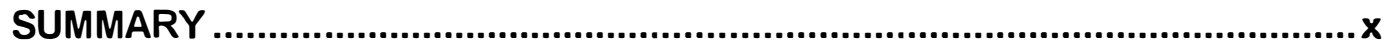

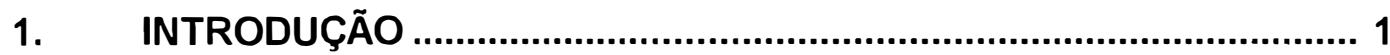

2. REVISÃO DE LITERATURA............................................................. 3

2.1. Histórico e Importância Econômica .......................................... 3

2.2. Aspectos Botânicos ............................................................. 6

2.3. Características Edafoclimáticas Requeridas pela Seringueira .......................................................................... 7

2.4. Efeito da Adubação Nitrogenada, Fosfatada e Potássica: .... 12

2.4.1. Na Fertilidade do Solo............................................. 12

2.4.2. No Desenvolvimento da Seringueira............................ 13

2.4.3. Na Concentração de Nutrientes nas Folhas .................. 16

2.4.4. Na Produção de Borracha Seca ................................. 17

2.5. Composição do Látex da Seringueira.................................... 20

2.6. Controle do Metabolismo do Látex.......................................21

2.7. Descrição e Significado dos Parâmetros Fisiológicos do Látex Relacionados com a Produção

2.7.1. Parâmetros Fisiológicos do Látex Relacionados com o Fluxo

2.7.2. Parâmetros Fisilógicos do Látex Associados com a Regeneração do Tecido Laticifero.

2.8. Diagnose Fisiológica do Látex e Produção da Seringueira.

2.8.1. Correlações Interparamétricas 26

2.9. Avaliação do Estado de Sub-Exploração ou de SuperExploração da Seringueira. 


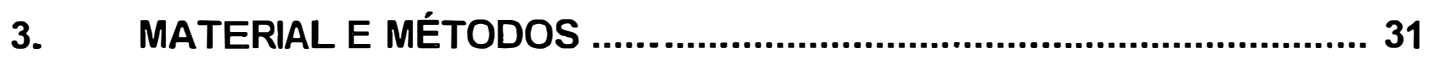

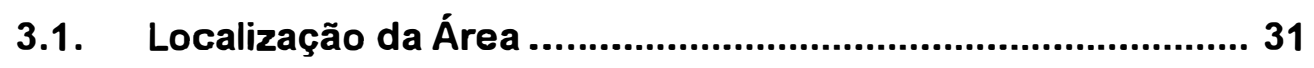

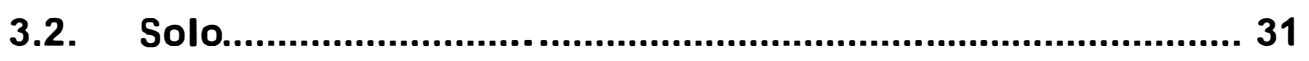

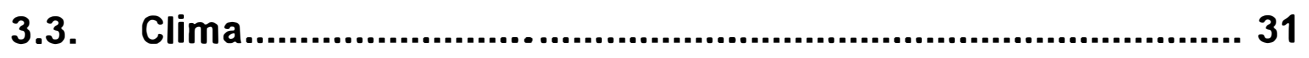

3.4. Área e Delineamento Experimental .................................... 32

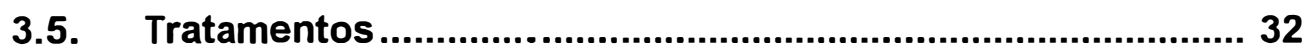

3.6. Instalação e Condução do Experimento................................ 33

3.7. Parâmetros Observados ........................................................ 36

3.7.1. Variação na Fertilidade do Solo .................................. 36

3.7.2. Concentração de Nutrientes nas Folhas ....................... 36

3.7.3. Perímetro do Tronco, Espessura da Casca e Produção Bimestral.................................................... 37

3.7.4. Diagnose do Látex por Parâmetros Fisiológicos ............. 38

3.7.4.1.Teores de Sacarose, Tióis, Fósforo Inorgânico, Magnésio, Cálcio e Potássio............................... 38

3.7.4.2. Conteúdo de Borracha Seca (\% DRC).............. 39

3.8. Análise Estatística do Experimento....................................... 41 
4.1. Aspectos Gerais da Fertilidade do Solo.

4.2. Influência dos Tratamentos em Algumas Características Químicas do Solo

4.3. Efeito da Adubação Nitrogenada, Fosfatada e Potássica no Estado Nutricional das Plantas

4.4. Efeito da Adubação Nitrogenada, Fosfatada e Potássica em Alguns Parâmetros de Crescimento.

4.5. Efeito da Adubação Nitrogenada, Fosfatada e Potássica no Perímetro do Caule e na Espessura da Casca do Caule da Seringueira

5. CONCLUSÕES 


\title{
ADUBAÇÃO NPK AFETANDO O DESENVOLVIMENTO DO CAULE DA SERINGUEIRA E PARÂMETROS FISIOLÓGICOS DO LÁTEX
}

\author{
Autor: Newton Paulo de Souza Falcão \\ Orientador: Prof.Dr. Takashi Muraoka
}

\section{RESUMO}

Com o objetivo de avaliar os efeitos das adubações nitrogenada, fosfatada e potássica sobre o desenvolvimento da seringueira, a redução do periodo de imaturidade, e alguns parâmetros fisiológicos do látex, nas condições edafoclimáticas do planalto do estado de São Paulo, conduziu-se um experimento de campo, instalado em Garça (SP), em solo Podzólico Vermelho Amarelo, variação Marilia (Pml).

O plantio foi efetuado em janeiro de 1984. O experimento de adubação iniciou-se em novembro de 1987. O clone utilizado foi o PB 235. A área total do experimento foi de $46080 \mathrm{~m}^{2}$, instalado em blocos ao acaso, em esquema fatorial fracionário $(1 / 4) 4^{3}$, totalizando 16 tratamentos e 4 repetições. Cada parcela, de $720 \mathrm{~m}^{2}$, continha 30 plantas dispostas em 3 linhas, em espaçamento de $8,0 \times 3,0 \mathrm{~m}$.

Os tratamentos foram constituídos pela combinação de quatro níveis de $\mathrm{N}, \mathrm{P}_{2} \mathrm{O}_{5}$ e $\mathrm{K}_{2} \mathrm{O}$. Os tratamentos testados foram: $\mathrm{N}_{0} \mathrm{P}_{0} \mathrm{~K}_{0}, \mathrm{~N}_{1} \mathrm{P}_{1} \mathrm{~K}_{0}, \mathrm{~N}_{1} \mathrm{P}_{0} \mathrm{~K}_{1}, \mathrm{~N}_{0} \mathrm{P}_{1} \mathrm{~K}_{1}$, $N_{1} P_{1} K_{1}, N_{2} P_{1} K_{1}, N_{3} P_{1} K_{1}, N_{1} P_{2} K_{1}, N_{1} P_{3} K_{1}, N_{1} P_{1} K_{2}, N_{1} P_{1} K_{3}, N_{2} P_{1} K_{2}, N_{3} P_{1} K_{2}, N_{2} P_{1} K_{3}$, $\mathrm{N}_{2} \mathrm{P}_{2} \mathrm{~K}_{2}$ e $\mathrm{N}_{3} \mathrm{P}_{3} \mathrm{~K}_{3}$. As fontes utilizadas foram: uréia $\left(450 \mathrm{~g} \mathrm{~kg}^{-1}\right.$ de $N$ ), superfosfato simples $\left(180 \mathrm{~g} \mathrm{~kg}^{-1}\right.$ de $\left.\mathrm{P}_{2} \mathrm{O}_{5}\right)$ e cloreto de potássio $\left(600 \mathrm{~g} \mathrm{~kg}^{-1}\right.$ de $\left.\mathrm{K}_{2} \mathrm{O}\right)$.

Do quarto ao sexto ano, utilizou-se $00,40,80$ e $160 \mathrm{~kg} \mathrm{ha}^{-1} \mathrm{ano}^{-1} \mathrm{de}$ $\mathrm{N} ; \quad 00,35,70$ e $140 \mathrm{~kg} \mathrm{ha}^{-1}$ ano $^{-1}$ de $\mathrm{P}_{2} \mathrm{O}_{5}$ e $00,35,70$ e $140 \mathrm{~kg} \mathrm{ha}^{-1}$ ano $^{-1}$ de $\mathrm{K}_{2} \mathrm{O}$. No sétimo ano as doses utilizadas foram $00,60,120$ e $240 \mathrm{~kg} \mathrm{ha}^{-1} \mathrm{ano}^{-1}$ de $\mathrm{N} ; \quad 00,35,70$ e $140 \mathrm{~kg} \mathrm{ha}^{-1} \mathrm{ano}^{-1}$ de $\mathrm{P}_{2} \mathrm{O}_{5}$ e 00, 40, 80 e $160 \mathrm{~kg} \mathrm{ha}^{-1} \mathrm{ano}^{-1}$ de $\mathrm{K}_{2} \mathrm{O}$. No oitavo ano utilizou-se 00, 75, 150 e $300 \mathrm{~kg} \mathrm{ha}^{-1} \mathrm{ano}^{-1}$ de $\mathrm{N} ; 00,35,70$ e $140 \mathrm{~kg} \mathrm{ha}^{-1} \mathrm{ano}^{-1}$ de $\mathrm{P}_{2} \mathrm{O}_{5} ; 00,50,100$ e $200 \mathrm{~kg} \mathrm{ha}^{-1}$ ano $^{-1}$ de $\mathrm{K}_{2} \mathrm{O}$. Do nono ao 
décimo primeiro anos foram utilizadas $00,80,160$ e $320 \mathrm{~kg} \mathrm{ha}^{-1} \mathrm{ano}^{-1}$ de $\mathrm{N} ; 00,40$, 80 e $160 \mathrm{~kg} \mathrm{ha}^{-1}$ ano $^{-1}$ de $\mathrm{P}_{2} \mathrm{O}_{5}$ e 00, 80, 160 e $320 \mathrm{~kg} \mathrm{ha}^{-1}$ ano ${ }^{-1}$ de $\mathrm{K}_{2} \mathrm{O}$.

Os parâmetros de crescimento foram coletados das 6 plantas centrais de cada parcela experimental, sendo a circunferência do tronco medida semestralmente, do quarto ao décimo primeiro ano; a espessura da casca foi mensurada no quarto, quinto e décimo primeiro anos de desenvolvimento das plantas. Para a diagnose do látex, foram retiradas amostras de 3 plantas úteis, de cada parcela experimental, no décimo primeiro ano, totalizando 192 amostragens.

O solo continuou ácido, com baixos teores de $\mathrm{Ca}$ e $\mathrm{Mg}$ trocáveis, necessitando, portanto, de uma calagem com calcário magnesiano. O K trocável encontrava-se baixo para a maioria dos tratamentos, requerendo a aplicação de dose mais alta $\left(320 \mathrm{~kg} \mathrm{ha}^{-1}\right)$.

A concentração de $N, P$ e $S$ nas folhas, e o teor de $P$ no solo encontrava-se em níveis adequados, portanto, recomenda-se adubação de manutenção.

A análise foliar efetuada em fevereiro de 1995 revelou baixos teores de $\mathrm{Cu}$ e $\mathrm{B}$, mostrando a necessidade de adubação para elevar a concentração desses micronutrientes nas seringueiras.

O $\mathrm{K}$ proporcionou maior desenvolvimento da seringueira $e$ apresentou resposta de natureza linear. Entre os níveis estudados, o nível $\mathrm{N}_{1} \mathrm{P}_{1} \mathrm{~K}_{3}$ foi quem possibilitou que a seringueira atingisse o diâmetro adequado para o início de exploração aos sete anos de idade.

As doses de $\mathrm{N}$ diminuiram o teor de fósforo inorgânico (Pi) de 29,45 para $15,72 \mathrm{mM}$; aumentaram o teor de sacarose de 1,79 para $3,07 \mathrm{mM}$; aumentaram a relação $\mathrm{Mg}^{++} / \mathrm{Pi}$ de 0,41 para $0,72 \mathrm{mM}$ no látex.

As doses de $\mathrm{P}_{2} \mathrm{O}_{5}$ diminuiram a percentagem de borracha seca $(\%$ DRC) de 34,23 para $29,50 \%$ no látex. As plantas que receberam o tratamento 80 $\mathrm{kg} \mathrm{ha}^{-1} \mathrm{ano}^{-1}$ de $\mathrm{N}, 160 \mathrm{~kg} \mathrm{ha}^{-1} \mathrm{ano}^{-1}$ de $\mathrm{P}_{2} \mathrm{O}_{5}$ e $80 \mathrm{~kg} \mathrm{ha}^{-1} \mathrm{ano}^{-1}$ de $\mathrm{K}_{2} \mathrm{O}$ apresentaram valores dos parâmetros fisiológicos indicando uma situação de super-exploração. As plantas dos tratamentos que receberam as menores doses de nitrogênio (00 e $80 \mathrm{~kg} \mathrm{ha}^{-1}$ ano $^{-1}$ ) também mostraram uma tendência de superexploração. 


\title{
NPK FERTILIZATION AFFECTING THE RUBBER TREE STEM \\ DEVELOPMENT AND PHYSIOLOGICAL PARAMETERS OF LATEX
}

\author{
Author: Newton Paulo de Souza Falcão
}

Adviser: Prof.Dr. Takashi Muraoka

\section{SUMMARY}

The effects of nitrogen, phosphorus and potassium fertilizations on the growth of rubber tree (Hevea brasiliensis Muell. Arg.), reduction of its period of immaturity and on some physiological parameters of latex were investigated. The study, started in 1987, was carried out at the Mundo Novo farm (Garça-São Paulo, Brazil), in an Ultisol, with a crop planted in 1984. The clone was PB 235.

The experiment was conducted in a fractional factorial $(1 / 4) 4^{3}$, and random block design with 16 treatments and 4 replications. Each plot, of $720 \mathrm{~m}^{2}$, contained 30 plants in three rows, spaced $8.0 \times 3.0 \mathrm{~m}$.

The treatments consisted of combination of four levels of $\mathrm{N}_{1}$ of $\mathrm{P}_{2} \mathrm{O}_{5}$ and of $\mathrm{K}_{2} \mathrm{O}: \mathrm{N}_{0} \mathrm{P}_{0} \mathrm{~K}_{0} ; \mathrm{N}_{1} \mathrm{P}_{1} \mathrm{~K}_{0} ; \mathrm{N}_{1} \mathrm{P}_{0} \mathrm{~K}_{1} ; \mathrm{N}_{0} \mathrm{P}_{1} \mathrm{~K}_{1} ; \mathrm{N}_{1} \mathrm{P}_{1} \mathrm{~K}_{1} ; \mathrm{N}_{2} \mathrm{P}_{1} \mathrm{~K}_{1} ; \mathrm{N}_{3} \mathrm{P}_{1} \mathrm{~K}_{1} ; \mathrm{N}_{1} \mathrm{P}_{2} \mathrm{~K}_{1}$; $N_{1} P_{3} K_{1} ; N_{1} P_{1} K_{2} ; N_{1} P_{1} K_{3} ; N_{2} P_{1} K_{2} ; N_{3} P_{1} K_{2} ; N_{2} P_{1} K_{3} ; N_{2} P_{2} K_{2}$ e $N_{3} P_{3} K_{3}$. The fertilizers sources utilized was urea $\left(450 \mathrm{~g} \mathrm{~kg}^{-1} \mathrm{~N}\right)$ ordinary superphosphate $\left(180 \mathrm{~g} \mathrm{~kg}^{-1} \mathrm{P}_{2} \mathrm{O}_{5}\right)$ and potassium chloride $\left(60 \mathrm{~g} \mathrm{~kg}^{-1} \quad \mathrm{~K}_{2} \mathrm{O}\right)$.

The NPK rates utilized were: a) during $4^{\text {th }}$ to $6^{\text {th }}$ year, $00,40,80$ and $160 \mathrm{~kg} \mathrm{ha}^{-1}$ of $\mathrm{N} ; 00,35,70$ and $140 \mathrm{~kg} \mathrm{ha}^{-1} \mathrm{P}_{2} \mathrm{O}_{5}$ and $00,35,70$ and $140 \mathrm{~kg} \mathrm{ha}^{-1}$ $\left.\mathrm{K}_{2} \mathrm{O}, \mathrm{b}\right)$ in the $7^{\text {th }}$ year, $00,60,120$ and $240 \mathrm{~kg} \mathrm{ha}^{-1}$ of $\mathrm{N} ; 00,35,70$ and $140 \mathrm{~kg}$ $\mathrm{ha}^{-1} \mathrm{P}_{2} \mathrm{O}_{5}$ and $00,40,80$ and $160 \mathrm{ha}^{-1} \mathrm{~K}_{2} \mathrm{O} ; \mathrm{c}$ ) in the $8^{\text {th }}$ year; 00, 75, 150 and 300 $\mathrm{kg} \mathrm{ha}^{-1}$ of $\mathrm{N} ; 00,35,70$ and $140 \mathrm{~kg} \mathrm{ha}^{-1}$ of $\mathrm{P}_{2} \mathrm{O}_{5} ; 00,50,100$ and $200 \mathrm{~kg} \mathrm{ha}^{-1}$ of $\left.\mathrm{K}_{2} \mathrm{O}, \mathrm{d}\right)$ during $9^{\text {th }}$ and $12^{\text {th }}$ years, $00,80,160$ and $320 \mathrm{~kg} \mathrm{ha}^{-1}$ of $\mathrm{N} ; 00,40,80$ and $160 \mathrm{~kg} \mathrm{ha}^{-1}$ of $\mathrm{P}_{2} \mathrm{O}_{5}$ and $00,80,160$ and $320 \mathrm{~kg} \mathrm{ha}^{-1}$ of $\mathrm{K}_{2} \mathrm{O}$. 
The growth parameters were collected from the six central plants of each plot. The trunk girths were measured at the intervals of six months, in the period of fourth to twelfth years and the bark thicknesses were measured in the four, five and twelve years old trees. Latex samples of three central plants of each plot were collected during cropping season of 1994/1995, for latex diagnosis.

The soil remained acid, with low exchangeable $\mathrm{Ca}$ and $\mathrm{Mg}$ contents, requiring, therefore, a liming with dolomitic lime. The exchangeable $\mathrm{K}$ contents were also low in most of treatment, needing application of higher dosis $(320 \mathrm{~kg}$ $\left.h a^{-1}\right)$. The leaf $N, P$, and $S$ and soil $P$ contents were in the adequate levels. It is, therefore, recommended the maintenance fertilization.

Potassium increased significantly the rubber tree growth and showed linear response to this parameters.

The treatment which gave adequate trunk girth to start explotation at the age of seven years was $N_{1} P_{1} K_{3}$.

The increasing rate of nitrogen reduced the latex inorganic phosphorus $(\mathrm{Pi}$ ) content from 29.45 to $15.72 \mathrm{mM}$; increased slightly the sucrose content from 1.79 to $3.07 \mathrm{mM}$; and increased the $\mathrm{Mg}^{++} / \mathrm{Pi}$ ratio from 0.41 to $0.72 \mathrm{mM}$ in the latex.

The increased rate of phosphorus decreased the latex Dry Rubber Content (\% DRC) from 34.23 to $29.50 \%$. The rubber trees which received the 80 $160-80$ rate presented values of physiological parameters indicating overexplotation.

The plants from the treatments with the lowest rates of $\mathrm{N}(0$ and 80 $\mathrm{kg} \mathrm{ha}^{-1}$ year $^{-1}$ ) showed also a tendency of over-explotation. 


\section{INTRODUÇÃO}

A produção brasileira de borracha natural, durante um longo periodo, foi oriunda dos seringais nativos da floresta Amazônica, e somente a partir de 1987 é que a produção de seringais de cultivo passaram a predominar, com o aumento da exploração de seringais plantados, principalmente, nos Estados de São Paulo, Mato Grosso, Bahia e Espírito Santo.

Os seringais implantados no planalto do Estado de São Paulo vêm apresentando bons resultados de desenvolvimento e produção. No entanto, algumas limitações exigem esforços concentrados de pesquisas para superá-las, destacando-se neste contexto os trabalhos nas áreas de adubação, nutrição e fisiologia da cultura, no sentido de tornar mínimo elou anular os efeitos negativos dos fatores edáficos que podem limitar o desenvolvimento e a produção da seringueira.

A literatura ainda limitada sobre a adubação da seringueira mostra que muitas vezes a resposta à aplicação de fertilizantes tem sido inconsistente, particularmente para alguns nutrientes, como o nitrogênio e o potássio. Tais fatos que levam a conclusão precipitada de que a adubação seria desnecessária para a seringueira, não podem ser tomados como definitivos. Alguns resultados experimentais tem evidenciado o efeito benéfico da aplicação de fertilizantes, não somente na fase de desenvolvimento como também na fase produtiva.

Os fatores primários limitantes na produção de látex da seringueira são: o fluxo que governa a quantidade de látex coletado durante a sangria e a regeneração do material celular entre duas sangrias. Sabe-se que quanto maior for a intensidade 
do fluxo, maior será a produção de látex. Quando o intervalo entre duas sangrias for suficiente para a regeneração total das células, este deixa de ser um fator limitante da produção.

$\mathrm{Na}$ diagnose do látex são determinados: $\mathrm{O} \mathrm{pH}$ a nivel de campo, extrato seco (\%ES), conteúdo de borracha seca (\%DRC), sacarose, fósforo inorgânico, tióis, magnésio e a relação $\mathrm{Mg} / \mathrm{Pi}$. Todos esses parâmetros fisiológicos do látex estão relacionados com os processos envolvidos no fenômeno de fluxo e a regeneração do tecido laticífero, tornando possivel avaliar a qualidade desses dois fatores essenciais para um dado tipo de planta em um tempo determinado. Conhecimento desses dados devem, por isso, ser úteis na determinação da capacidade produtiva de árvores estudadas.

A diagnose do látex é utilizada para orientar e otimizar a exploração de tal forma que evite o esgotamento dos sistemas laticiferos.

Portanto, torna-se necessário estudar para as condições do Estado de São Paulo, as possiveis limitações de ordem nutricional e fisiológica, durante os diferentes estádios de desenvolvimento da seringueira, bem como elaborar recomendações técnicas e agronômicas adequadas para sanar ou minimizar esses problemas.

O presente trabalho tem por objetivo avaliar a influência de diferentes níveis de nitrogênio, fósforo e potássio na redução do tempo para início da sangria, e em alguns parâmetros fisiológicos do látex da seringueira cultivada no planalto do estado de São Paulo. 


\section{REVISÃO DE LITERATURA}

\subsection{Histórico e Importância Econômica}

Os mais antigos relatos sobre a borracha vieram da América Central, onde bolas e outros objetos eram fabricados com ela. Obtinha-se essa borracha a partir do látex de árvores do gênero Castilhas (ou Castilloa). Colhida na selva, a borracha da Castilla, ou caucho, constituía um modesto artigo do comercio internacional até meados do século XVIII. Por volta de 1750 botas do exército, mochilas e outros artigos às vezes eram mandados de Lisboa para Belém a fim de ser impermeabilizadas (Dean, 1989).

A coleta de sementes bem sucedida pelo inglês Henry Alexander Wickham em 1876 foi um marco importante na domesticação da seringueira. Em 1872 Wickham publicou um livro sobre suas viagens da Venezuela ao Brasil e em 1870 contatou J.D. Maym, cônsul britânico em Belém e obteve uma cópia de um relatório que mostrava que as melhores seringueiras eram de Hevea brasiliensis da região do rio Tapajós (Gonçalves \& Cardoso, 1987).

Com ajuda dos índios Mura, Wickham teria coletado 70.000 sementes de seringueiras e enviadas a Londres pelo navio "Amazonas", que deixou o porto de Belém em 29-5-1876, as sementes chegaram ao seu destino dezesseis dias depois. Aproximadamente 2.800 das 70.000 sementes germinaram em casa de vegetação. A rapidez de crescimento das plântulas nas casas de vegetação do Jardim Botânico Real, no subúrbio de Kew, exigiu seu embarque imediato para os trópicos, e seu destino eventual 
foi o Jardim Botânico do Ceilão. Esse foi o ponto de partida das plantações que se estabeleceram na Ásia a partir de então (Gonçalves \& Cardoso, 1987; Dean, 1989)

$O$ interesse pela borracha aumentou, ainda mais, com as novas descobertas de suas propriedades e usos. A principal descoberta ocorreu em 1939, quando o americano Charles Goodyear e o inglês Thomas Hancock ampliaram muitíssimo as aplicações potenciais da borracha graças à descoberta da possibilidade de ela ser estabilizada quimicamente com a mistura de enxofre em presença de calor-processo conhecido pelo nome de vulcanização (Gonçalves et al., 1983; Dean, 1989)

Devido ao expressivo interesse pela cultura, por volta de 1910, os paises do Império Britânico da Ásia iniciavam suas exportações. Nesta fase o Brasil atingiu o maior volume de exportações, oriundas do extrativismo, com cerca de 31,1 mil toneladas. A última remessa expressiva do Brasil ocorreu em 1947, onde foram exportadas somente 7.000 toneladas (Miranda et al., 1975; Dean, 1989; Martin \& Arruda, 1993).

A introdução da seringueira no Estado de São Paulo aconteceu em 1916 no distrito de Gavião Peixoto, município de Boa Esperança do Sul, SP. Em 1942, o Instituto Agronômico de Campinas efetuou plantio de progênie de sementes originadas de Gavião Peixoto, em diversas Estações Experimentais (Cortez, 1986).

A partir de 1981, com a criação do PRÓ-BORRACHA, programa estadual de borracha natural, coordenado pela Coordenadoria de Assistência Técnica Integrada (CATI), os seringais implantados no Estado de São Paulo cresceram de forma significativa. Uma avaliação sobre a extensão dos plantios nos anos agrícolas 1978/1985, demonstrou um aumento de mais de sete vezes na área plantada (Cortez, 1986).

Por outro lado, a produção nacional esteve praticamente estabilizada nos anos 70 , crescendo de 1980 , até 1985, quando atingiu 40,4 mil toneladas e decrescendo nos anos 
seguintes. Desta forma, a participação no consumo nacional de $67,98 \%$ em 1970, decrosceu, com algum período de recuperação no início dos anos 80 , e atingiu, em 1992, uma participação de apenas $24,31 \%$, sendo o menor do período. Por outro lado, o consumo cresceu, cerca de $5,27 \%$ ao ano, sendo que, a partir da recessão econômica iniciada em 1990, entrou em estagnação e em 1992 sofreu uma redução de $10 \%$ (Martin \& Arruda, 1993).

$O$ aumento contínuo do consumo brasileiro de borracha natural tem sido suprido com importações crescentes do Sudeste Asiático, De uma importação de 11.763 toneladas em 1970, cresceu para 93.672 toneladas em 1989, decrescendo em 1992 para um total de 81.504 toneladas. A produção nacional estimada para 1992, seria de 26.181 toneladas, sendo 9.181 de seringais nativos e 17.000 de seringais de cultivos. São Paulo surge como maior produtor nacional com $27 \%$ de participação (Martin \& Arruda, 1993).

A produção de borracha natural no Sudeste Asiático e na África atingiu 5,34 milhões de toneladas em 1991, crescendo mais de $3 \%$ ao ano, em média, nos últimos quinze anos. Mesmo tendo sua produção distribuída em vários países, cerca de $75 \%$ a $85 \%$ concentram-se na Malásia, Tailândia e Indonésia, sendo a Tailândia o maior produtor com 1,5 milhões de t/ano, seguido da Indonésia com 1,25 milhões, e da Malásia com 1,1 milhão. O Brasil com sua produção de 29,6 mil toneladas em 1991 é um produtor inexpressivo no cenário mundial. Em 1993 o consumo brasileiro foi de 125 mil toneladas, com uma produção de 31 mil toneladas, sendo $40 \%$ proveniente de produção extrativa (Martin \& Arruda, 1993; Associação Paulista de Produtores e Beneficiadores de Borracha, 1994).

Somente no Estado de São Paulo, existe atualmente cerca de 37.000 ha de seringais plantados. O acompanhamento da produção, do consumo e do estoque mundial de borracha natural, nos últimos cinco anos, tem mostrado que, em janeiro de 1990 a produção se equilibrava ao consumo, girando em torno de 
5.100.000 t/ano. Embora em janeiro de 1994 a produção (5.200.000 t/ano) tenha sido inferior ao consumo $\mathbf{( 5 . 4 0 0 . 0 0 0}$ t/ano), o quadro se inverteu e em janeiro de 1995, com a produção alcançando 6.000 .000 t/ano, superando o consumo que ficou em torno de 5.700 .000 t/ano. Isto explica o aumento no estoque e a queda do preço no mercado mundial (International Rubber Digest, 1995).

\subsection{Aspectos Botânicos}

Em 1749, F. Fresnau descreveu a primeira espécie do gênero Hevea, a qual foi posteriormente identificada, em 1775 , por J.B. Fusée Aublet, como sendo a Hevea guianensis. Apesar do nome Hevea ter sido mantido até a atualidade pelo Código Internacional de Nomenclatura, em 1779, a sua mudança foi sugerida por Richard que propôs a denominação de Siphonia brasiliensis, sob autoria de Willdenow, com base nos desenhos diagnosticados de uma coleção feita por Siebert, provavelmente de uma das principais produtoras do Baixo Amazonas. Atualmente, esta espécie tem a denominação de Hevea brasiliensis (Willd. ex. Adr. de Juss.) Muell Arg.], sendo a principal produtora de borracha natural (Ducke, 1946 ; Gonçalves, 1986).

A seringueira pertence a família das Euforbiáceas. É uma dicotiledonea monóica, isto é, possui flores masculinas e femininas em um mesmo individuo. As flores são unissexuadas, pequenas, amareladas e dispostas em rácemos $e$ as folhas longamente pecioladas e repartidas em três folíolos. O fruto é uma cápsula grande que geralmente apresenta 3 sementes. Quando plenamente desenvolvida a seringueira pode alcançar até 50 metros de altura (Cardoso, 1980). 


\subsection{Caracteristicas Edafoclimáticas Requeridas pela Seringueira}

O gênero Hevea ocorre naturalmente em área superior a 4 milhões de $\mathrm{Km}^{2}$, abrangendo $3^{\circ}$ de latitude Norte a $15^{\circ}$ de latitude Sul no continente americano. A importância da cultura da seringueira para o ser humano, determinou a sua expansão geográfica, abrangendo regiões bem diferenciadas das suas áreas de origem. Atualmente as regiões de produção compreendem latitudes de $24^{\circ}$ ao Norte da China até $25^{\circ}$ ao Sul do Brasil. A possibilidade de cultivo comercial em áreas com climas tão diferenciados exige, como premissa básica, o desenvolvimento e adaptação de tecnologia de produção (Ortolani, 1987)

A distribuição do gênero Hevea na região amazônica abrange uma área em torno de seis milhões de $\mathrm{Km}^{2}$, onde este gênero, sem dúvida, localiza-se seis extremos tendo como limites na América do Sul, aproximadamente $6^{\circ}$ Norte, $15^{\circ}$ Sul, $46^{\circ}$ Leste e $77^{\circ}$ Oeste de Gr. W., também reconhecido como limites extremos da floresta amazônica (Figura 1) (Superintendência da Borracha, 1971a).

A temperatura média anual de $20^{\circ} \mathrm{C}$ tem sido adotada como um limite mínimo para o cultivo da seringueira, sendo de $26^{\circ}$ a $28^{\circ} \mathrm{C}$ a faixa tida como ideal para o seu bom desenvolvimento. Temperaturas muito baixas são consideradas limitantes por afetar - desenvolvimento, podendo ocasionar lesões tão graves que acabam por matá-las. Limites térmicos mais favoráveis à fotossintese da espécie estão entre $27^{\circ}$ e $30^{\circ} \mathrm{C}$.

Lemos Filho et al. (1991) observaram que folhas maduras de seringueiras podem apresentar maior tolerância a baixas temperaturas que as da cana-de-açúcar e as de cafeeiro, ressaltando que variações podem ocorrer, dependendo do estado nutricional e das características genéticas dos diversos clones de seringueiras. 


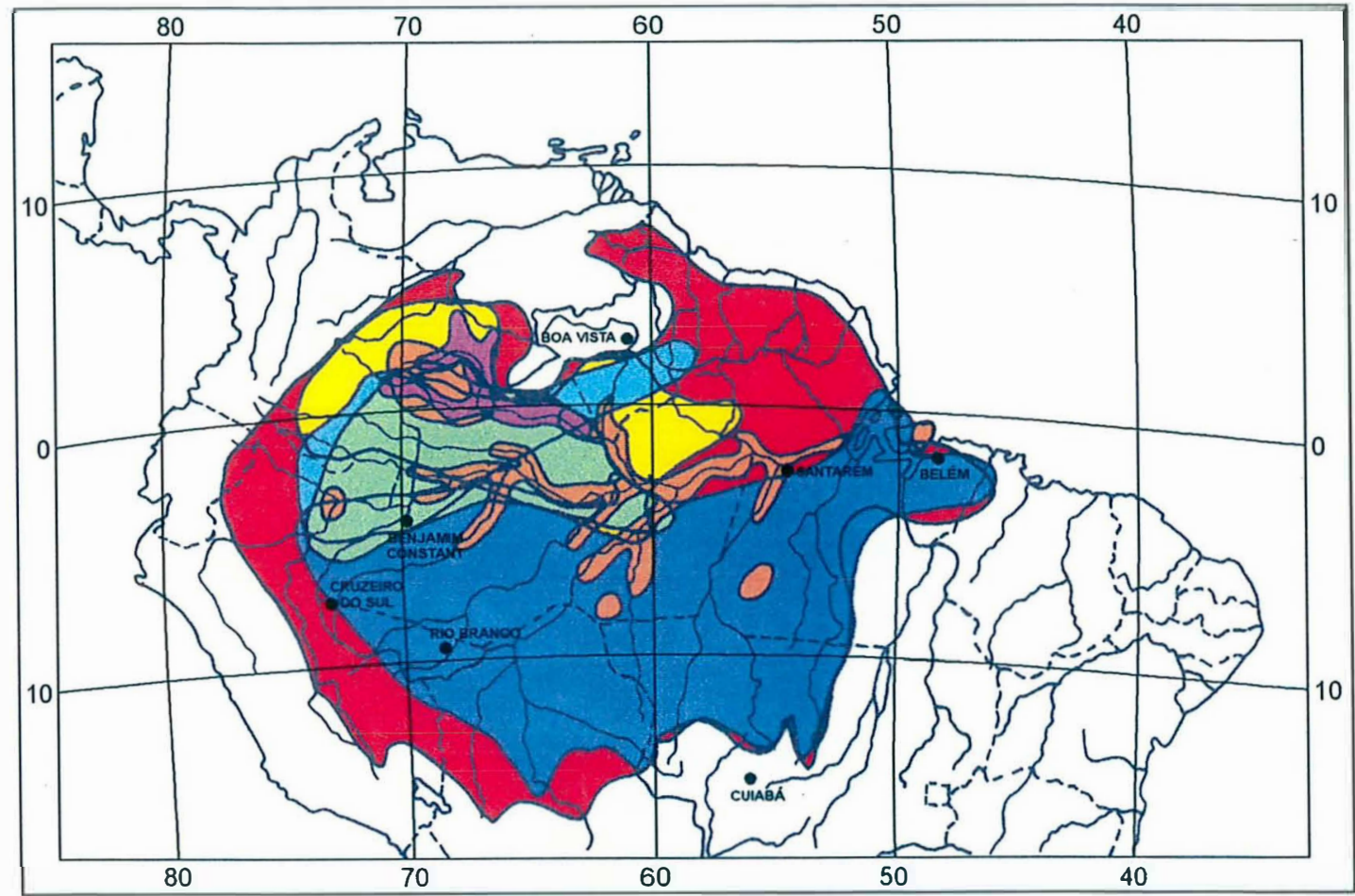

Hevea microphylla

Hevea pauciflora

Hevea guianensis
Hevea spruceana

Hevea benthamiana
Hevea nitida

Hevea brasiliensis

Figura 1. Limites extremos da distribuição do gênero Hevea na Amazônia (Fonte: Superintendência da Borracha, 1971a) 
Para o fluxo de látex, o intervalo entre $18^{\circ}$ e $28^{\circ} \mathrm{C}$, é o mais indicacio. Em relação as exigências hídricas, após o pleno desenvolvimento do sistema radicular, mesmo na juvenilidade, a seringueira demonstra boa tolerância a periodos prolongados de estiagem. Na maturidade, com o aprofundamento do sitiam radicular, essa tolerância é mais elevada (Cardoso, 1980 e Ortolani, 1987).

O adequado desenvolvimento do sistema radicular e a disponibilidade de água e nutrientes minerais no solo, são fatores preponderantes para o desenvolvimento vegetativo e consequentemente produção de látex. O relevo também é um fator importante que deve ser considerado pois, relevo muito acentuado tende a aumentar o custo de instalação, dificultar o controle da erosão e onerar a colheita.

A profundidade e a permeabilidade do solo são fatores preponderantes para a infiltração de água e para o desenvolvimento do sistema radicular. Camadas compactadas, solos lateríticos (Plintossolos) e lençol freático muito raso (menos de $1 \mathrm{~m}$ abaixo da superfície do solo) podem limitar o desenvolvimento das raízes, retardando o desenvolvimento das plantas e favorecer o tombamento das mesmas devido ao desequilibrio entre volume de raiz e volume de copa, levando a uma baixa produção.

As características físicas do solo são fatores importantes para o adequado desenvolvimento do sistema radicular, e capacidade de retenção de água. Krishnakumar et al. (1990), avaliando a influência de um seringal cultivado nas propriedades físicas do solo, observaram que o próprio plantio contribuiu para o enriquecimento da matéria orgânica do solo, com conseqüente melhoria das propriedades físicas, tais como: densidade aparente, porosidade total, retenção de umidade e infiltração. Estudos de infiltração revelaram que a relação do fluxo inicial e após o estabelecimento do plantio foram respectivamente, 
de $67.5 \%$ e $138 \%$ mais altas dentro do plantio, comparadas com avaliações efetuadas em culturas anuais.

Solos com textura muito argilosa e solos de textura muito arenosa limitaram o crescimento e a produção de látex. Solos arenoargilosos são os mais adequados. A presença de partículas grossas no perfil do solo não apresenta limitações se o conteúdo dessas partículas não ultrapassar 30\% (Chan et al., 1974).

Chan \& Pushparajah (1972), avaliando a produtividade da seringueira em solos com diferentes classes texturais, observaram que plantios instalados em solos contendo somente $5 \%$ de areia, produziram um pouco mais da metade da produção alcançada em plantios instalados em solos com $20 \%$ de areia.

Solos hidromórficos são desfavoráveis para o desenvolvimento e produção da seringueira. Solos com boa drenagem até uma profundidade de $50 \mathrm{~cm}$, apresentaram uma produção acumulada de até $5823 \mathrm{~kg}$ de borracha seca/ha/ano em um intervalo de 2 a 7 anos. Por outro lado, solos com boa drenagem até $100 \mathrm{~cm}$ de profundidade foi observado uma produção acumulada de até $7156 \mathrm{~kg}$ de borracha seca/ha/ano neste mesmo intervalo de tempo (Rubber Research Institute of Malaya, 1971).

Os solos onde ocorrem a maior parte dos seringais nativos estão situados na Amazônia legal e são extremamente pobres na sua fertilidade natural, especialmente em fósforo e bases trocáveis. Além desta pobreza, apresentam teores elevados de alumínio tóxico, associados a índices de $\mathrm{pH}$ muito baixo (Haag et al., 1986).

Observações feitas em vários locais da Amazônia e comparados com trabalhos existentes no Oriente, sugerem que a cultura da seringueira é pouco exigente em solo, notando-se, porém, que em solo de textura argilosa, o comportamento das plantas é melhor do que nas de textura arenosa ou média (Superintendência da Borracha, 1971b). 
Por outro lado, Cardoso (1980) discorda dessa afirmativa, dizendo que o tipo de solo mais adequado para a seringueira é aquele que apresenta uma relativa fertilidade em elementos minerais, indice de $\mathrm{pH}$ em torno de 5,5 a 6,5 , propriedades físicas adequadas, como: porosidade, capilaridade, poder de retenção de água disponivel, ou seja, solos soltos, porosos, profundos e de fácil drenagem. Os argilosos, pesados e com dificil capacidade de drenagem, retardam o desenvolvimento das plantas.

O cultivo da seringueira tem se intensificado com grande expressão no Sul da Bahia. Santana et al. (1977), avaliando o nivel de fertilidade dos solos sob a cultura, observaram que os mesmos são quimicamente pobres e apresentam elevada acidez. Tratando-se de uma espécie tolerante a solos ácidos, o uso de calcário ou outra fonte de $\mathrm{Ca}$ e $\mathrm{Mg}$, serviria apenas ao suprimento desses elementos, como fonte de nutrientes, em caso de comprovada deficiência na planta, ou niveis muito baixos no solo.

Bataglia et al. (1987b), avaliando a influência de diferentes tipos de solo no desenvolvimento de seringais, com 25 anos de idade, no Estado de São Paulo, verificaram maior desenvolvimento da seringueira em solos com melhor nivel de fertilidade, Latossolo Roxo, e menor nos solos do litoral, Podzólico Vermelho-Amarelo-orto e Latossolo Vermelho-Amarelo textura média. 
2.4. Efeito da Adubação Nitrogenada, Fosfatada e Fotássica

\subsubsection{Na Fertilidade do Solo}

A análise química de solo constitui a única técnica disponivel de fácil acesso, para a avaliação direta da fertilidade dos solos e das necessidades de adubação (Raij1991).

Bolton (1964), estudando os efeitos da adubação NPK no desenvolvimento da seringueira em solos derivados de argilitos ou folhelhos, observou diminuição do $\mathrm{Ca}^{++}, \mathrm{Mg}^{++}$e $\mathrm{K}^{+}$trocáveis nos tratamentos que receberam sulfato de amônio.

Reis et al. (1984a), estudando a influência da calagem e adubação $N, P$ e $K$ sobre a produção da seringueira no Sul da Bahia, observaram que a calagem contribuiu para a diminuição dos teores de potássio nas folhas, ao mesmo tempo que provocou aumentos nos teores de cálcio. Essa redução deve decorrer das mudanças nas relações catiônicas no solo, onde um aumento nos teores trocáveis de $\mathrm{Ca}$ e $\mathrm{Mg}$ pode ter provocado uma redução na absorção de potássio.

Reis et al. (1984b), estudando a influência da adubação $N, P$ e $K$ sobre o desenvolvimento da seringueira em solos do Sul da Bahia, observaram que os teores de $\mathrm{Ca}^{++}{\mathrm{e} \mathrm{Mg}^{++}}^{+}$ trocáveis decresceram com a adubação nitrogenada e foram incrementados com a adubação fosfatada e potássica.

Reis \& Cabala Rosand (1988), avaliando a eficiência de fertilizantes nitrogenado, fosfatado e potássico aplicados nas fases pré e pós-sangria da seringueira, observaram que os niveis de nitrogênio aplicados na forma de uréia e sulfato de amônio induziram a redução nos valores de $\mathrm{pH}$ e ao aumento nos teores de bases trocáveis e de Al. O fósforo disponivel no solo aumentou diretamente com as doses fósforo aplicadas $e$ os niveis. de potássio disponivel no solo não se alteraram com aplicação das doses de cloreto de potássio, diminuindo com o decorrer do tempo, 
mesmo para os tratamentos que receberam as maiores doses desse nutriente.

Joseph et al. (1990), investigando a dinâmica do K nos principais solos com seringais cultivados no Sul da Índia, observaram que a fração de $K$ disponivel foi mais alta nos horizontes superficiais do que nos de sub-superfícies, na maioria das regiões estudadas

Coelho et al. (1992), avaliando a necessidade de calagem, adubação potássica e a melhor relação $\mathrm{Ca}, \mathrm{Mg}$ e $\mathrm{K}$ para o crescimento de porta-enxertos de seringueiras, observaram que os porta-enxertos requerem para o seu crescimento baixos niveis de $\mathrm{Ca}+\mathrm{Mg}$ no solo $\left(6,7 \mathrm{mmol}_{\mathrm{c}} / \mathrm{dm}^{3}\right)$, como também niveis baixos de $\mathrm{K}(35 \mathrm{mg} / \mathrm{kg})$, refletindo equilíbrio ótimo de $(\mathrm{Ca}+\mathrm{Mg}) / \mathrm{K}$ no solo próximo a 7,5 e baixa saturação de bases. O crescimento dos porta-enxertos de seringueira foram influenciados pela calagem e pelo $\mathrm{K}$, e maiores acréscimos de matéria seca foram obtidos quando foram aplicados calagem e $\mathrm{K}$ em baixas concentrações.

\subsubsection{No Desenvolvimento da Seringueira}

O potencial de produção de látex da seringueira é geralmente influenciado por fatores como: a) a circunferência do caule que se reflete na redução do periodo de imaturidade e início da exploração e b) espessura da casca virgem, que pode reduzir a possibilidade de danificações no painel de sangria. Em geral, plantas de um determinado clone que apresentam maiores valores para a circunferência do caule e espessura da casca indicam, também maiores médias para a produção de borracha (Gonçalves et al., 1979).

Syvanadian et al. (1975) mencionaram que na Malásia seringais bem manejados levam de 5 a 6 anos para alcançarem o diâmetro ideal $(50 \mathrm{~cm})$ para início de sangria, enquanto que pequenos plantios de seringueiras consorciados com outras 
espécies podem demorar de 7 a 8 anos. Os seringais formados em solos com cobertura de leguminosas apresertam uma percentagem de árvores ideal para início de exploração mais cedo (5 anos), do que aqueles que foram formados em área sem cobertura com leguminosas, os quais chegam a demorar até 8 anos para atingir o diâmetro ideal.

Considerando os efeitos da adubação sobre a circunferência do caule e espessura da casca da seringueira, inúmeros trabalhos têm sido conduzidos na Malásia, tais como o de Haines \& Crowther (1940), que obtiveram um acréscimo de $8,0 \mathrm{~cm}$ na circunferência do caule da seringueira com a aplicação da dose mais elevada de fósforo $\left(\mathrm{P}_{2} \mathrm{O}_{5}\right)$, antecipando o início da sangria por um período de aproximadamente 2 anos.

Avaliações do desenvolvimento de seringueira na Malásia, em Latossolo Amarelo, com cobertura de leguminosa, mostraram que incrementos de circunferência foram alcançados com aplicação de nitrogênio e fósforo, somente até quatro anos após o plantio. Para o potássio, não foi observada resposta até cinco anos após o plantio. Resultado semelhante foi observado também na índia, quando quatro diferentes clones foram submetidos a diferentes niveis de fertilizantes (Kalam, 1970; Pannoje \& Potty, 1975; Syvanadian et al., 1975).

Syvanadian et al. (1975) observaram que a necessidade de $\mathrm{K}$ para a seringueira pode variar de acordo com o seu estádio de desenvolvimento. A carência desse nutriente durante a fase de crescimento pode limitar a atividade da área foliar e reduzir a atividade fotossintética das folhas, resultando em um incremento mais lento do diâmetro do caule, e consequentemente, demorando mais tempo para atingir o tamanho ideal para sangria.

Por outro lado, Ananth et al. (1966) encontraram resposta negativa do $\mathrm{K}$ relacionado aos parâmetros de crescimento de seringueiras jovens cultivadas em solos lateríticos derivados de rochas graníticas. 
Reis et al. (1984b), estudando a influência da adubação $N, P$ e K sobre o desenvolvimento da seringueira em solos do Sul da Bahia, observaram que o nitrogênio e o potássio não apresentaram efeito sobre o desenvolvimento do tronco da seringueira. Por outro lado, as doses de fósforo responderam de forma quadrática sobre o desenvolvimento do tronco, alcançando incrementos máximos com $26 \mathrm{~kg} \mathrm{ha}^{-1}$ de $\mathrm{P}_{2} \mathrm{O}_{5}$ no $1^{\circ}$ ano; $45 \mathrm{~kg} \mathrm{ha}^{-1}$ no $2^{\circ}, 3^{\circ}$ e $4^{\circ}$ anos e com $112 \mathrm{~kg} \mathrm{ha}^{-1}$ de $\mathrm{P}_{2} \mathrm{O}_{5}$ no $5^{\circ}$ ano.

Berniz (1987), avaliando o efeito de três níveis de NPK durante 3 anos de observação, verificou que a aplicação de nitrogênio não contribuiu para o incremento da circunferência do caule, espessura da casca e altura da planta de seringueira jovem. Por outro lado, a adubação fosfatada apresentou efeito linear para a altura da planta no primeiro ano, circunferência do caule no primeiro, segundo e terceiro ano e espessura da casca no segundo e terceiro anos.

Reis \& Cabala Rosand (1988), avaliando a eficiência de fertilizantes nitrogenado, fosfatado e potássico aplicados nas fases de pré e pós-sangria de seringais cultivados em Latossolo vermelho amarelo no Sul da Bahia, observaram que a dose de $90 \mathrm{~kg} \mathrm{ha}^{-1}$ de $\mathrm{P}_{2} \mathrm{O}_{5}$ é a mais indicada do ponto de vista econômico, promovendo o incremento da circunferência do tronco até o décimo ano e elevando a produtividade em mais de $90 \%$, quando comparado com os tratamentos que não receberam adubação fosfatada. Por outro lado, a aplicação de nitrogênio, potássio, calcário dolomítico e micronutrientes não influenciaram o incremento da circunferência do tronco da seringueira.

Kitamura (1992) observou que a aplicação de fósforo na forma de superfosfato triplo aumentou a circunferência do tronco da seringueira apenas no quinto ano, e os demais nutrientes não influenciaram no incremento da circunferência do tronco nos primeiros cinco anos após o plantio da seringueira.

Reis (1992), estudando a influência do fracionamento e método de aplicação de fertilizantes no desenvolvimento da 
seringueira, observou que nos resultados da circunferência do tronco da seringueira, em função dos fracionamentos e dos métodos de aplicação dos fertilizantes, não demonstraram nenhum efeito significativo, durante os seis primeiros anos de idade.

\subsubsection{Na Concentração de Nutrientes na Folhas}

Chapman (1941) relatou pela primeira vez o uso do conteúdo de nutrientes nas folhas como um indicativo da absorção de nutrientes pela seringueira. Shorrocks (1962) formulou os procedimentos padrões para a coleta de amostras foliares em seringueira para análise químicas.

Trabalhos posteriores relataram métodos de amostragens e interpretação em relação as características das plantas e condições de crescimento para os diferentes clones de seringueira (Guha \& Narayanam (1969); Pushparajah \& Tan (1972).

Beaufils (1957) observou que a concentração de N,P e $\mathrm{K}$ nas folhas diminui com a idade das plantas, enquanto que o $\mathrm{Ca}$ e Mg tenderam a aumentar.

Reis et al. (1984a), estudando a influência da calagem e adubação $N, P$ e K sobre a produção da seringueira no Sul da Bahia, observaram que o clone Fx 2261 apresentou maiores concentrações de $\mathrm{P}, \mathrm{Ca}^{++}$e $\mathrm{Mg}^{++}$nas folhas quando comparado com o clone Fx 3899, que, por sua vez, apresentou concentrações mais elevadas de $\mathrm{K}$.

Kitamura (1992) verificou que a adubação nitrogenada aumentou a concentração de $\mathrm{N}$ nas folhas no terceiro ano e a concentração do $P$ no terceiro e quinto anos, enquanto que a concentração de $\mathrm{Mg}^{++}$diminuiu no segundo ano. A adubação fosfatada proporcionou um aumento na concentração de Ca nas folhas no segundo e quarto anos. A adubação potássica aumentou a concentração de potássio nas folhas no quarto e quinto anos e 
diminuiu a de $\mathrm{Mg}$ no primeiro e terceiro anos e do Ca no segundo ano.

Joseph et al. (1993), estudando a formulação de normas através do DRIS para a seringueira no Sul da índia, observaram relações de variância altamente significativas do $\mathrm{Mg}$, mostrando o papel direto deste elemento na produção de látex.

\subsubsection{Na Produção de Borracha Seca}

O objetivo da aplicação de fertilizantes nos seringais em formação é acelerar o seu desenvolvimento e, consequentemente, antecipar o início da explotação bem como manter as plantas vigorosas a fim de garantir satisfatórios niveis de produção de látex.

Mainstone (1963) mencionou que o efeito residual do fósforo aplicado desde o inicio do plantio até o fim da fase de desenvolvimento propicia uma produção de borracha duas vezes maior que aquele que somente recebeu baixas doses de fósforo nos primeiros anos depois do plantio.

Pushparajah et al. (1971), avaliando a necessidade de nutrientes da seringueira quando submetida a diferentes tipos de estimulantes e quantidades diferentes de fertilizantes NPK e Mg, observou que a quantidade de nutrientes exportados foi maior quando se aplicou o Ethephon (10\%). As quantidades de N,P,K e $\mathrm{Mg}$ explotados foram $14,5,14$ e $2 \mathrm{~kg} / \mathrm{ha}$ /ano a mais, em relação às da testemunha, mostrando que a estimulação pode levar a uma depreciação do estado nutricional das plantas. As plantas estimuladas com ethrel a $10 \%$ apresentaram um acréscimo de produção da ordem de $1150 \mathrm{~kg}$ de borracha seca/ha/ano comparada com as plantas não estimuladas.

Reis et al. (1984a), mencionaram que a redução nos niveis de produção em plantas estimuladas é decorrência de limitações de ordem nutricionais, que podem ser evitadas 
aplicando maiores doses de adubos, admitindo-se, portanto, que, plantas estimuladas requerem, para manter elevados niveis de produção, maiores doses de nutrientes.

Reis et al. (1984a), estudando a influência da calagem e adubação $N, P$ e K sobre a produção da seringueira no Sul da Bahia, observaram que embora os tratamentos com a adubação e calagem e a combinação de ambos não tenham apresentado efeitos estatisticamente significativos na produção, os níveis de produção alcançados em parcelas relativamente grandes foram bastantes elevados em relação a produção média anual da região, evidenciando a importância da adubação entre as práticas agronômicas recomendadas para esta cultura.

Em geral, plantas que apresentam maior capacidade fotossintética demandam maior consumo de nutrientes para o seu desenvolvimento e reprodução. O consumo de nutrientes destinados à formação dos diferentes órgãos da seringueira é muito elevado quando comparado com a quantidade de nutrientes exportados no látex.

Para cada tonelada de borracha seca produzida, são exportados aproximadamente $7,5 \mathrm{~kg}$ de $\mathrm{N} ; 3,0 \mathrm{~kg}$ de $\mathrm{P}_{2} \mathrm{O}_{5}$ e $6,0 \mathrm{~kg}$ de $\mathrm{K}_{2} \mathrm{O}$. Seringueiras com idade média de 17 anos apresentam consumo médio anual de $293 \mathrm{~g}$ de $\mathrm{N} ; 29 \mathrm{~g}$ de $\mathrm{P} ; 125 \mathrm{~g}$ de $\mathrm{K} ; 46 \mathrm{~g}$ de $\mathrm{Mg} ; 178 \mathrm{~g}$ de $\mathrm{Ca}$ e $36 \mathrm{~g}$ de $\mathrm{S}$. Esses dados mostram que os elementos $P$ e $S$ são os requeridos em menores quantidades, enquanto que o $\mathrm{N}, \mathrm{Ca}$ e $\mathrm{K}$ são requeridos em maiores quantidades (Miranda et al., 1975)

Para uma produção de $2.600 \mathrm{~kg}$ de borracha seca/ha/ano em plantio com sangria estimulada, com ethephon a $10 \%$, as quantidades de nutrientes anualmente removidos com a exportação do látex foram de $23,9 \mathrm{~kg} / \mathrm{ha}$ de $N, 7,2 \mathrm{~kg} / \mathrm{ha}$ de $P$, $22,3 \mathrm{~kg} / \mathrm{ha}$ de $\mathrm{K}$ e $4,1 \mathrm{~kg} / \mathrm{ha}$ de $\mathrm{Mg}$, enquanto que tratamentos não estimulados, com uma produção de $1390 \mathrm{~kg}$ de borracha seca/ha/ano as quantidades de nutrientes removidos no látex 
foram de $9,4 \mathrm{~kg} / \mathrm{ha}$ de $\mathrm{N}, 2,3 \mathrm{~kg} / \mathrm{ha}$ de $P, 8,3 \mathrm{~kg} / \mathrm{ha}$ de $\mathrm{K}$ e 1,7 $\mathrm{kg} / \mathrm{ha}$ de $\mathrm{Mg}$ (Rubber Research Institute of Malaya, 1972).

Através do Sistema Integrado de Diagnose e Recomendação (DRIS), diversos autores têm elaborado relações entre os macronutrientes, com o objetivo de diagnosticar os nutrientes limitantes e recomendar adequada fertilização para aumentar a produção.

Beaufils (1957) estabeleceu relações para os nutrientes N,P e $K$ sob condições do Vietnã, encontrando valores considerados adequados em torno de 12,7-16,1 (N/P); 3,4-4,3 $(\mathrm{N} / \mathrm{K})$ e 3,4-4,3 (K/P). Para as condições da Malasia, Fallows (1961) fixou valores em torno de 13,0-17,2 (N/P); 1,9-3,1 (N/K) e 4,7-7,1 (K/P).

Comparando os resultados acima com os de Joseph et al. (1993), obtidos em solos da índia, observa-se que o valor médio de N/P $(13,87)$ está dentro da faixa de valores encontrados para as outras duas regiões. Para as relações $N / K(2,73)$ e K/P $(5,26)$ os valores encontrados na Malásia e na Índia ficaram bem próximos, enquanto que, os valores de N/K e K/P encontrados no Vietnã foram mais altos e baixos respectivamente, fato ocorrido, possivelmente, devido o baixo conteúdo de $K$ nas folhas. Como os solos do Vietnã são Oxisols derivados de rochas basálticas ricos em $\mathrm{Mg}^{++}$, isto pode levar a uma baixa absorção de $\mathrm{K}$ pela seringueira.

Vários trabalhos desenvolvidos tem evidenciado que alto conteúdo de $\mathrm{P}$ e baixas relações $\mathrm{Mg}^{++} / \mathrm{P}$ e $\mathrm{Mg}^{++}+\mathrm{Ca}^{++} / \mathrm{P}$ estão associados com a boa estabilidade do látex. $O \mathrm{Mg}^{++}$ desempenha importante papel no metabolismo dos vasos laticíferos e na estabilidade do látex (Beaufils, 1957; Yip \& Gomez, 1980).

Bataglia \& Cardoso (1987), comparando seringais com diferentes niveis de produtividade, verificaram que os nutrientes que possivelmente mais contribuiram para essas diferenças foram o $\mathrm{N}$ e o K. 
Reis \& Rosand (1988), avaliando a eficiência dos fertilizantes aplicados nas fases pré-pós sargria da seringueira, observaram que o fósforo foi o nutriente que proporcionou maiores respostas no desenvolvimento da circunferência do tronco e na produção de borracha.

\subsection{Composição do Látex da Seringueira}

O látex da seringueira é um líquido de aspecto leitoso, de função desconhecida na planta. É considerado um citoplasma de um sistema de células anastomosadas que é especializado na sintese do cis-polisopreno. Este contém de 25 a $50 \%$ de matéria seca, das quais $90 \%$ é composta de borracha. É obtido através da sangria (incisão na casca) em árvores do gênero Hevea, em especial de Hevea brasiliensis (Webster \& Paadekooper, 1989).

Autores como D'auzac \& Jacob (1989), Webster \& Paadekooper (1989), relataram que o látex é um sistema coloidal polifásico que, quando submetido a ultracentrifugação, pode ser dividido em até onze fases, das quais as principais são:

a) Uma fase leve, constituída essencialmente de borracha (hidrocarboneto isoprênico), responsável por cerca de $37 \%$ do volume total; b) Uma fase aquosa, límpida, denominada de soro citoplasmático ou soro $C$, que representa cerca de $48 \%$ do volume total;

c) Uma fração de fundo, pesada, denominada de soro de sedimentação ou soro $S$ que representa cerca de $15 \%$ do volume total, constituido por diversas partículas, sendo as principais os lutóides que são vesículas ou vacúolos envolvidos em uma membrana frágil, semi-permeável e que contém em seu interior um líquido denominado soro $B$, com pH em torno de 5,5 constituído de proteínas de alto ponto isoelétrico, enriquecidas de cátions divalentes $\left(\mathrm{Mg}^{++}\right.$e $\left.\mathrm{Ca}^{++}\right)$, sendo capaz de provocar a floculação das partículas de borracha quando liberados; 
d) As partículas de Frey-Wyssling, que constituem um percentual reduzido em relação ao volume total (1-3\%), composta de carotenóides e lipídeos e cuja função ainda não foi esclarecida. São encontrados em seu interior, polifenol oxidases, que podem reagir com substrato do citosol e o oxigênio do ar, com reflexos no mecanismo de fluxo do látex

\subsection{Controle do Metabolismo do Látex}

Conforme descrito por Condurú Neto (1987) e Castro (1990), a sacarose, o pH, cátions divalentes como cálcio e magnésio, grupos tióis são alguns dos fatores que atuam na regeneração do látex. A sacarose é o carboidrato predominante transportado na seiva do floema, em direção aos drenos da planta. O teor de sacarose no látex é função, por um lado, da velocidade de suprimento desse carboidrato e, por outro, da velocidade de sua utilização celular na glicólise.

$0 \mathrm{pH}$ do citosol é responsável pela regulação metabólica no látex, e, ligeiras oscilações nesse fator podem alterar profundamente a atividade de certas enzimas chaves.

Cátions divalentes, em especial os teores de $\mathrm{Ca}^{++} \mathrm{e}$ $\mathrm{Mg}^{++}$, e sua compartimentação atuam na atividade de enzimas chaves do metabolismo, como é o caso da fosfoenolpiruvato carboxilase e da piruvato quinase.

Os tióis ou grupo $\mathrm{R}-\mathrm{SH}$, representados no látex principalmente pela glutationa, cisteína e metionina, são ativadores fisiológicos de reações importantes mediadas pelas enzimas piruvatos quinase, invertase e 3-hidroxi 3-metil glutaril Coenzima A redutase (HMGCoA redutase) (Jacob \& Prevot, 1989). 
2.7. Descrição e Significado dos Parâmetros Fisiológicos do Látax Relacionados com a Produção

\subsubsection{Parâmetros Fisiológicos do Látex Relacionados com o Fluxo.}

A causa principal da paralisação do fluxo do látex é a obstrução das extremidades cortadas dos vasos laticíferos. Blocos formados de partículas de borracha e lutóides danificados, com grande quantidade de proteínas com cargas positivas, prótons e cátions divalentes, formam os microflocos, provocando a obstrução na região do corte. Este fenômeno é causado pela neutralização das cargas negativas das membranas dessas partículas de borracha e por ação simultânea de vários fatores (D'Auzac, 1988b; Jacob et al., 1995b).

Um dos fatores mais importantes é, provavelmente, a liberação de soro dos lutóides (que contém cátions divalentes como o $\mathrm{Ca}^{++}$e $\mathrm{Mg}^{++}$, ácidos orgânicos, proteinas carregadas positivamente e várias hidrolases) e também o conteúdo de partículas de Frey-Wyssling que inclui polifenol-oxidase que podem reagir com o substrato do citosol e o oxigênio do ar. Os lutóides $e$ as partículas de Frey-Wyssling são praticamente degradados no momento da sangria (Jacob et al., 1989b).

Dentre os principais parâmetros fisiológicos do látex ligados ao mecanismo de fluxo, Jacob et al., 1989a, relatam a importância do extrato seco (ou conteúdo de sólidos totais), presença de tióis (grupos $\mathrm{R}-\mathrm{SH}$ ) e teores de magnésio. De acordo com os mesmos autores, outras conclusões podem ser extraídas tais como: o conteúdo de borracha seca (Dry Rubber Content, DRC) contribui com mais de $90 \%$ do conteúdo de sólidos totais (Total Solid Contents, TSC) do látex. Este valor é muito alto quando comparado com o TSC das células vegetais em geral. Altos valores de TSC pode limitar a produção e mais precisamente o fluxo devido a elevada viscosidade do látex. 
Os tióis no látex consistem de cisteina, metionina e principalmente glutationa. A presença dessas moléculas é indispensável em todas as células, uma vez que, são capazes de neutralizar várias formas de oxigênio tóxicos que são considerados produtos resultantes de algum metabolismo celular. Os tióis aprisionam as formas tóxicas de oxigênio, protegendo a compartimentação celular do látex, e portanto, o perfeito funcionamento dos vasos laticíferos, em particular o fluxo durante a sangria. Isso evidencia a existência de alta correlação positiva entre o conteúdo de tióis e a produção (Jacob et al., 1989; D'auzac \& Jacob, 1989).

O magnésio é compartimentado no látex e acumulado nos lutóides. Uma análise geral do $\mathrm{Mg}^{++}$é, portanto, mais difícil de ser interpretada, uma vez que, este desempenha papel mais complexo e em algumas situações, papéis opostos. Com respeito ao fluxo, as cargas eletronegativas de partículas de borrachas responsáveis pela estabilidade coloidal do látex podem ser neutralizadas pelo $\mathrm{Mg}^{++}$. Este cátion é liberado em grande quantidade quando os lutóides são degradados, implicando numa efetiva paralisação do fluxo. Clones como AVROS 308 ou GT 1 , cujo látex tem um alto conteúdo de $\mathrm{Mg}^{++}$, freqüentemente apresentam coagulação no momento do corte (D'auzac \& Jacob, 1989).

\subsubsection{Parâmetros Fisiológicos do Látex Associados com a Regeneração do Tecido Laticífero}

Um baixo valor do conteúdo de sólidos totais (TSC) pode indicar uma discreta regeneração in situ do isopreno, que normalmente é, ou pode tornar-se, um fator limitante na produção. Em casos de explotação intensiva, os valores baixos desse parâmetro indicam uma regeneração insuficiente entre duas sangrias. Por outro lado, elevado valor do TSC pode indicar 
efetiva regeneração, chegando aos extremos, provocando distúrbios no fluxo devido o aumento da viscosidade do látex. (Jacob et al., 1989b; Jacob et al., 1995b).

Elevado conteúdo de sacarose no látex pode indicar um bom suprimento desse fotossintetizado nos vasos laticiferos que pode ser acompanhado por um metabolismo ativo. Por outro lado, alto conteúdo de sacarose no látex pode também indicar baixa utilização metabólica deste açúcar, e portanto, baixa produção de látex. Como exemplo, a sacarose tende a se acumular quando a regeneração in situ é completada e, consequentemente, ocorre diminuição no metabolismo dos vasos laticiferos. Exploração excessiva pode causar uma diminuição no conteúdo de açúcar correlacionado ao esforço biológico exigido pela planta. É evidente que, nesse caso a sacarose torna-se um fator limitante na produção. Além disso, se a explotação é excessiva e contínua as plantas poderão apresentar um secamento do painel, e, portanto, uma certa degradação dos sistemas laticiferos e seu metabolismo (Jacob et al., 1989b).

Conforme descrito por Sá (1991), o valor do pH medido no látex fresco é aquele encontrado no compartimento do citosol, onde se desenvolve a maior parte dos processos de sintese de borracha. A alcalinização do meio ativa a glicólise, particularmente através da invertase que catalisa o ponto chave no metabolismo dos laticiferos, e que é extremamente sensivel a variações fisiológicas do $\mathrm{pH}$. Correlações positivas altamente significativas têm sido encontradas entre $\mathrm{pH}$ e produção sob certas condições. Tem sido amplamente aceito também que baixo valores de $\mathrm{pH}$ corresponderá fraco catabolismo dos glucideos, fraca sintese do isopreno, e, portanto, baixo conteúdo de borracha e baixa produção de látex.

O teor de fósforo inorgânico ( $\mathrm{Pi}$ ) no látex pode refletir seu metabolismo de energia, contribuição no catabolismo de sacarose, na sintese de nucleotideos envolvidos na transferência de energia (em particular fosfato de adenosina) ou acarreta 
redução de potencial NADPH, para a produção de ácidos nucleicos e, evidentemente, para síntese isoprênica. Isto pode derivar in situ da hidrólise da molécula fosforilada e acima de tudo da fosfatase inorgânica (PPi) produzida pela transferase da borracha responsável pelo alongamento de cadeia de polisopreno ( Jacob et al., 1989b).

O conteúdo de magnésio no látex é, geralmente, analisado sem levar em consideração a sua distribuição entre o citosol e o soro intralutóide onde este se acumula e devido a essa compartimentação, pode desempenhar papéis diferentes, ou até mesmo papéis opostos. O $\mathrm{Mg}^{++}$é um ativador indispensável no funcionamento de numerosas enzimas no látex tais como: ATPase em geral; transferase, PEPcarboxilase e pirofosfatase ( Jacob et al., 1989b).

O $\mathrm{Mg}^{++}$é também um inibidor de outras enzimas como a invertase e fosfatase ácida relacionada com o fosfato de nucleotídeos. Esta diversidade de função do magnésio resulta em fenômeno de equilíbrio, e é de se esperar uma relação complexa com a produção. Alguns autores têm encontrado uma relação inversa significativa entre o conteúdo de $\mathrm{Mg}^{++}$e a produção, enquanto outros têm observado relação direta entre $\circ \mathrm{Mg}^{++}$e a produção. Entretanto, estudos posteriores tem demonstrado que o papel do $\mathrm{Mg}^{++}$como um ativador de enzimas do citosol supera a sua função desestabilizadora. Pode-se considerar que $\circ \mathrm{Mg}^{++}$pode refletir ativação ou diminuição da atividade metabólica, mas através de um processo menos perceptível e mais complexo do que o fósforo inorgânico ( Jacob et al., 1989b).

Os Tióis ou grupos $\mathrm{R}-\mathrm{SH}$, representados no látex pela cisteína, metionina e principalmente pela glutationa, são ativadores fisiológicos de reações importantes, mediadas pelas enzimas piruvato quinase, invertase e HMGCoA redutase. Atuam também na proteção das membranas das organelas do látex retendo as formas tóxicas de oxigênio e portanto promovendo a estabilidade coloidal e o fluxo. A deficiência de tióis 
provavelmente afetaria a compartimentação celular e a atividade metabólica conduzindo a um mau funcionamento dos laticíferos e portanto diminuindo a produção (Jacob et al., 1988a).

\subsection{Diagnose Fisiológica do Látex e Produção da} Seringueira

\subsubsection{Correlações Interparamétricas}

De acordo com as condições biológicas do meio, alguns desses parâmetros como a sacarose, o fósforo inorgânico, os tióis, o pH do citosol e o conteúdo de borracha seca podem desempenhar papéis antagônicos. Para demonstrar as bases sólidas de uma diagnose do látex, Jacob, et al., 1989b relataram que é necessário examinar as relações interparamétricas, se possivel conjuntamente, ligando esse critério com a produção, podendo essa relação ser ou não significativa. Um grande número de fatores estão envolvidos neste contexto, que pode variar de acordo com as condições ambientais e com as características genéticas do próprio clone, tanto podendo revelar como esconder ou mascarar a ligação com a produção. Trata-se de um fenômeno complexo, mas a demonstração de um relacionamento entre esses parâmetros é sempre útil e freqüentemente pode detectar um problema. Essa abordagem pode ser caracterizada através das seguintes correlações.

Correlação positiva do teor de sacarose com 0 conteúdo de sólidos totais que pode ser avaliado através da \%DRC - Elevado conteúdo de sacarose corresponde a um elevado teor de sólidos totais. Isso evidencia que provavelmente o abastecimento de sacarose para as células dos laticíferos é um fator limitante na regeneração. Plantas sangradas em espiral completa e a posição do corte efetuado na base do painel podem explicar este fenômeno (Jacob, et al., 1989b) 
Correlação positiva entre TSC, e produção - É evidente que a produção tem uma relação direta e posiłiva com o TSC. Baixo conteúdo de sólidos totais é acompanhado por uma baixa produção e vice-versa. Em outras palavras, regeneração, refletida pelo TSC é capaz de limitar a produção (Jacob, et al., $1989 b)$.

Correlação positiva entre tióis e produção. 0 relacionamento entre esses parâmetros foi confirmado pela observação desta correlação. Baixa produção corresponde a um baixo conteúdo de tióis e vice versa. O baixo conteúdo de tiol não é suficiente para proteger compartimentação efetivamente.

O conhecimento das correlações interparamétricas e das correlações entre os parâmetros e a produção, torna-se possivel determinar os fatores comumente limitantes da produção sob certas condições.

Do ponto de vista prático, é possivel, através de adaptação de sistema de exploração como tipo de sangria, intensidade de sangria, época de aplicação e concentração de estimulantes, recomendar soluções que podem reduzir ou eventualmente eliminar os fatores limitantes em desequilibrio pela análise dos parâmetros fisiológicos, levando a otimização da produção.

2.9. Avaliação do Estado de Sub-Exploração ou de Super-Exploração da Seringueira.

Conforme descrito por Jacob et al. (1989), a aplicação industrial da diagnose do látex para determinar se as plantas estão bem exploradas, sub ou super-exploradas, necessita dos valores limiares fixos para os parâmetros diagnósticos do látex.

Deve-se, todavia, ser observado que os valores de parâmetros brutos são todos relativos e freqüentemente dependem dos clones. É, portanto, necessário ter informações sobre as 
médias neste respeito. Adicionalmente, o sistema de explotação deve ser levado em consideração e correções devem ser feitas, se necessário, para compensar a variação sazonal.

A tabela 1 mostra um exemplo do procedimento usado e os valores limitantes propostos para os parâmetros fisiológicos do látex para o clone GT 1 (Jacob et al., 1989b).

Super-exploração implica em baixo $\mathrm{pH}$ do citosol do látex $(<6,80)$, refletindo em distúrbios metabólicos, seguido por uma alta demanda dos tecidos laticíferos. Este fenômeno é acompanhado provavelmente por uma certa descompartimentação celular confirmada por um alto potencial redox. O TSC, refletindo um anabolismo isoprênico, é logicamente baixo $(<30,00 \%)$. Em casos extremos todavia, mal funcionamento dos laticíferos, conduz a um leve aumento no TSC, resultando sérios problemas de translocação de água (Jacob et al., 1989b).

Baixo conteúdo de sacarose no látex $(<5,00 \mathrm{mM})$, provavelmente é indicação de fornecimento limitado (esgotamento do estoque e/ou fenômeno de translocação ativa). A fase final da super-explotação é acompanhada por um aumento do conteúdo de açúcar (sacarose), indicando a paralisação do metabolismo nos laticíferos esgotados.

Alto conteúdo de P-inorgânico no látex $(>20,00 \mathrm{mM})$ deve indicar hidrólise ativa do PPi e éster fosforilases e/ou a pobre ou ineficiente utilização desse ânion no metabolismo na fase final da super-explotação; Estes niveis diminuem em correlação com a atividade metabólica mencionada acima.

O conteúdo de $\mathrm{Mg}^{++}$comporta-se de maneira similar ao fósforo inorgânico para as reações fisiológicas descritas acima. Da mesma forma que $\mathrm{Pi}$, valores excessivamente altos de tióis $(>0,90 \mathrm{mM})$ indicam que o metabolismo tem sido desviado deste caminho metabólico. Baixos valores podem também ser encontrados, provavelmente como resultado da degeneração oxidativa. No caso de super-exploração, o secamento de painel que se desenvolve é a prova mais evidente da existência de 
mecanismos que degradam os sistemas laticiferos (Jacob et al., 1989b).

Dentro da sub-exploração, a proporção muito baixa do secamento de painel deve ser desequilibrada, refletindo a menor lesão dos sistemas laticíferos. Isto contribui para um alto valor do $\mathrm{pH}(>7,05)$ observado e relativamente menor redução do potencial redox (os lutóides são perfeitamente funcionais); anabolismo isoprênico é discreto.

Alto conteúdo de sólidos totais $(>35,0 \%)$ indica que in situ a regeneração está terminando e que o metabolismo está diminuindo. Isto pode ser confirmado por um baixo conteúdo de $\mathrm{Pi}$ $(<10,00 \mathrm{mM})$ e tióis $(<0,50 \mathrm{mM})$ (a reutilização dessas moléculas torna-se lenta) e pelo conteúdo de sacarose relativamente alto $(>8,00 \mathrm{mM})$ uma vez que mais tarde o uso é menos ativo.

Os valores dos parâmetros fisiológicos do látex são em geral de origem clonal. A coerência dos dados obtidos deve ser enfatizado, apesar de diferenças consideráveis na locação (clima, solo, etc) e painel de sangria. Dependendo das condições experimentais, esses parâmetros podem ser correlacionados com a produção. É possivel, apesar disso, que eles atuem como fator limitante nos mecanismos de fluxo e/ou regeneração em que eles estão envolvidos.

Tomando os valores absolutos individualmente, não há possibilidade de nenhum significado especial sob condições normais, mas um exame compreensivo em relação com a produção permite um melhor aproveitamento dos fenômenos que governam a produção e servem para estimar sua importância sob dadas condições (Jacob et al., 1989b). 


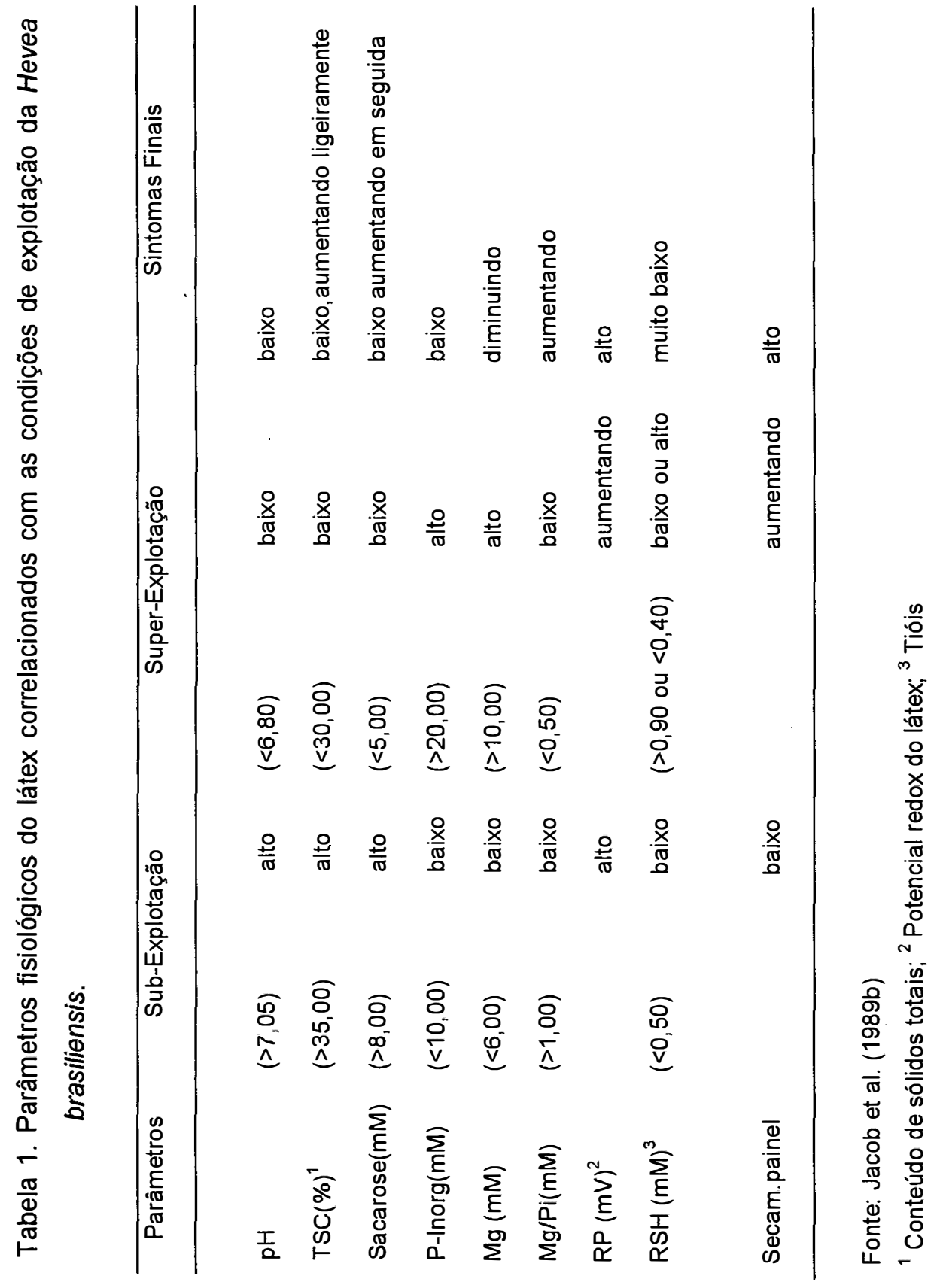




\section{MATERIAL E MÉtOdOS}

\subsection{Localização da Área}

O estudo foi conduzido em um seringal já implantado com 4 anos de idade, na fazenda Mundo Novo, localizada no município de Garça (latitude de $22^{\circ} 24^{\prime} \mathrm{S}$, longitude de $49^{\circ} 40^{\prime} \mathrm{W}$ e altitude de $663 \mathrm{~m}$ ), no sudoeste do Estado de São Paulo, Planalto Paulista, onde se encontra uma alta concentração de seringais em fase de desenvolvimento e produção.

\subsection{Solo}

O solo da área experimental é um Podzólico Vermelho Amarelo-variação Marilia (Pml). Esta unidade de mapeamento é formada por solos pouco mais rasos do que a variação Lins e apresentam iluviação mais intensa das partículas mais finas do solo. Quando seco, o horizonte A mostra-se esbranquiçado devido ao grande acúmulo de areia, contrastando com a coloração vermelha do horizonte B. (Ministério da Agricultura, 1960).

\subsection{Clima}

De acordo com a classificação internacional de Köppen, a área do experimento encontra-se èm tipo climático Cwa (clima mesotérmico de inverno seco em que a temperatura média do mês mais frio é inferior a $18^{\circ} \mathrm{C}$ e a do mês mais quente 
ultrapassa $22^{\circ} \mathrm{C}$; o total das chuvas do mês mais seco não ultrapassa $30 \mathrm{~mm}$; o indice pluviométrico deste tipo climático varia entre 1100 e $1700 \mathrm{~mm}$ ). A estação seca nesta região ocorre entre os meses de abril e setembro, sendo julho o mês em que atinge a máxima intensidade. O mês mais chuvoso oscila entre janeiro e fevereiro. A temperatura do mês mais quente oscila entre 22 e $24^{\circ} \mathrm{C}$ (Ministério da Agricultura, 1960).

\section{4. Área e Delineamento Experimental}

A área total do experimento constou de $46080 \mathrm{~m}^{2}$, subdividida em 4 blocos, sendo cada bloco constituido de 16 parcelas experimentais de $720 \mathrm{~m}^{2}$. O espaçamento adotado foi de $8,0 \mathrm{~m} \times 3,0 \mathrm{~m}$, totalizando 30 plantas dispostas em três linhas com 10 plantas. As avaliações foram efetuadas nas 6 plantas centrais de cada parcela. O experimento foi instalado em blocos ao acaso, em esquema fatorial fracionário $(1 / 4) 4^{3}$, totalizando 16 tratamentos e 4 repetições (Box et al., 1973; Gomes, 1979).

\subsection{Tratamentos}

Os tratamentos foram constituidos pela combinação dos quatro niveis de $\mathrm{N}, \mathrm{P}_{2} \mathrm{O}_{5}$ e $\mathrm{K}_{2} \mathrm{O}$. As fontes utilizadas foram: uréia $(45 \%$ de $N)$, superfosfato simples $\left(18 \%\right.$ de $\left.\mathrm{P}_{2} \mathrm{O}_{5}\right)$ e cloreto de potássio $\left(60 \%\right.$ de $\left.\mathrm{K}_{2} \mathrm{O}\right)$. Os tratamentos testados foram: $\mathrm{N}_{0} \mathrm{P}_{0} \mathrm{~K}_{0}$, $N_{1} P_{1} K_{0}, N_{1} P_{0} K_{1}, N_{0} P_{1} K_{1}, N_{1} P_{1} K_{1}, \quad N_{2} P_{1} K_{1}, N_{3} P_{1} K_{1}, N_{1} P_{2} K_{1}, N_{1} P_{3} K_{1}$, $N_{1} P_{1} K_{2}, N_{1} P_{1} K_{3}, N_{2} P_{1} K_{2}, N_{3} P_{1} K_{2}, N_{2} P_{1} K_{3}, N_{2} P_{2} K_{2}, N_{3} P_{3} K_{3}$.

As doses de $\mathrm{N}, \mathrm{P}_{2} \mathrm{O}_{5}$ e $\mathrm{K}_{2} \mathrm{O}$ foram constantes até $\mathrm{O}$ terceiro ano agrícola. No quarto ano agrícola as doses de $\mathrm{N}$ foram acrescidas em $50 \%$ e as de $\mathrm{K}_{2} \mathrm{O}$ em $15 \%$. No quinto ano agrícola as doses de $\mathrm{N}$ sofreram um acréscimo de $90 \%$, as de 
$\mathrm{P}_{2} \mathrm{O}_{5}$ continuaram constante e as de $\mathrm{K}_{2} \mathrm{O}$ foram aumentadas em $43 \%$.

Em relação as doses empregadas até o terceiro ano, a partir do sexto ano agrícola as doses de $\mathrm{N}, \mathrm{P}_{2} \mathrm{O}_{5}$ e $\mathrm{K}_{2} \mathrm{O}$ foram elevadas em $100 \%, 14 \%$ e $130 \%$ respectivamente. Esses acréscimos basearam-se nas doses utilizadas no primeiro ano agrícola. A tabela 2 apresenta o cronograma de adubação seguido nos últimos 8 anos. O estabelecimento dessas doses foi baseado nas recomendações de Raij (1985).

Efetuou-se a calagem em julho de 1989, na dosagem

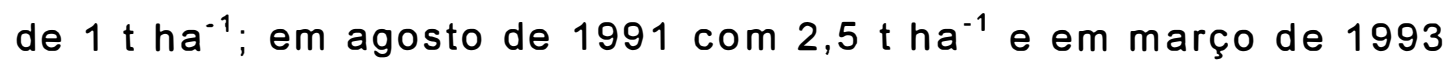
com 1,5 $\mathrm{t} \mathrm{ha}^{-1}$ de calcário dolomítico em toda a área experimental, com as seguintes características físicas e químicas: $30,24 \%$ de $\mathrm{CaO}, 18,55 \%$ de $\mathrm{MgO}, \mathrm{PN}\left(\% \mathrm{ECaCO}_{3}\right)=100, \mathrm{RE}=89 \%, \mathrm{PRNT}=$ $89 \%$.

3.6. Instalação e Condução do Experimento

O plantio das mudas foi efetuado em janeiro de 1984 e até meados de 1985 procedeu-se o replantio. O experimento foi instalado em novembro de 1987, época em que o seringal apresentava 4 anos de idade. 
Tabela 2. Quantidades de nitrogênio, fósforo e potássio aplicados no período 1987/1995.

\begin{tabular}{|c|c|c|c|}
\hline Ano agrícola & $\mathrm{N}$ & $\mathrm{P}_{2} \mathrm{O}_{5}$ & $\mathrm{~K}_{2} \mathrm{O}$ \\
\hline $87 / 88$ & $\begin{array}{c}0 \\
40 \\
80 \\
160\end{array}$ & $\begin{array}{c}0 \\
35 \\
70 \\
140\end{array}$ & $\begin{array}{c}0 \\
35 \\
70 \\
-140\end{array}$ \\
\hline $88 / 89$ & $\begin{array}{c}0 \\
40 \\
80 \\
160\end{array}$ & $\begin{array}{c}0 \\
35 \\
70 \\
140\end{array}$ & $\begin{array}{c}0 \\
35 \\
70 \\
140\end{array}$ \\
\hline $89 / 90$ & $\begin{array}{c} \\
0 \\
40 \\
80 \\
160\end{array}$ & $\begin{array}{c}0 \\
35 \\
70 \\
140\end{array}$ & $\begin{array}{c}0 \\
35 \\
70 \\
140\end{array}$ \\
\hline $90 / 91$ & $\begin{array}{c}0 \\
60 \\
120 \\
240\end{array}$ & $\begin{array}{c}0 \\
35 \\
70 \\
140\end{array}$ & $\begin{array}{c}0 \\
40 \\
80 \\
160\end{array}$ \\
\hline $91 / 92$ & $\begin{array}{c}0 \\
75 \\
150 \\
300\end{array}$ & $\begin{array}{c}0 \\
35 \\
70 \\
140\end{array}$ & $\begin{array}{c}0 \\
50 \\
100 \\
200\end{array}$ \\
\hline $92 / 93$ & $\begin{array}{c}80 \\
80 \\
320 \\
320\end{array}$ & $\begin{array}{c}0 \\
40 \\
80 \\
160\end{array}$ & $\begin{array}{c}0 \\
80 \\
160 \\
320\end{array}$ \\
\hline $93 / 94$ & $\begin{array}{c}0 \\
80 \\
160 \\
320 \\
\end{array}$ & $\begin{array}{c}0 \\
40 \\
80 \\
160\end{array}$ & $\begin{array}{c}0 \\
80 \\
160 \\
320\end{array}$ \\
\hline $94 / 95$ & $\begin{array}{c}0 \\
80 \\
160 \\
320 \\
\end{array}$ & $\begin{array}{c}0 \\
40 \\
80 \\
160\end{array}$ & $\begin{array}{c}0 \\
80 \\
160 \\
320\end{array}$ \\
\hline
\end{tabular}


O clone utilizado foi $O$ PB 235, resultante do cruzamento intra-específico de Hevea brasiliensis (PB 5/51 x PB 5/78) de origem malaia. De acordo com Gonçalves et al. (1993), trata-se de um clone que apresenta baixa incidência de árvores secas, alta produção nos primeiros anos, desenvolvimento de casca virgem superior aos clones mais plantados no Estado de São Paulo como o RRIM 600 e o GT 1.

Nos três primeiros anos agrícolas, as adubações foram efetuadas a lanço, em faixas, a $1,00 \mathrm{~m}$ das plantas. Nos cinco últimos anos agrícolas as adubações nitrogenada e potássica foram efetuadas a lanço, em faixas, a $1,50 \mathrm{~m}$ das plantas. A adubação fosfatada foi aplicada em sulcos, a $1,50 \mathrm{~m}$ das plantas, alternados a cada ano, sendo um ano agrícola à direita das plantas úteis, invertendo no ano seguinte. Os sulcos foram abertos com sucador de cana, em uma profundidade de 10 a 15 $\mathrm{cm}$ aproximadamente.

O superfosfato simples foi aplicado na sua totalidade por ocasião da primeira aplicação da uréia e do cloreto de potássio no início do período chuvoso (novembro), de cada ano agrícola. A segunda e a terceira dose da uréia e do cloreto de potássio foram aplicadas geralmente nos meses de janeiro e março, respectivamente. Variações na época de aplicação dos fertilizantes ocorreram em função das condições climáticas. Entretanto, tais variações não comprometeram o cronograma de atividade do projeto.

Antes da instalação do experimento, foi coletada amostra representativa da área experimental, na profundidade de $0-20 \mathrm{~cm}$, cujos resultados analiticos encontraram-se na tabela 3 .

O sistema de sangria utilizado foi em meia espiral, a cada quatro dias com seis dias de sangria por semana, com balanceamento anual de painel, estimulação com Ethrel 2,5\%, aplicação de $1 \mathrm{~g} /$ planta em faixa de $1 \mathrm{~cm}$ sobre o painel de sangria, sendo efetuada 8 aplicações anuais (1/2S d/4 6d/7 (2xy) ET $2,5 \%$ Pa $1 / 18 / y)$. 


\subsection{Parâmetros Observados}

\subsubsection{Variação na Fertilidade do Solo}

Amostras de solo foram coletadas no ano agrícola 1994/1995, nas profundidades de $0-20 \mathrm{~cm}$ e $20-40 \mathrm{~cm}$. Em cada parcela experimental retiraram-se 15 amostras simples, em ziguezague, sendo posteriormente homogeneizadas para coleta de uma amostra composta para cada profundidade.

As determinações analíticas foram realizadas, segundo métodos descritos por Raij \& Quaggio (1983). (a) índice de acidez ( $\mathrm{pH}$ em $\mathrm{CaCl}_{2}$ 0,01M); (b) $\mathrm{P} ; \mathrm{K}$; $\mathrm{Ca}$ e $\mathrm{Mg}$, extraídos em resina trocadora de ions; ( c ) acidez potencial $(H+A l)$, extraida em solução de $\mathrm{KCl} 1 \mathrm{~N}$ e determinado por titulação com $\mathrm{NaOH} 0,02 \mathrm{~N}$ e a matéria orgânica (\% M.O.). Com essas variáveis calculou-se os seguintes parâmetros: Soma de bases trocáveis (SB); capacidade de troca de cátions a pH 7,0 (T); percentagem de saturação de bases da CTC a pH 7,0 (V\%).

\subsubsection{Concentração de Nutrientes nas Folhas}

Nos anos de 1992, 1993 e 1995 coletou-se amostras foliares para as análises. A coleta foi realizada no verão (primeira semana de fevereiro), época em que as folhas lançadas no início da primavera completavam seis meses de idade e nessa fase atingiram sua maturidade fisiológica. As folhas selecionadas foram as quatro basais, com pecíolos, localizadas no último lançamento maduro de ramos sombreados no interior da copa. De cada parcela foram tomadas 20 folhas, coletadas de 6 plantas da parcela útil. (Shorrocks, 1962; Pushpadas \& Ahammed, 1980).

Após a lavagem, secagem e moagem, as amostras foram analisadas quanto aos teores de macronutrientes ( $N, P, K$, $\mathrm{Ca}, \mathrm{Mg}$ e S) e micronutientes ( $\mathrm{Fe}, \mathrm{Cu}, \mathrm{Zn}, \mathrm{Mn}$ e B). 
O nitrogênio total foi extraido por digestão ácida à quente, seguida de destilação em aparelho semi-micro Kjeldahil e titulação (Bremner, 1965). Os macronutrientes $\mathrm{P}, \mathrm{K}, \mathrm{Ca}, \mathrm{Mg}$, e S e os micronutrientes $\mathrm{Fe}, \mathrm{Cu}, \mathrm{Zn}$ e $\mathrm{Mn}$ foram extraidos por digestão nitro-perclórica, sendo que o $P$ foi determinado por colorimetria de molibdato vanadato; o $\mathrm{K}$ por fotometria de chama, o $\mathrm{Ca}, \mathrm{Mg}, \mathrm{Fe}$, $\mathrm{Cu}, \mathrm{Zn}$ e $\mathrm{Mn}$ por espectrofotometria de absorção atômica, o S por turbidimetria de sulfato de bário, e o $B$ analisado pelo método da curcumina (Sarruge \& Haag, 1974).

\subsubsection{Perímetro do Tronco, Espessura da Casca e Produção Bimestral}

A circunferência do tronco foi medida a $1,30 \mathrm{~m}$ do solo, com fita métrica, semestralmente até janeiro de 1994. Posteriormente, essa variável foi mensurada anualmente, de modo que, até o final do ano agricola 94/95, totalizaram-se 14 avaliações.

A espessura da casca foi tomada com auxilio de um paquímetro, com aproximação de $1 / 10$ de $\mathrm{mm}$, na mesma altura em que realizou-se a medida da circunferência do tronco e em um ponto pré-determinado da casca virgem.

As avaliações da espessura da casca foram efetuadas por ocasião da instalação do experimento de adubação, um ano após a instalação do experimento e sete anos após o plantio, totalizando 3 medições até o ano agrícola 94/95.

As produções acumuladas dos meses de junho e julho foram analisadas objetivando correlacioná-las com alguns dos parâmetros fisiológicos determinados. Os coágulos de cada parcela experimental foram pesados em balança digital e os resultados finais foram expressos em $\mathrm{kg}$ de borracha seca/tratamento. O peso referente a umidade dos coágulos foi 
retirado com base no DRC (Dry Rubber Content ou conteúdo de borracha seca) de $37 \%$ (IRCA, 1985).

\subsubsection{Diagnose do Látex por Parâmetros} Fisiológicos

\subsubsection{Teores de Sacarose, Tióis, Fósforo Inorgânico, Magnésio, Cálcio e Potássio}

Na quarta semana do mês de julho de 1995 coletou-se uma amostra do látex de três plantas de cada parcela útil, totalizando 192 amostragens, para a diagnose do látex. Determinaram-se os seguintes parâmetros fisiológicos: conteúdo de borracha seca (\%DRC), sacarose, fósforo inorgânico ( $\mathrm{Pi}$ ), tióis, $\mathrm{Mg}^{++}, \mathrm{Mg} / \mathrm{Pi}, \mathrm{Ca}^{++}, \mathrm{K}^{+}$, os quais estão relacionados com o fluxo do látex e a regeneração dos tecidos laticiferos e, consequentemente, com a produção (IRCA, 1985).

Para coletar as amostras no campo adotou-se os seguintes critérios: iniciou-se a sangria o látex exsudado nos primeiros 5 minutos. Em seguida coletou-se o látex exsudado no intervalo de 5 a 30 minutos, em tubo de ensaio $(25 \mathrm{ml})$, devidamente identificado e acondicionado dentro de um recipiente de isopor $(300 \mathrm{ml})$ com gelo, para manter a temperatura baixa durante toda a coleta. Lógo apos a coleta procedeu-se imediatamente a determinação do $\mathrm{pH}$ do citosol do látex, em nivel de campo.

O sistema adotado para conservação do latex, foi a utilização de recipientes de isopor, com tampa, contendo um orifício no centro, que permitiu a introdução o tubo de ensaio. Um dia antes da coleta encheu-se o mesmo com água da torneira, introduziu-se o tubo de ensaio e colocou-se em um freezer para formar um bloco de gelo. Este sistema permitiu a manutenção da 
temperatura baixa por mais de 24 horas, evitando a coagulação do látex durante a coleta (Figuras 2a, 2b,). Para frascos previamente identificados, pipetou-se $1 \mathrm{ml}$ do látex e adicionou-se $9 \mathrm{ml}$ de ácido tricloro acético a $2,5 \%$. Essa mistura foi feita no campo, pois, após a sua realização, não é mais necessário manter o látex em temperatura baixa (Figuras $2 c$ e $2 d$ ). Conhecida como soro TCA, essa suspensão é usada para determinação dos teores de sacarose, P-inorgânico, magnésio, tióis, cálcio e potássio.

\subsubsection{Conteúdo de Borracha Seca (\%DRC)}

A determinação da \%DRC foi realizada retirando-se uma terceira alíquota de $1 \mathrm{ml}$ do látex coletado, juntando-se a $9 \mathrm{ml}$ do ácido tricloro acético a $2,5 \%$ em frascos de $15 \mathrm{ml}$ previamente identificados e tarados. A borracha é coagulada quando da formação do soro TCA. Após a filtragem, esse coágulo é colocado a secar, em estufa, com circulação forçada de ar a cerca de $70^{\circ} \mathrm{C}$ e posteriormente pesado.

O cálculo do conteúdo de borracha seca, expresso em percentagem, foi determinado através da fórmula: $D R C \%=(P B S /$ PBF) $\times 100$, onde PBS é o peso da borracha seca, PBF é o peso da borracha fresca, subtraindo ambos os valores o peso do vidro. 


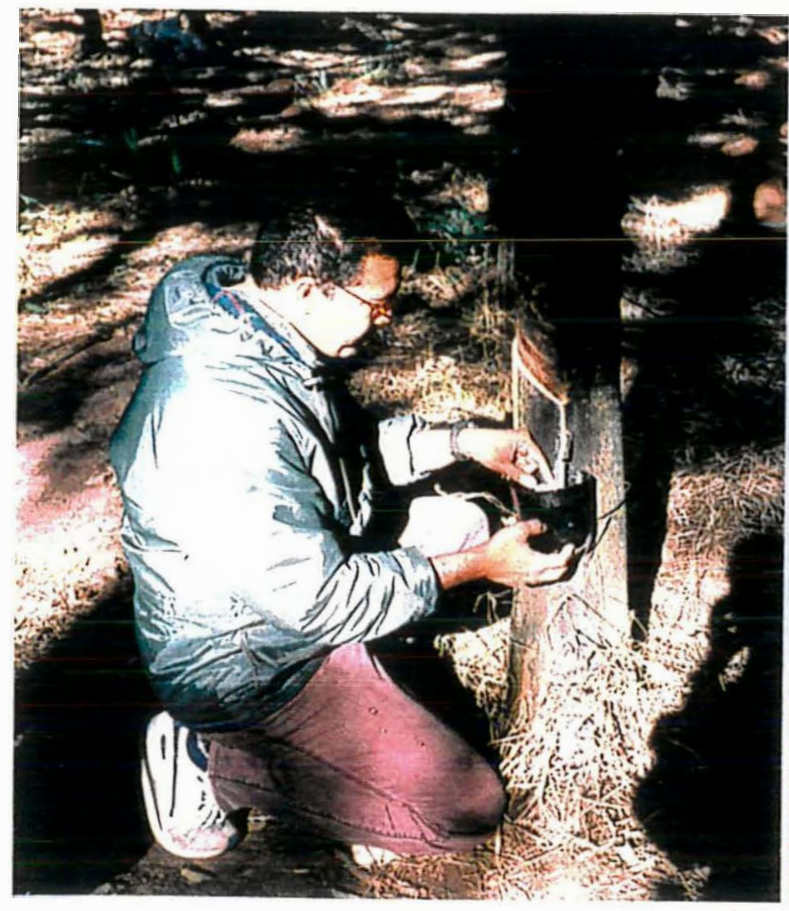

A

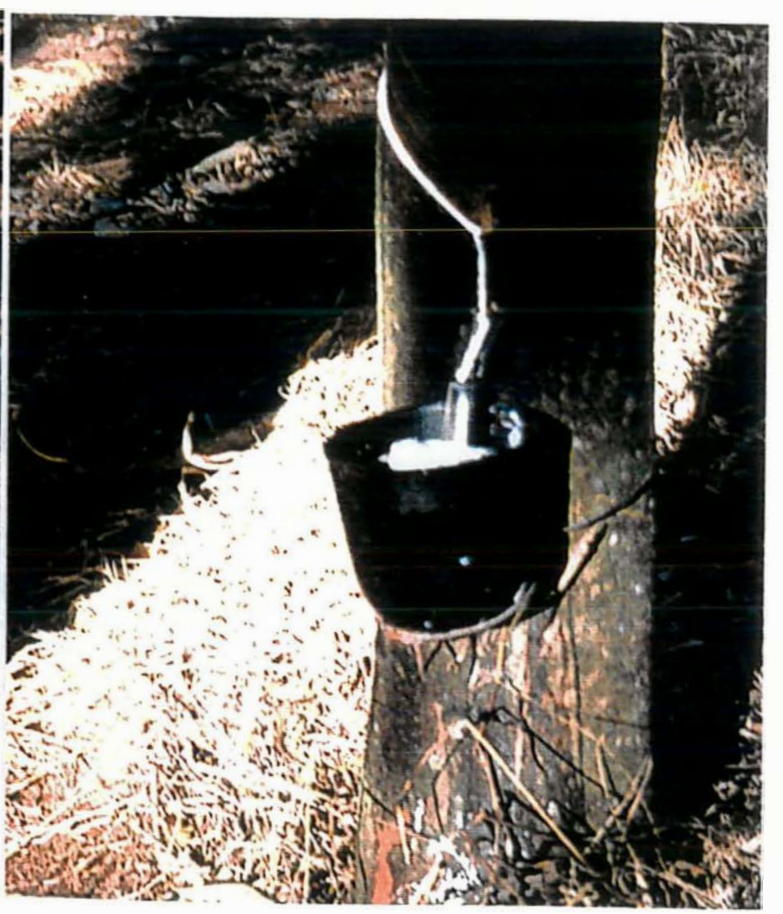

B

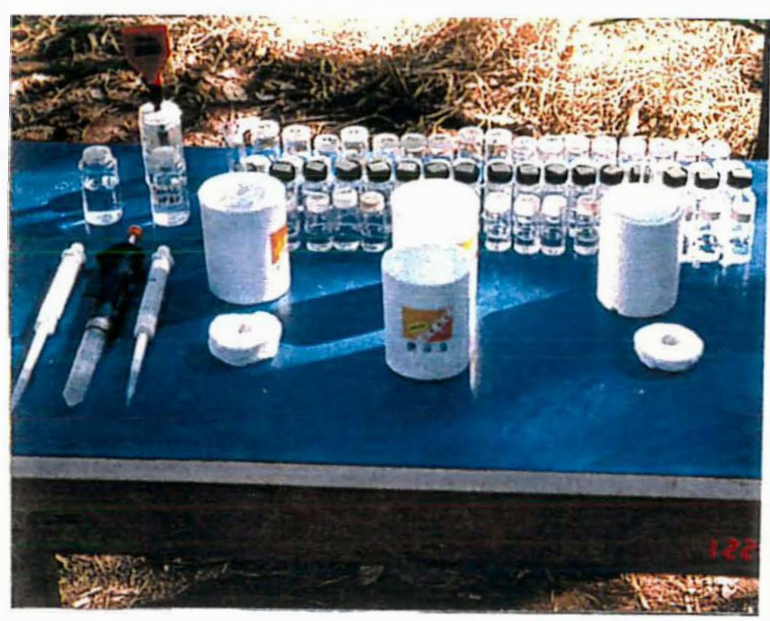

C

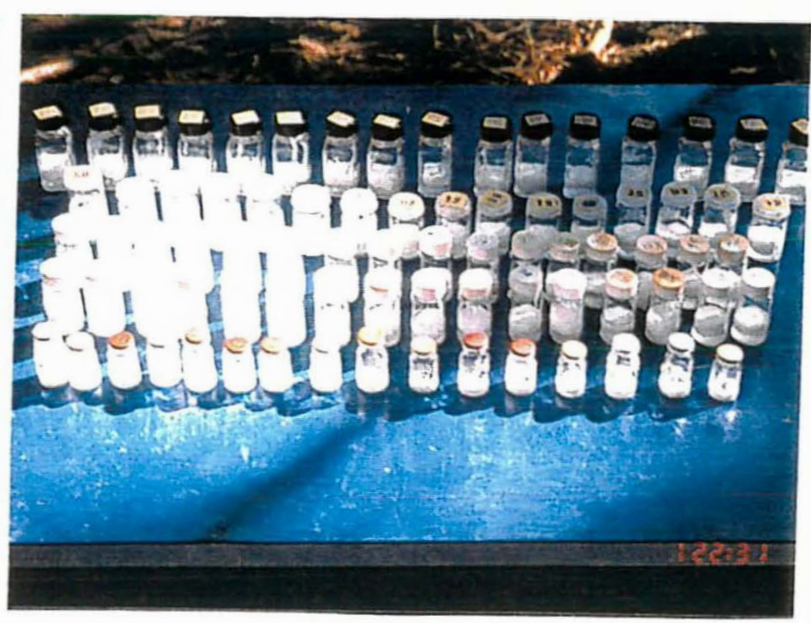

D

Fotografias 2. Técnicas de amostragem do látex para diagnosticar os parâmetros fisiológicos(A e $B)$ e frascos previamente identificados para acondicionar o soro TCA (C e D). 


\subsection{Análise Estatística do Experimento}

Os dados obtidos foram analisados estatisticamente através de análise de variância (teste F) segundo o delineamento em blocos casualizados com 16 tratamentos (fatorial fracionado com 3 nutrientes (NPK) e quatro doses). Para identificar tratamentos com melhor resposta, foram realizadas as comparações dos tratamentos pelo teste Tukey (5\%). Para complementar a análise das diferenças entre tratamentos realizouse análises segundo uma superfície de resposta de segunda ordem, nos tratamentos N, P e K.

Realizou-se também a análise de variância das regressões para identificar o grau de correlação entre as doses de cada nutriente, em cada época, e os parâmetros avaliados, sendo que, quando a regressão foi significativa na análise de variância, as regressões foram utilizadas para a confecção das curvas de resposta. Todas as análises supracitadas foram efetuadas utilizando-se o programa SAS - Sistema de Análises Estatisticas. 


\section{RESULTAdOS E disCUSSÃO}

\subsection{Aspectos Gerais da Fertilidade do Solo}

$\mathrm{Na}$ tabela 3 encontram-se os resultados analíticos de algumas características químicas do solo, obtidos antes da instalação do experimento e após oito anos de condução do mesmo, em um tratamento controle, na profundidade de 0 $20 \mathrm{~cm}$. Observa-se que, apesar da elevação dos valores do $\mathrm{pH}$, - solo apresenta condições fortemente ácidas e baixa fertilidade caracterizada principalmente pelo baixo conteúdo de $\mathrm{K}^{+}, \mathrm{Ca}^{++}$e $\mathrm{Mg}^{++}$disponiveis.

Apesar dos valores de $\mathrm{H}^{+}+\mathrm{Al}^{+++}$se encontrarem em niveis baixos, esses apresentam valores um pouco elevados quando comparados com os teores das bases trocáveis. O decréscimo nos conteúdos de $\mathrm{H}^{+}+\mathrm{Al}^{+++}$e $\mathrm{K}^{+}$e o acréscimo nos teores de $\mathrm{Ca}^{++}$e $\mathrm{Mg}^{++}$, determinado oito anos após a condução do ensaio, revela que essas variáveis contribuíram para a ligeira variação na capacidade de troca de cátions potencial (CTC a pH 7,0). A saturação por bases aumentou significativamente passando de $37 \%$ para $50,3 \%$. Estes resultados são semelhantes aos encontrados por Reis et al. (1984b), pois, a calagem aumentou os teores de $\mathrm{Ca}^{++}$e $\mathrm{Mg}^{++}$, provocando uma mudança nas relações catiônicas no solo.

As características químicas do calcário utilizado mostram que o mesmo apresenta um baixo efeito residual, com PRNT de $89 \%$. Considerando que a amostra 2 foi coletada dois 
Tabela 3. Características químicas do solo da área experimental antes da instalação do experimento, após oito anos da condução do mesmo, na profundidade de $0-20 \mathrm{~cm}$. Amostras $\begin{gathered}\mathrm{pH} \\ \mathrm{CaCl}_{2}\end{gathered}$ M.O.

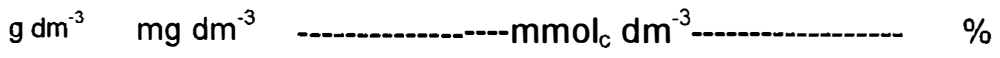

$\begin{array}{lllllllllll}1 & 4,4 & 14,9 & 10,75 & 0,8 & 6,9 & 5,6 & 22,5 & 13,3 & 35,8 & 37,1 \\ 2 & 4,9 & 11,2 & 4,3 & 0,6 & 12,0 & 6,7 & 18,8 & 19,2 & 38,1 & 50,3\end{array}$

Análises realizadas no laboratório do Centro de Energia Nuclear na Agricultura CENA/USP. Piracicaba-SP.

Tabela 4. Características químicas de um perfil, coletado no tratamento testemunha da área, após oito anos da condução do experimento

\section{Profundidades}

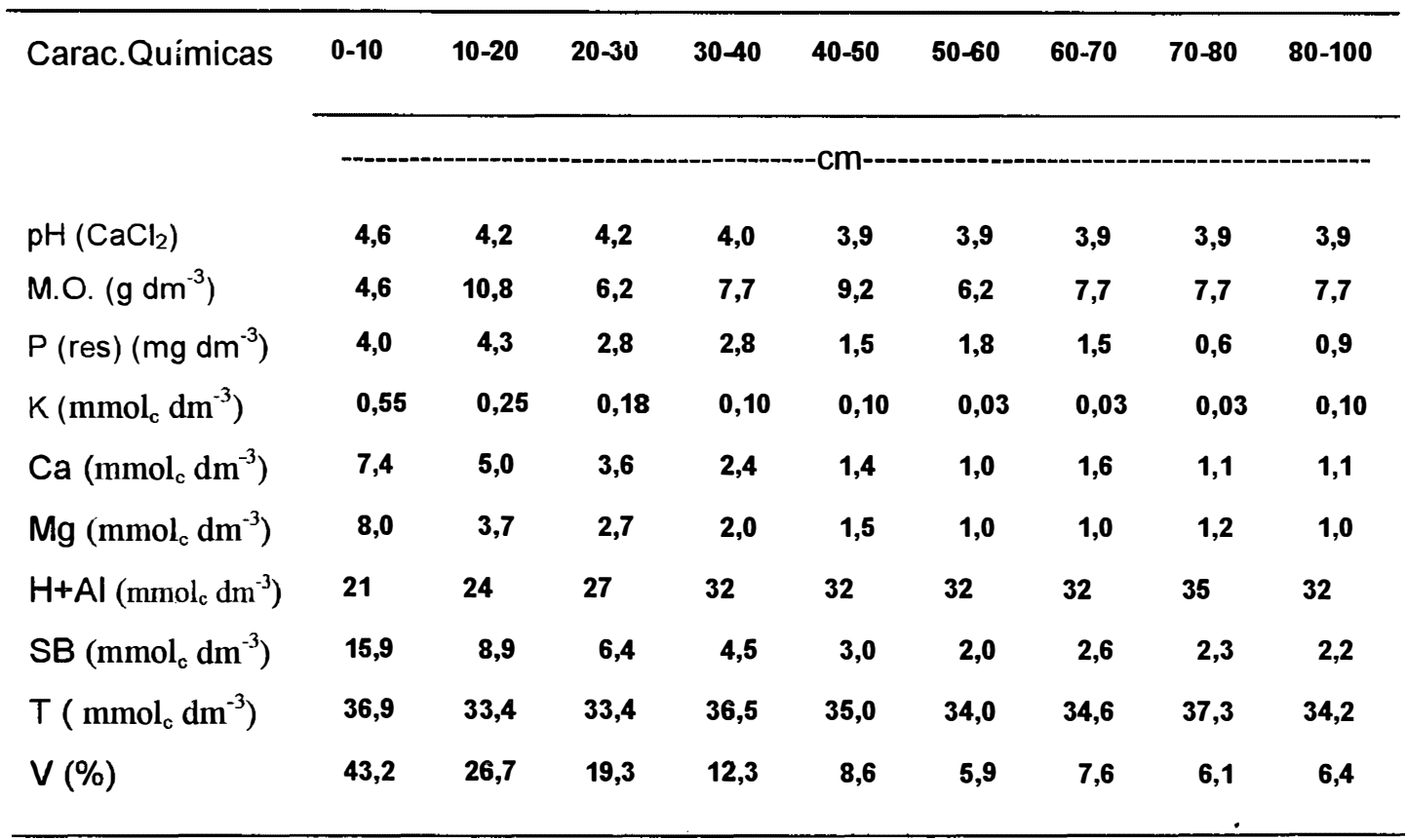

Análises realizadas no laboratório do Centro de Energia Nuclear na Agricultura CENA/USP. Piracicaba-SP. 
anos após a ultima calagem efetuada, e que os resultados analíticos apresentam um incremento nos teores de $\mathrm{Ca}^{++}$e $\mathrm{Mg}^{++}$trocáveis, redução significativa no conteúdo de $\mathrm{H}^{+}+\mathrm{Al}^{+++}$ e uma saturação por bases $(\mathrm{V} \%)$ dentro da faixa considerada adequada para cultura da seringueira, a qual foi estabelecida em torno de 40-50\% (RAIJ, 1991), pressupõe-se que, provavelmente, as quantidades de calcário aplicadas em julho de 1989, agosto de 1991 e março de 1993 foram suficientes para diminuir a acidez, aumentar a saturação de bases a níveis adequados e reduzir o conteúdo de $\mathrm{H}^{+}+\mathrm{Al}^{++}$somente nos anos em que a calagem foi realizada.

A redução no conteúdo de matéria orgânica, que já se encontrava em nivel baixo, não foi tão significativa. Entretanto essa diminuição reflete a importância da introdução de leguminosas de cobertura em seringais, principalmente na fase de desenvolvimento.

Em geral, grande quantidade de nutrientes imobilizados nas plantas de cobertura retornam ao solo, através da liteira, e são reaproveitados pela seringueira na fase de desenvolvimento. A eventual disponibilidade dos nutrientes $\mathrm{N}, \mathrm{P}, \mathrm{K}$ e $\mathrm{Mg}$ e em especial do $\mathrm{N}$, resulta em um crescimento mais rápido e, consequentemente, antecipa 0 início da produção (Rubber Research Institute of Malaya, 1972).

Os dados analíticos de algumas características químicas de um perfil, coletado em fevereiro de 1995, dentro do tratamento controle, encontram-se na tabela 4 . Verifica-se que os valores de $\mathrm{pH}$ apresentaram uma variação de 0,7 unidades com a profundidade. As bases trocáveis $\left(\mathrm{K}^{+}, \mathrm{Ca}^{++} \mathrm{e}\right.$ $\mathrm{Mg}^{++}$) diminuiram drasticamente chegando a valores extremamente baixos, implicando em baixos valores da soma de bases e saturação de bases nas camadas subsuperficiais. Resultado similar, com relação a fração mais alta de $K$ disponivel encontrado na camada superficial do solo foi obtido 
por Joseph et al. (1990) em seringais cultivados no Sul da Índia. $\mathrm{O}^{+}+\mathrm{Al}^{+++}$aumentou com a profundidade, alcançando niveis considerados médios, levando a uma estabilização dos valores da CTC a pH 7,0 ao longo do perfil. A matéria orgânica e o fósforo disponivel segue a mesma tendência dos cátions básicos, ou seja, diminuem com a profundidade, permanecendo em niveis extremamente baixos.

\subsection{Influência dos Tratamentos em Algumas Características Químicas do Solo}

Nas tabelas 5 e 6 são apresentados os valores do teste $F$ das regressões, médias gerais e coeficientes de variação, obtidos mediante análises da variância para os resultados analíticos, das amostras coletadas nas profundidades de $0-20 \mathrm{~cm}$ e $20-40 \mathrm{~cm}$, respectivamente. Na tabela 5 observa-se que o conteúdo de matéria orgânica e o $\mathrm{K}^{+}$ trocável foram afetados linearmente pela adubação potássica. A adubação fosfatada causou efeito linear no teor de $P$ disponivel. Os demais parâmetros não foram afetados pela adubação NPK.

Com respeito aos resultados alcançados na camada subsuperficial $(20-40 \mathrm{~cm})$, nota-se na tabela 6 , que a adubação nitrogenada causou um efeito linear e quadrático no

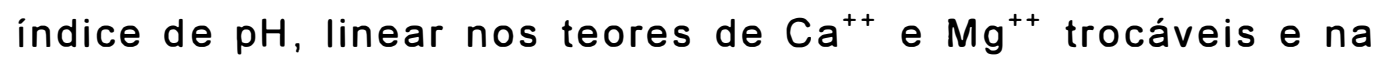
soma de bases. O conteúdo de matéria orgânica, a CTC potencial, $0 \mathrm{H}^{+}+\mathrm{Al}^{+++}$e a saturação por bases não foram afetados pela adubação NPK. O conteúdo de $P$ disponivel variou de forma linear com a adubação nitrogenada, e principalmente com adubação fosfatada, o mesmo ocorrendo com o $\mathrm{K}^{+}$trocável, o qual foi alterado de forma linear pela adubação potássica. Através das figuras $3 a$ e $3 b$ verifica-se que, embora a análise de regressão revele uma diminuição 


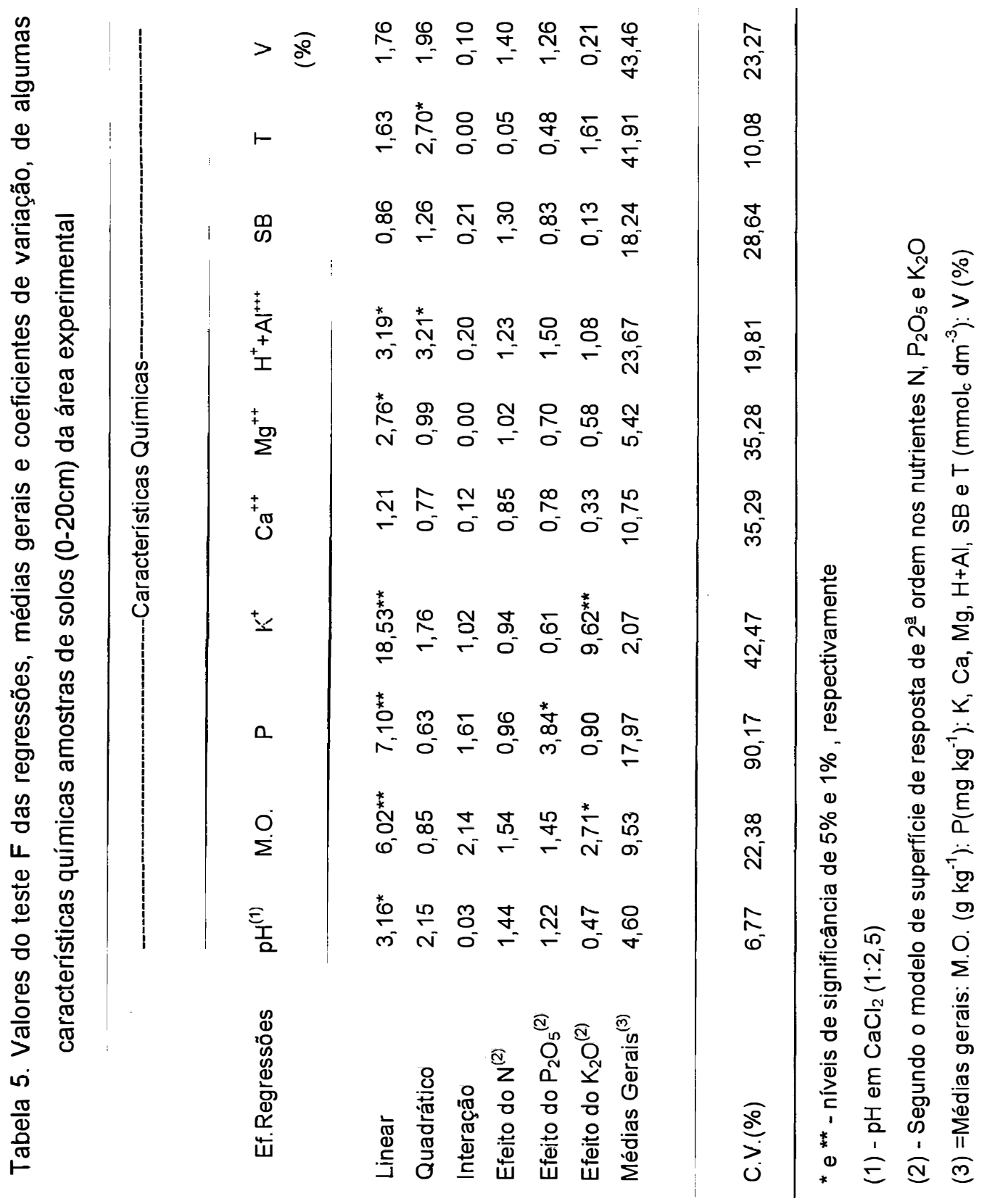




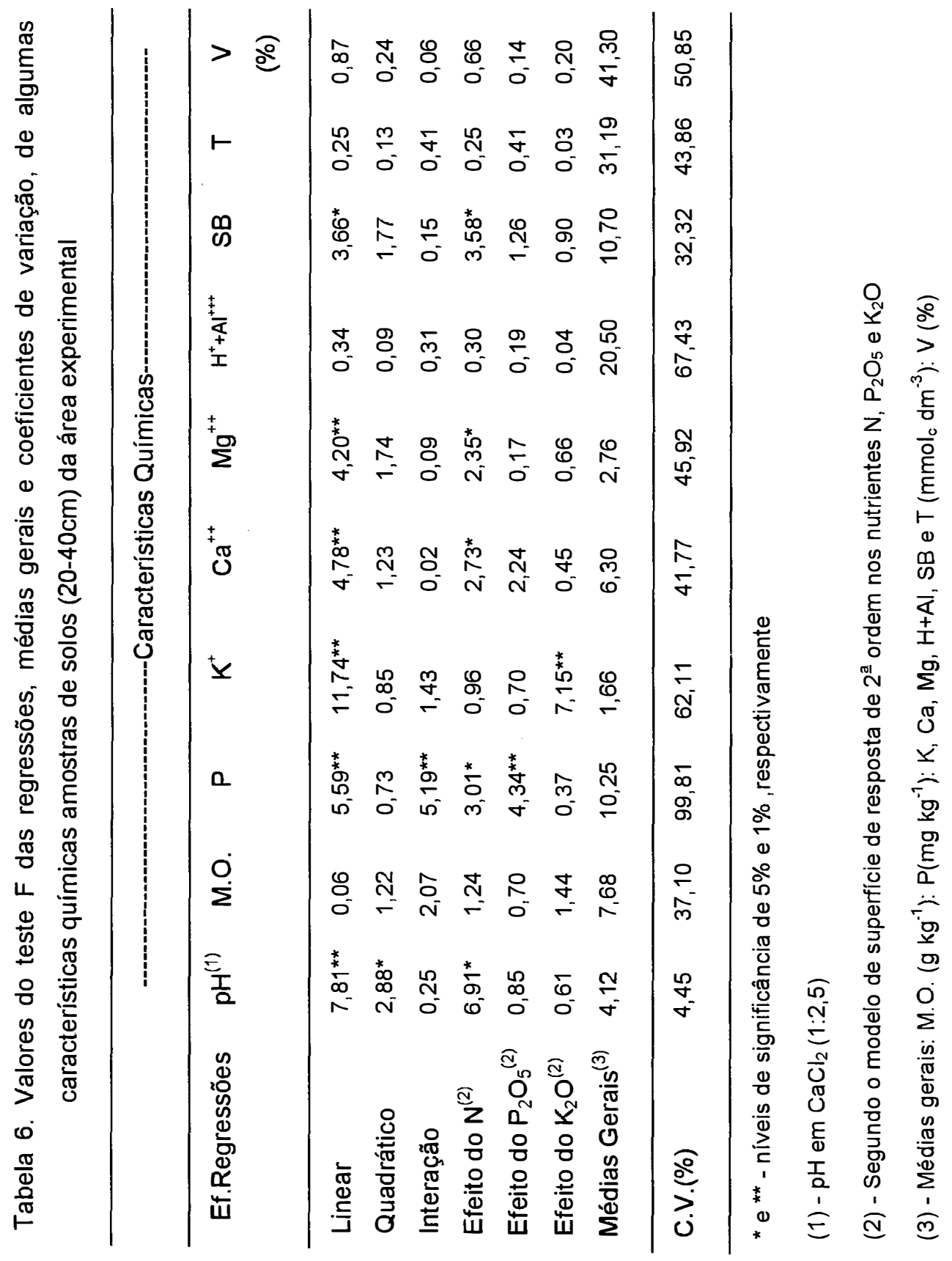



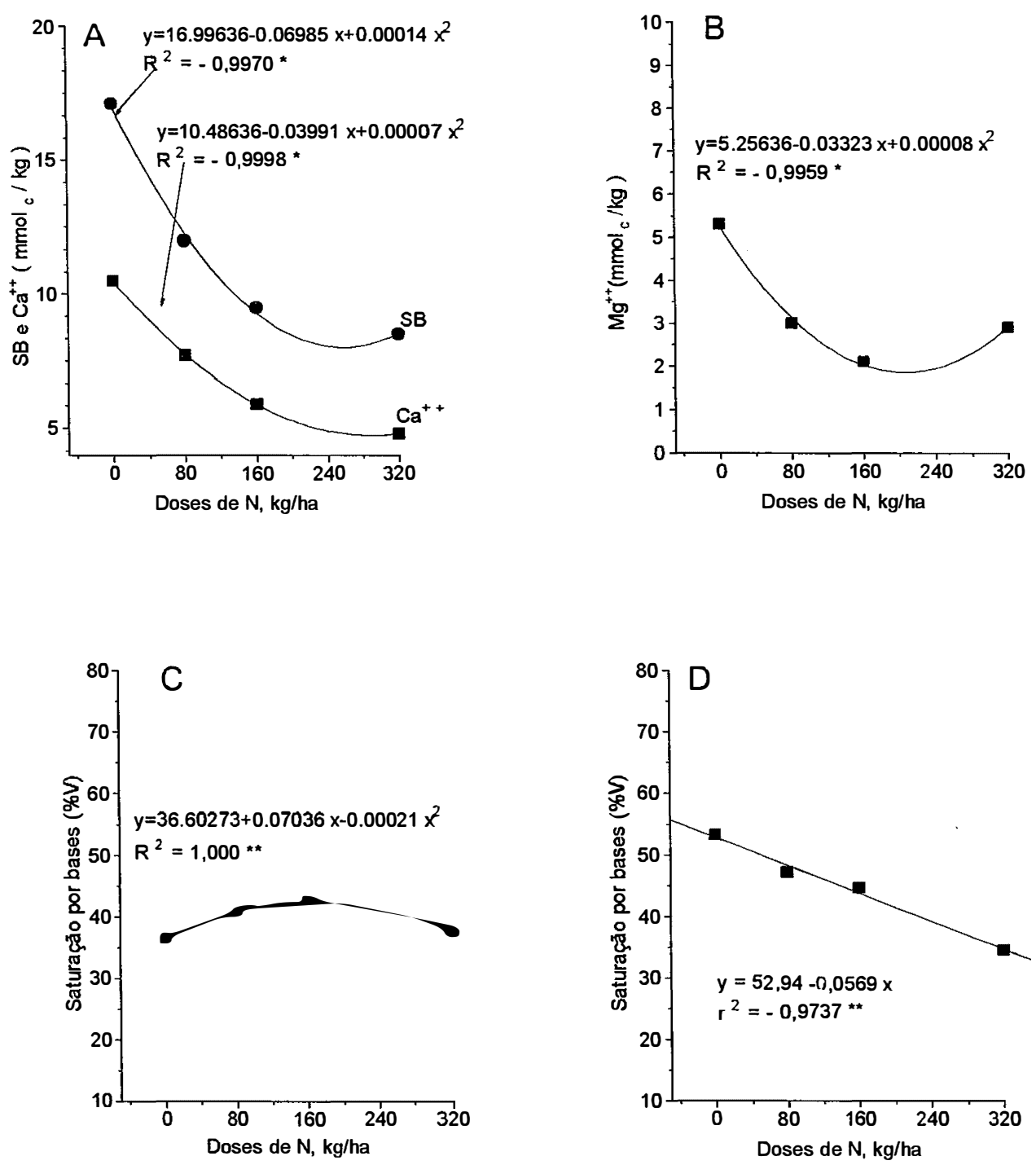

Figura 3. Efeito da adubação nitrogenada nos teores de cálcio e na soma de bases (A); magnésio trocável (B); na saturação por bases (C) na camada de 0$20 \mathrm{~cm}$ e na saturação por bases na camada de $20-40 \mathrm{~cm}$ (D). 
estatisticamente significativa dos teores de $\mathrm{Ca}^{++}, \mathrm{Mg}^{++}$e da SB, com as doses crescentes de nitrogênio aplicadas, tal decréscimo pouco influenciou na fertilidade do solo, uma vez que todas as variáveis continuaram apresentando niveis considerados baixos, exceto o $\mathrm{Mg}$ que apresentou nível médio (5,3 $\left.\mathrm{mmol}_{\mathrm{c}} \mathrm{kg}^{-1}\right)$ para o tratamento que não recebeu adubação nitrogenada.

Embora a aplicação de doses crescentes de nitrogênio tenha afetado significativamente 0 índice de saturação por bases na camada superficial do solo (figura $3 \mathrm{c}$ ), levando em consideração os limites considerados baixo, médio e alto e também a faixa considerada adequada para a cultura da seringueira, pode-se inferir que essa variação $(36,6 \%$ $42,5 \%$ ) influenciou pouco na fertilidade do solo.

Por outro lado, nota-se que o indice de saturação por bases determinado na camada subsuperficial do solo, equivalente a $53,4 \%$ para o tratamento que não recebeu adubação nitrogenada, e $34,6 \%$ para o tratamento que recebeu $320 \mathrm{~kg} \mathrm{ha}^{-1}$, mostra que a adubação nitrogenada conduziu o V\% a nível considerado abaixo da faixa considerada média (Figura 3d).

Este decréscimo pode ser atribuído ao aumento da acidez do solo devido à elevada quantidade de adubo nitrogenado aplicado durante vários anos, conduzindo a uma maior perda dos cátions básicos por lixiviação, e também às características físicas e químicas inerentes aos Podzólicos (Figura 3d). Resultados semelhantes foram obtidos em solos da Malasia por Bolton (1964) e Pushparajah et al. (1983) e no Brasil por Viegas \& Haag (1985), onde a aplicação de sulfato de amônio causou um abaixamento no índice de $\mathrm{pH}$, acarretando em diminuição da CTC potencial, e 
consequentemente, uma lixiviação de cálcio, magnésio e potássio.

A aplicação de doses crescentes de superfosfato simples causou um incremento altamente significativo no teor de fósforo disponivel na camada de $0-20 \mathrm{~cm}$ (Figura 5a). É importante frisar que apesar do efeito linear apresentado com as doses crescentes de fósforo aplicado, os valores encontrados de $23,9 \mathrm{mg} \mathrm{kg}^{-1}\left(P_{0}\right)$ e de $51,1 \mathrm{mg} \mathrm{kg}^{-1}\left(P_{3}\right)$, situam-se na classe de teores considerados médio e alto respectivamente (Raij, 1991).

Estes resultados são semelhantes aos encontrados por Viegas \& Haag (1985) no estado do Pará onde a aplicação de superfosfato triplo aumentou o teor de fósforo disponível no solo. Reis \& Cabala Rosand (1988) no Sul da Bahia, também observaram aumento no teor de fósforo disponivel no solo com as doses de fertilizantes fosfatados aplicados. Observa-se ainda na figura $5 b$ que, a adubação fosfatada influenciou muito pouco o teor de matéria orgânica no solo.

Conforme se pode constatar nas figuras $4 a$ e $4 b$, de maneira geral, a aplicação de doses crescentes de cloreto de potássio proporcionou um aumento estatisticamente significativo no teor de $K$ trocável no solo, tanto na camada de $0-20 \mathrm{~cm}$ como em $20-40 \mathrm{~cm}$ de profundidade. 

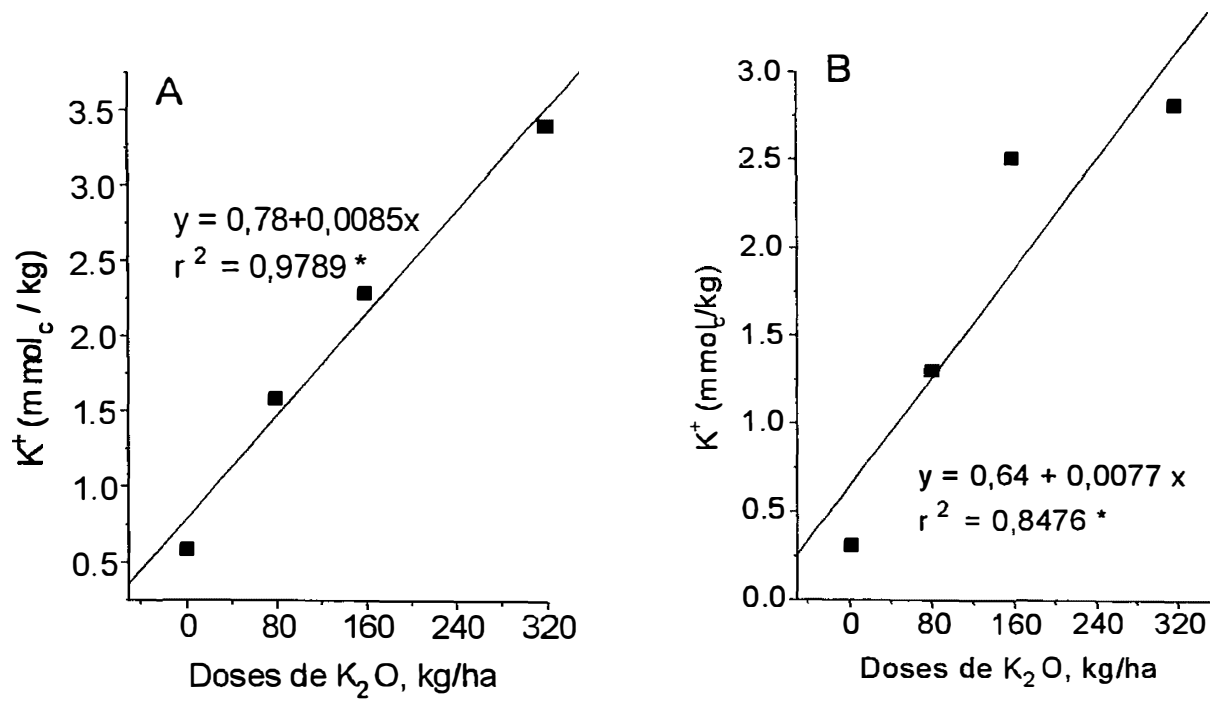

Figura 4. Influência das doses de cloreto de potássio aplicadas sobre os teores de potássio trocável no solo nas camadas de $0-20 \mathrm{~cm}(A)$ e $20-40 \mathrm{~cm}(B)$
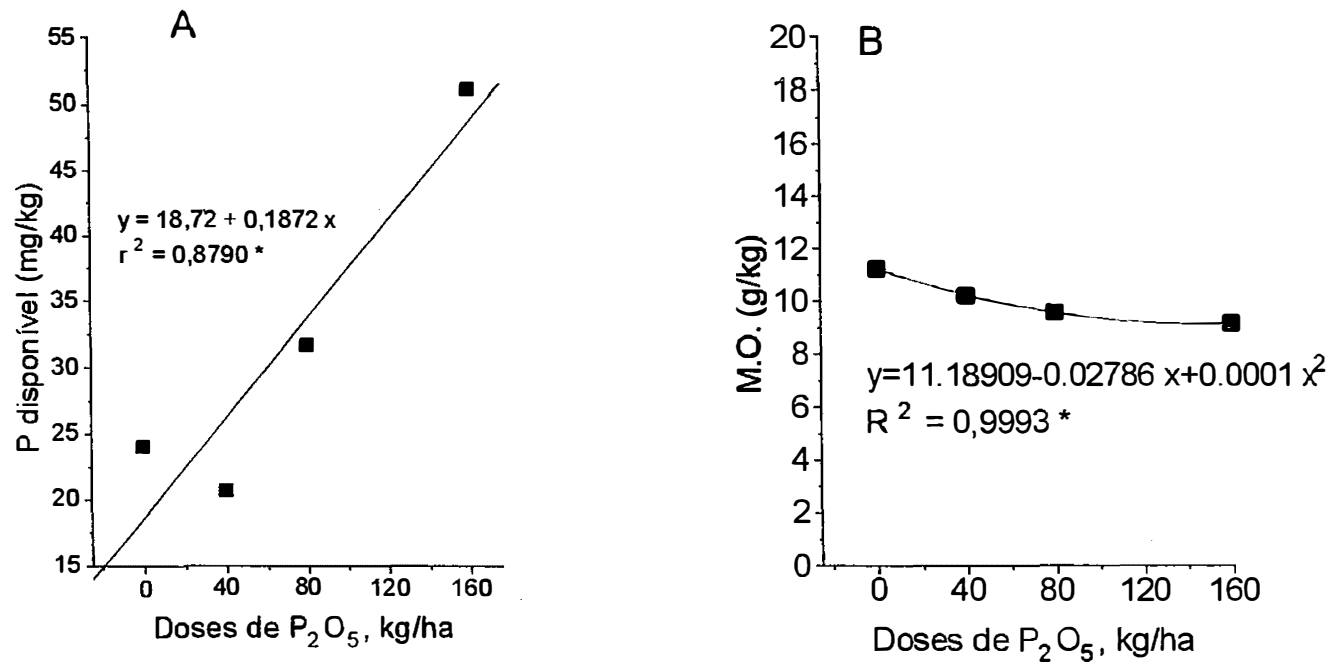

Figura 5. Efeito da adubação fosfatada nos teores de fósforo disponiveis $(A)$ e no teor de matéria orgânica $(B)$ na camada de $0-20 \mathrm{~cm}$. 
Pushparajah (1977) relata que a adubação potássica, em solos cauliníticos, tende a aumentar o teor de potássio, enquanto que, a adubação potássica, em solos que contém micas e ilitas, tem sido observado um maior incremento de potássio disponivel do que de potássio trocável, provavelmente devido a fixação do potássio.

A comparação das médias pelo teste de Tukey ao nivel de $5 \%$ de probabilidade (Tabelas 7 e 8 ) revelaram que 0 efeito dos tratamentos foi significativo somente para os teores de potássio e fósforo disponíveis, determinados na camada de $0-20 \mathrm{~cm}$ do solo. Considerando que o nível médio de $\mathrm{K}^{+}$no solo estabelecido é de 1,6 a $3,0 \mathrm{mmol}_{\mathrm{c}} \mathrm{dm}^{-3}$ (Raij, 1991), verifica-se que quase todos os tratamentos apresentam teores classificados como baixo desse nutriente, exceto os tratamentos T11 $\left(\mathrm{N}_{1} \mathrm{P}_{1} \mathrm{~K}_{3}\right)$, T12 $\left(\mathrm{N}_{2} \mathrm{P}_{1} \mathrm{~K}_{2}\right)$ e T16 $\left(\mathrm{N}_{3} \mathrm{P}_{3} \mathrm{~K}_{3}\right)$ os quais receberam as maiores doses de potássio, apresentando, dessa forma, altos teores de $\mathrm{K}$ trocáveis.

Percebe-se também (Tabela 8 ) que, o teor de $P$ disponivel encontrado para a maioria dos tratamentos, em torno de 16 a $40 \mathrm{mg} \mathrm{kg}^{-1}$, pode ser classificado como teor médio (Raij, 1991). Somente os tratamentos T9 $\left(N_{1} P_{3} K_{1}\right)$, T10 $\left(\mathrm{N}_{1} \mathrm{P}_{1} \mathrm{~K}_{2}\right)$, T15 $\left(\mathrm{N}_{2} \mathrm{P}_{2} \mathrm{~K}_{2}\right)$ e T16 $\left(\mathrm{N}_{3} \mathrm{P}_{3} \mathrm{~K}_{3}\right)$, alcançaram teores considerados altos, enquanto que 0 tratamento controle apresentou teor baixo.

O valor da CTC a pH 7,0 (Tabelas 7 e 9) variando em torno de 26,6 - 45,7 $\mathrm{mmol}_{\mathrm{c}} \mathrm{kg}^{-1}$ (niveis baixos) na profundidade de $0-40 \mathrm{~cm}$, indica que este solo apresenta baixa capacidade de reter cátions, refletindo ainda que, as argilas deste solo são de baixa atividade, formadas provavelmente por 
Tabela 7. Influência dos níveis de nitrogênio, fósforo e potássio sobre algumas características químicas do solo, profundidade de 0-20 cm, efetuada em fevereiro de 1995.

\begin{tabular}{|c|c|c|c|c|c|c|c|c|c|c|}
\hline \multirow[b]{2}{*}{ Tratamentos } & \multirow[b]{2}{*}{$\mathrm{N}$} & \multirow[b]{2}{*}{$\mathrm{P}_{2} \mathrm{O}_{5}$} & \multirow[b]{2}{*}{$\mathrm{K}_{2} \mathrm{O}$} & \multicolumn{7}{|c|}{ Características Químicas-_-_-_-_-_-_- } \\
\hline & & & & \multicolumn{2}{|l|}{$\mathrm{K}^{+}$} & $\mathrm{Ca}^{++}$ & $\mathrm{Mg}^{++}$ & $\mathrm{H}+\mathrm{Al}^{+++}$ & SB & $\mathrm{T}$ \\
\hline & \multicolumn{3}{|c|}{--------kg ha ${ }^{-1}---\cdot-\cdots---$} & \multicolumn{7}{|c|}{ - $\mathrm{mmol}_{\mathrm{c}} \mathrm{dm}^{-3}$} \\
\hline $\mathrm{T}_{1}$ & 00 & 00 & 00 & 0,6 & d & 12,0 & 6,7 & 18,8 & 19,2 & 38,1 \\
\hline $\mathrm{T}_{4}$ & 00 & 40 & 80 & 1,4 & cd & 9,1 & 4,8 & 26,4 & 15,3 & 41,6 \\
\hline $\mathrm{T}_{5}$ & 80 & 40 & 80 & 1,6 & $c d$ & 9,3 & 4,7 & 22,5 & 15,6 & 38,1 \\
\hline $\mathrm{T}_{6}$ & 160 & 40 & 80 & 1,6 & $c d$ & 12,1 & 5,8 & 26.1 & 19,5 & 45,6 \\
\hline $\mathrm{T}_{7}$ & 320 & 40 & 80 & 1,6 & cd & 9,1 & 4,4 & 25,1 & 15,1 & 40,3 \\
\hline $\mathrm{T}_{3}$ & 80 & 00 & 80 & 1,8 & bcd & 13,2 & 7,8 & 18,5 & 22,9 & 41,4 \\
\hline$T_{5}$ & 80 & 40 & 80 & 1,6 & $c d$ & 9,3 & 4,7 & 22,5 & 15,6 & 38,1 \\
\hline $\mathrm{T}_{8}$ & 80 & 80 & 00 & 2,0 & abcd & 13,4 & 7,6 & 21,9 & 23,0 & 44,9 \\
\hline $\mathrm{T}_{9}$ & 80 & 160 & 80 & 1,5 & $c d$ & 12,9 & 5,6 & 23,4 & 20,0 & 43,4 \\
\hline $\mathrm{T}_{2}$ & 80 & 40 & 160 & 0,6 & d & 11,0 & 5,8 & 19,7 & 17,3 & 37,1 \\
\hline $\mathrm{T}_{5}$ & 80 & 40 & 320 & 1,6 & $\mathrm{~cd}$ & 9,3 & 4,7 & 22,5 & 15,6 & 38,1 \\
\hline$T_{10}$ & 80 & 40 & 160 & 2,3 & abcd & 11,8 & 4,8 & 22,7 & 18,9 & 41,7 \\
\hline $\mathrm{T}_{11}$ & 80 & 40 & 320 & 3,4 & $a b$ & 10,6 & 5,2 & 22,9 & 19,2 & 42,1 \\
\hline$T_{12}$ & 160 & 40 & 160 & 3,5 & $a b$ & 8,2 & 4,9 & 26,0 & 16,7 & 42,7 \\
\hline$T_{13}$ & 320 & 40 & 160 & 1,8 & bed & 8,7 & 4,5 & 29,1 & 15,1 & 44,2 \\
\hline$T_{14}$ & 160 & 40 & 320 & 3,0 & $a b c$ & 9,4 & 4,7 & 23,7 & 17,2 & 40,9 \\
\hline$T_{15}$ & 160 & 80 & 160 & 2,5 & $a b c$ & 11,3 & 5,2 & 26,6 & 19,1 & 45,7 \\
\hline$T_{16}$ & 320 & 160 & 320 & 3,6 & a & 9,9 & 3,8 & 25,1 & 17,4 & 42,5 \\
\hline
\end{tabular}

Médias seguidas pela mesma letra não diferem entre si estatisticamente pelo teste de Tukey ao nível de $5 \%$ de probabilidade, 
Tabela 8. Influência dos níveis de nitrogênio, fósforo e potássio sobre algumas características quimicas do solo, profundidade de $0-20 \mathrm{~cm}$, efetuada em fevereiro de 1995.

\begin{tabular}{|c|c|c|c|c|c|c|c|c|}
\hline \multirow{3}{*}{ Tratamentos } & \multirow[b]{2}{*}{$N$} & \multirow[b]{2}{*}{$\mathrm{P}_{2} \mathrm{O}_{5}$} & \multirow[b]{2}{*}{$\mathrm{K}_{2} \mathrm{O}$} & \multicolumn{5}{|c|}{ Características Químicas } \\
\hline & & & & \multirow{2}{*}{$\frac{\mathrm{pH}}{\left(\mathrm{CaCl}_{2}\right)}$} & \multirow{2}{*}{$\frac{\text { M.O. }}{\mathrm{g} \mathrm{kg}^{-1}}$} & \multicolumn{2}{|l|}{$\mathrm{P}$} & \multirow{2}{*}{$\begin{array}{r}\text { V } \\
(\%)\end{array}$} \\
\hline & - & g ha ${ }^{-1}-$ & $\ldots$ & & & $\mathrm{mg} \mathrm{kg}^{-1}$ & & \\
\hline $\mathrm{T}_{1}$ & 00 & 00 & 00 & 4,93 & 11,2 & 4,3 & b & 50,3 \\
\hline $\mathrm{T}_{4}$ & 00 & 40 & 80 & 4,43 & 9,2 & 12,4 & $a b$ & 36,6 \\
\hline $\mathrm{T}_{5}$ & 80 & 40 & 80 & 4,52 & 10,2 & 20,7 & $a b$ & 40,9 \\
\hline $\mathrm{T}_{6}$ & 160 & 40 & 80 & 4,56 & 11,9 & 33,4 & $a b$ & 42,5 \\
\hline $\mathrm{T}_{7}$ & 320 & 40 & 80 & 4,40 & 10,4 & 23,5 & $a b$ & 37,7 \\
\hline $\mathrm{T}_{3}$ & 80 & 00 & 80 & 4,95 & 11,2 & 23,9 & $a b$ & 54,2 \\
\hline $\mathrm{T}_{5}$ & 80 & 40 & 80 & 4,52 & 10,2 & 20,7 & $a b$ & 40,9 \\
\hline $\mathrm{T}_{8}$ & 80 & 80 & 00 & 4,82 & 9,6 & 31,6 & $a b$ & 50,7 \\
\hline $\mathrm{T}_{9}$ & 80 & 160 & 80 & 4,68 & 9,2 & 51,1 & $a b$ & 46,1 \\
\hline $\mathrm{T}_{2}$ & 80 & 40 & 160 & 4,76 & 11,1 & 16,7 & $a b$ & 46,4 \\
\hline$T_{5}$ & 80 & 40 & 320 & 4,52 & 10,2 & 20,7 & $a b$ & 40,9 \\
\hline$T_{10}$ & 80 & 40 & 160 & 4,61 & 10,4 & 48,8 & $a b$ & 45,5 \\
\hline $\mathrm{T}_{11}$ & 80 & 40 & 320 & 4,67 & 10,0 & 12,6 & $a b$ & 45,4 \\
\hline $\mathrm{T}_{12}$ & 160 & 40 & 160 & 4,48 & 8,8 & 13,3 & $a b$ & 39,6 \\
\hline$T_{13}$ & 320 & 40 & 160 & 4,35 & 3,1 & 19,3 & $a b$ & 35,3 \\
\hline $\mathrm{T}_{14}$ & 160 & 40 & 320 & 4,54 & 8,1 & 18,6 & $a b$ & 41,9 \\
\hline $\mathrm{T}_{15}$ & 160 & 80 & 160 & 4,49 & 7,3 & 44,4 & $a b$ & 41,3 \\
\hline$T_{16}$ & 320 & 160 & 320 & 4,43 & 6,5 & 74,3 & $a$ & 40,7 \\
\hline
\end{tabular}

Médias seguidas pela mesma letra não diferem entre si estatisticamente pelo teste de Tukey ao nivel de $5 \%$ de probabilidade, 
caulinitas e/ou óxidos e hidróxidos de ferro e alumínio. O baixo conteúdo de matéria orgânica, entre $5,0-11,9 \mathrm{~g} \mathrm{~kg}^{-1} \mathrm{na}$ camada de $0-40 \mathrm{~cm}$, reforça a suposição de que este solo apresenta alto grau de perdas de nutrientes por lixiviação e/ou percolação (Tabelas 8 e 10).

Os tratamentos T13 $\left(\mathrm{N}_{3} \mathrm{P}_{1} \mathrm{~K}_{2}\right)$ e T16 $\left(\mathrm{N}_{3} \mathrm{P}_{3} \mathrm{~K}_{3}\right)$, que receberam as maiores doses de uréia e de cloreto de potássio, foram os que apresentaram os menores valores de $\mathrm{pH}$, tanto na profundidade de $0-20 \mathrm{~cm}$ como na de $20-40 \mathrm{~cm}$ (Tabelas 8 e 10).

As tabelas 9 e 10 evidenciam os resultados da comparação das médias efetuada pelo teste de Tukey, ao nível de $5 \%$ de probabilidade, para os resultados analíticos das amostras de solos coletadas na profundidade de $20-40 \mathrm{~cm}$.

Verifica-se que as variáveis indice de $\mathrm{pH}$, concentrações de fósforo disponível, potássio e magnésio trocáveis e soma de bases foram alteradas significativamente pelos tratamentos testados. Embora os teores de potássio trocáveis, determinados para os diferentes tratamentos, tenham apresentado diferenças estatisticamente significativas, todos os valores encontrados estão nas faixas média e baixa, exceto no tratamento $\mathrm{T} 16\left(\mathrm{~N}_{3} \mathrm{P}_{3} \mathrm{~K}_{3}\right)$ com valor de $3,2 \mathrm{mmol}_{\mathrm{c}} \mathrm{dm}^{3}$, o qual pode ser considerado alto.

Nota-se que os tratamentos que receberam as maiores doses de cloreto de potássio, apresentaram teores de $K$ trocáveis 3 a 6 vezes maiores do que os tratamentos que não foram adubados com fertilizante potássico. Apesar das diferenças estatisticamente significativas encontradas entre os tratamentos, tanto o cálcio como o magnésio e a soma de bases apresentaram teores considerados baixos. O mesmo aconteceu com o fósforo. O índice de $\mathrm{pH}$ foi menor para os 
Tabela 9. Influência dos níveis de nitrogênio, fósforo e potássio sobre algumas características quimicas do solo na profundidade de 20-40 cm, efetuadas em fevereiro de 1995.

\begin{tabular}{|c|c|c|c|c|c|c|c|c|c|c|c|c|}
\hline Tratamentos & $N$ & $\mathrm{P}_{2} \mathrm{O}_{5}$ & $\mathrm{~K}_{2} \mathrm{O}$ & $\mathrm{K}^{+}$ & & $\mathrm{Ca}^{++}$ & $\mathrm{Mg}^{++}$ & & $\mathrm{H}+\mathrm{Al}^{+++}$ & SB & & $\mathrm{T}$ \\
\hline & --.-- & $h a^{-1}$ & -.. & & & ----- & -----m & $\mathrm{nol}_{\mathrm{c}} \mathrm{d}$ & & & & \\
\hline $\mathrm{T}_{1}$ & 00 & 00 & 00 & 0,6 & de & 5,9 & 3,1 & $a b$ & 19,4 & 9,7 & $a b$ & 29,1 \\
\hline $\mathrm{T}_{4}$ & 00 & 40 & 80 & 1,4 & abcde & 10,5 & 5,3 & $a$ & 16,7 & 17,1 & $a$ & 33,9 \\
\hline $\mathrm{T}_{5}$ & 80 & 40 & 80 & 1,3 & abcde & 7,7 & 3,0 & $a b$ & 17,8 & 12,0 & $a b$ & 29,9 \\
\hline$T_{6}$ & 160 & 40 & 80 & 1,5 & abcde & 5,9 & 2,1 & $b$ & 21,6 & 9,5 & $a b$ & 29,9 \\
\hline $\mathrm{T}_{7}$ & 320 & 40 & 80 & 0,8 & cde & 4,8 & 2,9 & $a b$ & 21,2 & 8,5 & $a b$ & 29,7 \\
\hline $\mathrm{T}_{3}$ & 80 & 00 & 80 & 1,3 & abcde & 5,1 & 3,5 & $a b$ & 17,6 & 9,9 & $a b$ & 27,5 \\
\hline $\mathrm{T}_{5}$ & 80 & 40 & 80 & 1,3 & acbde & 7,7 & 3,0 & $a b$ & 17,8 & 12,0 & $a b$ & 29,9 \\
\hline $\mathrm{T}_{8}$ & 30 & 80 & 00 & 1,3 & abcde & 5,5 & 2,9 & $a b$ & 21,6 & 9,8 & $a b$ & 31,4 \\
\hline $\mathrm{T}_{9}$ & 80 & 160 & 80 & 0,9 & bcde & 9,0 & 3,0 & $a b$ & 16,9 & 12,9 & $a b$ & 29,8 \\
\hline $\mathrm{T}_{2}$ & 80 & 40 & 160 & 0,3 & e & 6,7 & 3,0 & $a b$ & 22,1 & 10,0 & $a b$ & 32,2 \\
\hline$T_{5}$ & 80 & 40 & 320 & 1,3 & abcde & 7,7 & 3,0 & $a b$ & 17,8 & 12,0 & $a b$ & 29,9 \\
\hline$T_{10}$ & 80 & 40 & 160 & 2,5 & abcde & 6,4 & 2,1 & b & 20,3 & 11,0 & $a b$ & 31,4 \\
\hline$T_{11}$ & 80 & 40 & 320 & 2,8 & $a b c$ & 5,5 & 2,3 & $a b$ & 19,4 & 10,6 & $a b$ & 30,1 \\
\hline$T_{12}$ & 160 & 40 & 160 & 2,8 & $a b c$ & 4,9 & 2,2 & $a b$ & 16,7 & 9,9 & $a b$ & 26,6 \\
\hline$T_{13}$ & 320 & 40 & 160 & 1,4 & abcde & 4,4 & 1,9 & $b$ & 21,6 & 7,7 & b & 29,3 \\
\hline$T_{14}$ & 160 & 40 & 320 & 2,7 & $a b c$ & 4,7 & 1,9 & $b$ & 19,7 & 9,3 & $a b$ & 29,1 \\
\hline$T_{15}$ & 160 & 80 & 160 & 1,7 & abcde & 7,9 & 3,0 & $a b$ & 29,3 & 12,7 & $a b$ & 42,0 \\
\hline$T_{16}$ & 320 & 160 & 320 & 3,2 & a & 5,4 & 1,7 & b & 26,7 & 10,4 & $a b$ & 37,0 \\
\hline
\end{tabular}

Médias seguidas pela mesma letra não diferem entre si estatisticamente pelo teste de Tukey ao nível de $5 \%$ de probabilidade. 
Tabela 10. Influência dos níveis de nitrogênio, fósforo e potássio sobre algumas características químicas do solo na profundidade de $20-40 \mathrm{~cm}$, efetuada em fevereiro de 1995.

-Características Químicas

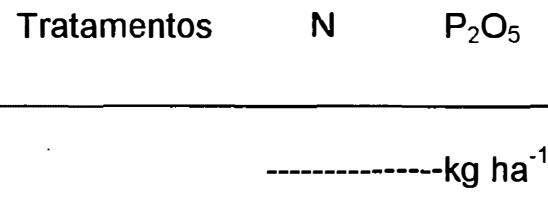

$\mathrm{pH} \quad$ M.O.

$\mathbf{P}$

V

\begin{tabular}{|c|c|c|c|c|c|c|c|c|c|}
\hline $\mathrm{T}_{1}$ & 00 & 00 & 00 & 4,12 & $a b$. & 8,4 & 2,1 & b & 41,5 \\
\hline $\mathrm{T}_{4}$ & 00 & 40 & 80 & 4,59 & $a$ & 9,2 & 17,4 & $a b$ & 53,4 \\
\hline$T_{5}$ & 80 & 40 & 80 & 4,17 & $a b$ & 6,9 & 9,2 & $a b$ & 47,2 \\
\hline $\mathrm{T}_{6}$ & 160 & 40 & 80 & 4,02 & $b$ & 7,7 & 10,3 & $a b$ & 33,7 \\
\hline $\mathrm{T}_{7}$ & 320 & 40 & 80 & 4,01 & b & 6,9 & 6,7 & $a b$ & 34,6 \\
\hline $\mathrm{T}_{3}$ & 80 & 00 & 80 & 4,17 & $a b$ & 8,1 & 2,7 & $b$ & 41,4 \\
\hline $\mathrm{T}_{5}$ & 80 & 40 & 80 & 4,17 & $a b$ & 6,9 & 9,2 & $a b$ & 47,2 \\
\hline$T_{8}$ & 80 & 80 & 00 & 4,17 & $a b$ & 7,3 & 6,8 & $a b$ & 37,3 \\
\hline $\mathrm{T}_{9}$ & 80 & 160 & 80 & 4,19 & $a b$ & 7,7 & 11,2 & $a b$ & 51,2 \\
\hline $\mathrm{T}_{2}$ & 80 & 40 & 160 & 4,15 & $a b$ & 7,7 & 12,7 & $a b$ & 37,7 \\
\hline $\mathrm{T}_{5}$ & 80 & 40 & 320 & 4,17 & $a b$ & 6,9 & 9,2 & $a b$ & 47,2 \\
\hline$T_{10}$ & 80 & 40 & 160 & 4,11 & b & 8,8 & 10,1 & $a b$ & 41,7 \\
\hline $\mathrm{T}_{11}$ & 80 & 40 & 320 & 4,18 & $a b$ & 5,0 & 4,1 & $b$ & 42,9 \\
\hline$T_{12}$ & 160 & 40 & 160 & 4,07 & $b$ & 5,8 & 4,8 & $b$ & 49,7 \\
\hline$T_{13}$ & 320 & 40 & 160 & 3,93 & $b$ & 7,7 & 4,6 & b & 33,3 \\
\hline $\mathrm{T}_{14}$ & 160 & 40 & 320 & 4,01 & $b$ & 10,4 & 6,1 & $a b$ & 35,8 \\
\hline$T_{15}$ & 160 & 80 & 160 & 4,11 & b & 5,4 & 21,7 & $a b$ & 35,2 \\
\hline$T_{16}$ & 320 & 160 & 320 & 3,94 & b & 9,6 & 32,5 & $a$ & 33,1 \\
\hline
\end{tabular}

Médias seguidas pela mesma letra não diferem entre si estatisticamente pelo teste de Tukey ao nivel de $5 \%$ de probabilidade. 
tratamentos que receberam as maiores doses do fertilizante nitrogenado.

\subsection{Efeito da Adubação Nitrogenada, Fosfatada e Potássica no Estado Nutricional das Plantas}

Nas tabelas 11 e 12 pode-se observar que a adubação nitrogenada afetou significativamente os teores de $\mathrm{N}$ e $\mathrm{Cu}$; a adubação fosfatada influenciou significativamente os teores de $\mathrm{P}$ e $\mathrm{S} ; \quad$ a adubação potássica afetou significativamente os teores de $\mathrm{K}, \mathrm{Mg}, \mathrm{Fe}$ e $\mathrm{Cu}$ nas folhas das seringueiras com oito anos de idade.

Nas folhas das plantas com nove anos, as adubações nitrogenada e fosfatada afetaram significativamente os teores de $\mathrm{K}, \mathrm{Cu}$ e $\mathrm{B}$, enquanto que a adubação potássica afetou significativamente os teores de $\mathrm{N}$, $\mathrm{K}, \mathrm{Fe}$ e Mn (tabelas 13 e 14).

Em relação aos efeitos dos tratamentos nos teores de nutrientes nas folhas das seringueiras com onze anos de idade, observa-se também pelas tabelas 15 e 16 que a adubação nitrogenada afetou significativamente os teores de $\mathrm{P}, \mathrm{K}, \mathrm{Ca}, \mathrm{Mn}$ e $\mathrm{B}$; e a adubação potássica influenciou significativamente os teores de $\mathrm{K}, \mathrm{Ca}, \mathrm{Mg}$ e $\mathrm{Cu}$, ao passo que a adubação fosfatada não afetou.

O estabelecimento de faixas adequadas de concentração de macronutrientes e micronutrientes nas folhas da seringueira tem sido sugerida por diversos autores (tabela 17). 
Tabela 11. Valores de $F$ das regressões, médias gerais e coeficientes de variação, dos teores de masronutrientes nas folhas de seringueiras com oito anos de idade.

-Macronutrientes nas Folhas--...-.-.

$\begin{array}{lllllll}\text { Efeitos de Regressões } & N & P & K & C a & M g & S\end{array}$

\begin{tabular}{lccccccc}
\hline Linear & $6,24^{* *}$ & $4,40^{* *}$ & $34,24^{* *}$ & 1,83 & $4,55^{\star *}$ & $2,43^{*}$ \\
Quadrático & $3,46^{*}$ & 1,17 & 0,08 & 0,32 & 0,11 & $2,93^{*}$ \\
Interação & 1,80 & 0,96 & 1,91 & 0,23 & 0,20 & 0,10 \\
Efeito do ${ }^{(1)}$ & $3,90^{* *}$ & 1,64 & 1,33 & 0,47 & 0,10 & 1,14 \\
Efeito do $\mathrm{P}_{2} \mathrm{O}_{5}^{(1)}$ & 0,94 & $2,54^{*}$ & 1,06 & 0,74 & 0,12 & $2,24 *$ \\
Efeito do $\mathrm{K}_{2} \mathrm{O}^{(1)}$ & 2,09 & 1,98 & $29,01^{* *}$ & 1,09 & $2,73^{*}$ & 1,13 \\
\hline Médias Gerais & & 21,78 & 1,12 & 5,11 & 27,34 & 5,38 & 2,08 \\
\hline C.V. (\%) & 9,17 & 15,36 & 16,84 & 23,03 & 24,60 & 11,58
\end{tabular}

$e^{* *}$ - niveis de significância de $5 \%$ e $1 \%$ respectivamente

(1)- segundo o modelo de superficie de resposta de $2^{\text {a }}$ ordem dos nutrientes $\mathrm{N}, \mathrm{P}_{2} \mathrm{O}_{5}$ e $\mathrm{K}_{2} \mathrm{O}$

(2)- teores em g kg-1 
Tabela 12. Valores de $F$ das regressões, médias gerais e coeficientes de variação, dos teores de micronutrientes nas folhas de seringueiras com oito anos de idade.

-Micronutrientes nas Folhas

$\begin{array}{llllll}\text { Efeitos de Regressões } & \mathrm{Fe} & \mathrm{Cu} & \mathrm{Zn} & \mathrm{Mn} & \mathrm{B}\end{array}$

\begin{tabular}{llllll}
\hline Linear & $2,66^{* *}$ & $18,71^{* *}$ & 0,92 & 1,99 & 6,72 \\
Quadrático & 0,19 & 1,70 & 0,32 & 0,06 & 0,95 \\
Interação & 1,78 & $6,40^{* *}$ & 1,36 & 1,54 & 0,17 \\
Efeito do $\mathrm{N}^{(1)}$ & 0,89 & $3,96^{* *}$ & 1,11 & 0,89 & 1,61 \\
Efeito do $\mathrm{P}_{2} \mathrm{O}_{5}^{(1)}$ & 1,34 & 1,70 & 1,02 & 0,27 & 1,45 \\
Efeito do $\mathrm{K}_{2} \mathrm{O}^{(1)}$ & $3,06^{*}$ & $6,90^{* *}$ & 1,31 & 0,42 & 0,76 \\
\hline Médias Gerais & 113,50 & 4,22 & 16,39 & 935,72 & 10,98 \\
\hline C.V. (\%) & 32,07 & 18,07 & 19,68 & 23,02 & 28,89 \\
\hline
\end{tabular}

$e^{* *}$ - níveis de significância de $5 \%$ e $1 \%$ respectivamente

(1) - segundo o modelo de superficie de resposta de $2^{\text {a }}$ ordem dos nutrientes $\mathrm{N}, \mathrm{P}_{2} \mathrm{O}_{5}$ e $\mathrm{K}_{2} \mathrm{O}$

(2)- teores em mg kg-1 
Tabela 13. Valores de $F$ das regressões, médias gerais e coeficientes de variação, dos teores de macronutrientes nas folhas de seringueiras com nove anos de idade.

Macronutrientes nas Folhas

\begin{tabular}{lllllllll}
\hline Efeitos de Regressões & $N$ & $P$ & $K$ & $C a$ & $M g$ & $S$
\end{tabular}

\begin{tabular}{|c|c|c|c|c|c|c|}
\hline Linear & $4,26^{\star \star}$ & 0,96 & $46,15^{\star \star}$ & 1,45 & 1,44 & 1,47 \\
\hline Quadrático & $2,63^{*}$ & 0,05 & $11,08^{\star \star}$ & 3,09 & 0,46 & 0,01 \\
\hline Interação & 1,55 & 1,16 & $4,04^{*}$ & 0,56 & 0,83 & 0,60 \\
\hline Efeito do $N^{(1)}$ & 0,85 & 1,72 & $5,54^{\star \star}$ & 1,61 & 0,42 & 0,90 \\
\hline Efeito do $\mathrm{P}_{2} \mathrm{O}_{5}^{(1)}$ & 0,86 & 1,60 & $3,71^{\star}$ & 0,43 & 0,82 & 0,23 \\
\hline Efeito do $\mathrm{K}_{2} \mathrm{O}^{(1)}$ & $3,99 * *$ & 0,92 & $49,81^{\star \star}$ & 0,05 & 0,69 & 1,10 \\
\hline Médias Gerais ${ }^{(2)}$ & 32,66 & 2,33 & 15,13 & 6,70 & 3,82 & 2,02 \\
\hline C.V. $(\%)$ & 6,63 & 3,51 & 4,86 & 11,98 & 11,65 & 13,42 \\
\hline
\end{tabular}

$e^{* *}$ - niveis de significância de $5 \%$ e $1 \%$ respectivamente

(1) - segundo o modelo de superfície de resposta de $2^{\underline{a}}$ ordem dos nutrientes $\mathrm{N}, \mathrm{P}_{2} \mathrm{O}_{5}$ e $\mathrm{K}_{2} \mathrm{O}$

(2)- teores em g kg-1 
Tabela 14. Valores de F das regressões, médias gerais e coeficientes de variação, dos teores de micronutrientes nas folhas de seringueiras com nove anos de idade.

-Micronutrientes nas Folhas

\begin{tabular}{lllllll}
\hline Efeitos de Regressões & Fe & $\mathrm{Cu}$ & $\mathrm{Zn}$ & $\mathrm{Mn}$
\end{tabular}

\begin{tabular}{|c|c|c|c|c|c|}
\hline Linear & $4,34^{* *}$ & $9,71^{* *}$ & 0,23 & $6,96^{\star \star}$ & 7,50 ** \\
\hline Quadrático & 0,36 & 0,87 & 1,55 & 1,76 & 1,85 \\
\hline Interação & $3,10^{*}$ & 2,52 & 0,08 & 1,76 & 0,65 \\
\hline Efeito do $N^{(1)}$ & 1,64 & $3,80 * \star$ & 0,98 & 1,65 & $2,82^{\star}$ \\
\hline Efeito do $\mathrm{P}_{2} \mathrm{O}_{5}{ }^{(1)}$ & 0,70 & $4,23 * \star$ & 0,17 & 1,96 & $2,91^{\star}$ \\
\hline Efeito do $\mathrm{K}_{2} \mathrm{O}^{(1)}$ & $1,92^{\star}$ & 0,54 & 1,03 & $3,69^{*}$ & 1,14 \\
\hline Médias Gerais ${ }^{(2)}$ & 72,86 & 10,08 & 23,44 & 235,48 & 16,95 \\
\hline C.V. $(\%)$ & 13,87 & 6,76 & 15,34 & 17,54 & 16,59 \\
\hline
\end{tabular}

$e^{* *}$ - niveis de significância de $5 \%$ e $1 \%$ respectivamente

(1) - segundo 0 modelo de superfície de resposta de $2^{\underline{a}}$ ordem dos nutrientes $\mathrm{N}, \mathrm{P}_{2} \mathrm{O}_{5}$ e $\mathrm{K}_{2} \mathrm{O}$

(2)- teores em $\mathrm{mg} \mathrm{kg}^{-1}$ 
Tabela 15. Valores de $F$ das regressões, médias gerais e coeficientes de variação, dos teores de macronutrientes nas folhas de seringueiras com onze anos de idade.

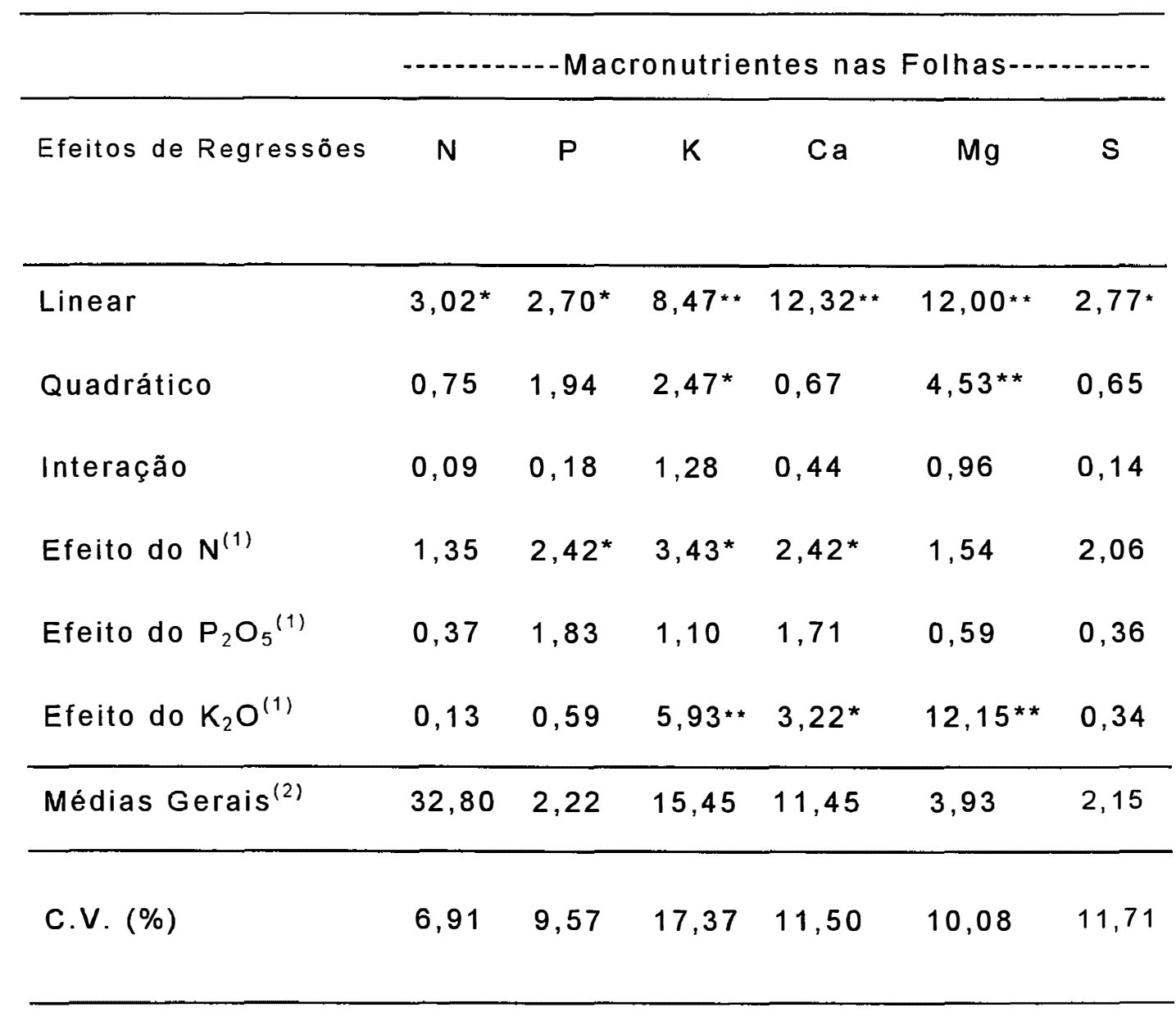

$e^{* *}$ - níveis de significância de $5 \%$ e $1 \%$ respectivamente

(1) - segundo o modelo de superfície de resposta de $2^{\underline{a}}$ ordem dos nutrientes $\mathrm{N}, \mathrm{P}_{2} \mathrm{O}_{5}$ e $\mathrm{K}_{2} \mathrm{O}$

(2)- teores em g kg ${ }^{-1}$ 
Tabela 16. Valores de $F$ das regressões, médias gerais e coeficientes de variação, dos teores de micronutrientes nas folhas de seringueiras com onze anos de idade.

Micronutrientes nas Folhas

\begin{tabular}{|c|c|c|c|c|c|}
\hline Efeitos de Regressões & $\mathrm{Fe}$ & $\mathrm{Cu}$ & $\mathrm{Zn}$ & $M n$ & B \\
\hline Linear & 0,81 & $14,70^{* *}$ & 1,86 & $5,35^{* *}$ & $10,89^{* *}$ \\
\hline Quadrático & 0,12 & $2,97^{*}$ & 1,15 & 1,17 & $3,58^{*}$ \\
\hline Interação & 0,26 & 0,66 & 0,24 & 0,07 & 0,29 \\
\hline Efeito do $N^{(1)}$ & 0,23 & 1,30 & 1,36 & $3,49 *$ & $3,47^{*}$ \\
\hline Efeito do $\mathrm{P}_{2} \mathrm{O}_{5}{ }^{(1)}$ & 0,27 & 2,13 & 0,11 & 0,69 & 1,54 \\
\hline Efeito do $\mathrm{K}_{2} \mathrm{O}^{(1)}$ & 0,57 & $3,53^{\star}$ & 0,68 & 0,58 & 0,83 \\
\hline Médias Gerais ${ }^{(2)}$ & 143,34 & 9,78 & 21,73 & 302,66 & 16,65 \\
\hline C.V. $(\%)$ & 22,78 & 7,63 & 15,33 & 20,00 & 23,60 \\
\hline
\end{tabular}

$e^{* *}$ - niveis de significância de $5 \%$ e $1 \%$ respectivamente

(1) - segundo o modelo de superficie de resposta de $2^{\text {a }}$ ordem dos nutrientes $\mathrm{N}, \mathrm{P}_{2} \mathrm{O}_{5}$ e $\mathrm{K}_{2} \mathrm{O}$

(2)- teores em $\mathrm{mg} \mathrm{kg}^{-1}$ 


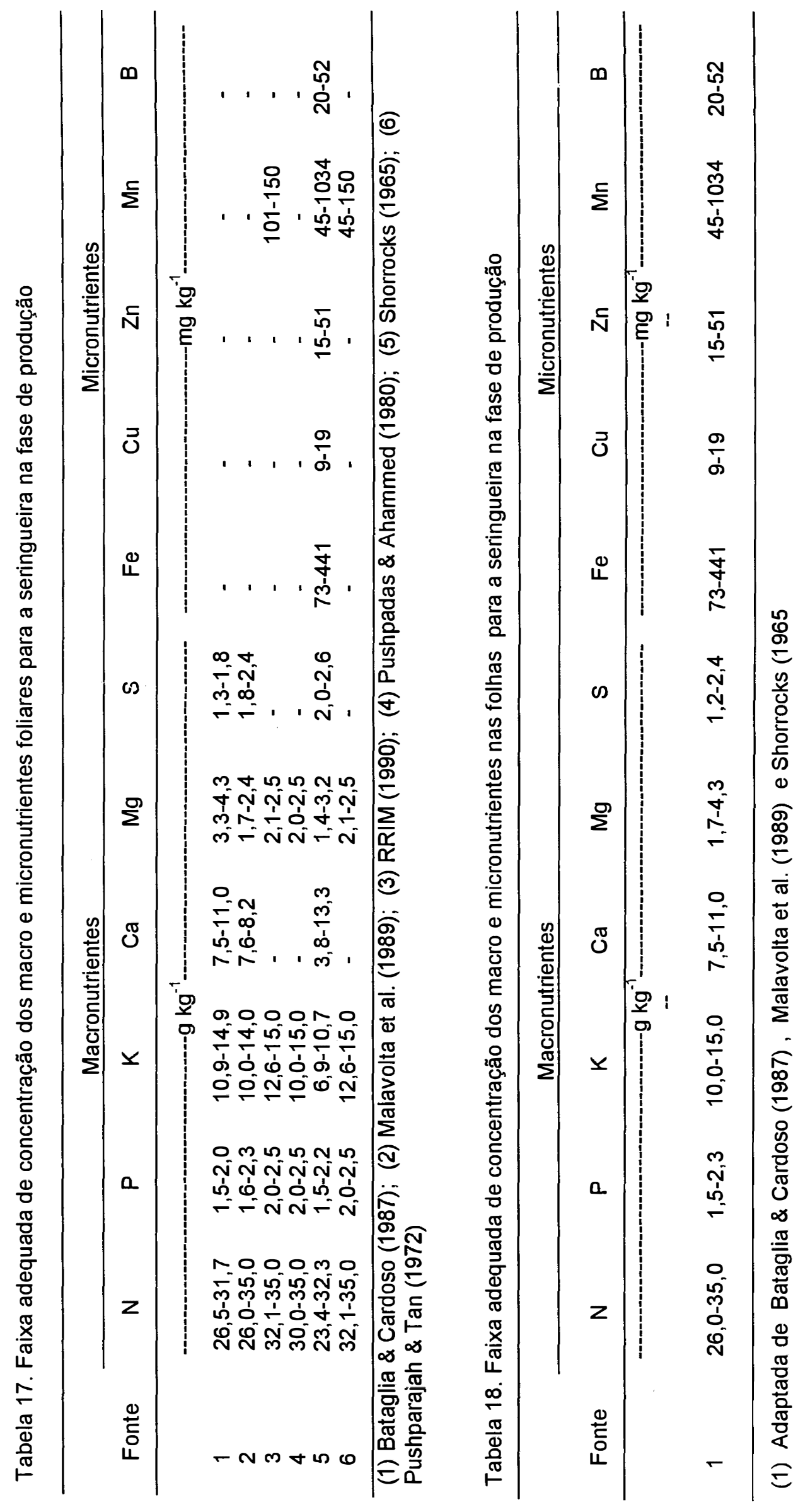


Para efeito de comparação e discussão dos resultados encontrados no presente estudo, elaborou-se a tabela 18 caracterizando faixas adequadas de concentração de macronutrientes, contidos nas folhas da seringueira na fase de produção, adaptada dos valores pré-estabelecidos por Bataglia \& Cardoso (1987), Malavolta et al. (1989) e Shorrocks (1965).

A figura 6a demonstra a significativa elevação da concentração de nitrogênio nas folhas das plantas com oito anos de idade devido ao aumento nas doses de nitrogênio aplicadas. Entretanto, percebe-se também que, a dose mais elevada de nitrogênio causou um efeito depressivo no $\mathrm{N}$ foliar.

Embora a adubação nitrogenada tenha contribuido para a elevação da concentração de $N$ nas folhas, os teores médios de $17,97 \mathrm{~g} \mathrm{~kg}^{-1}$ de $\mathrm{N}$ da dose $\left(\mathrm{N}_{0}\right)$ e $22,75 \mathrm{~g} \mathrm{~kg}^{-1} \mathrm{da}$ dose $\left(\mathrm{N}_{2}\right)$ (160 kg ha-1 de $\mathrm{N}$ ) determinados nas plantas com oito anos de idade, encontram-se muito abaixo da faixa considerada adequada apresentada na tabela tabela 18. Esses valores podem indicar que a quantidade de $\mathrm{N}$ disponivel no solo não era suficiente para suprir as necessidades da seringueira.

Pushparajah \& Tan (1972) observaram aumento da produção com a aplicação de fertilizantes nitrogenados, quando o $\mathrm{N}$ foliar encontrava-se na faixa de $35-37 \mathrm{~g} \mathrm{~kg}^{-1}$ para o clone GT 1 e $35 \mathrm{~g} \mathrm{~kg}^{-1}$ para o clone Tjir 1.

Viegas \& Haag (1985) encontraram valores de $N$ foliar na faixa de 29,7 - 32,6 $\mathrm{g} \mathrm{kg}^{-1}$ em mudas de seringueiras com 220 dias de idade. Ensaio conduzido por Berniz (1987) apresentou concentrações médias de $\mathrm{N}$ nas folhas variando de $30,3 \mathrm{~g} \mathrm{~kg}^{-1}$ na presença do nivel zero, a $29,0 \mathrm{~g} \mathrm{~kg}^{-1}$ na presença do nivel 2 de $\mathrm{N}$ indicando que houve um decréscimo no teor de $\mathrm{N}$ nas folhas. 
A

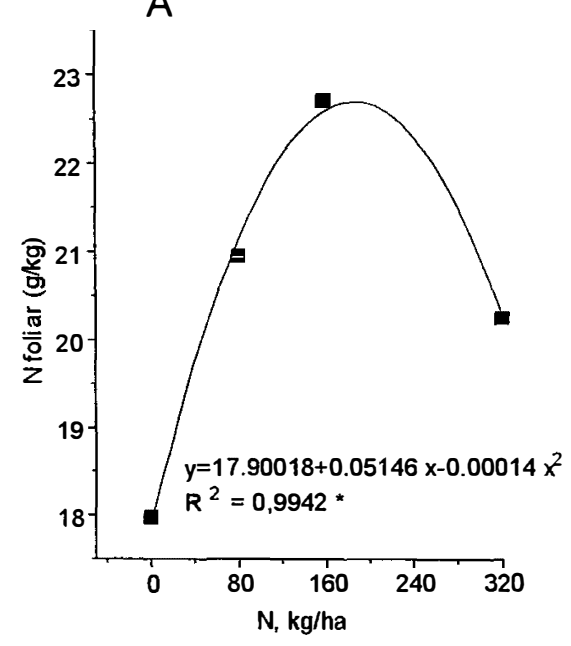

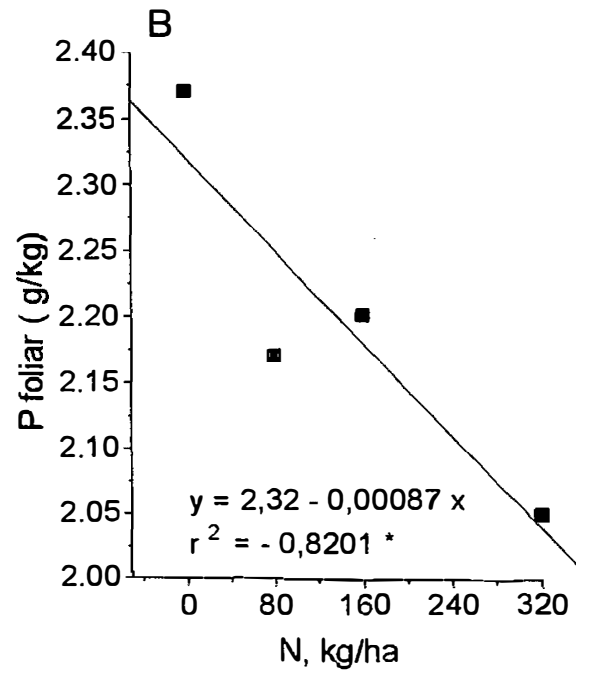

Figura 6. Influência da adubação nitrogenada na concentração de nitrogênio nas folhas da seringueira com oito anos de idade $(A)$; na concentração de fósforo nas folhas da seringueira com onze anos de idade (B).
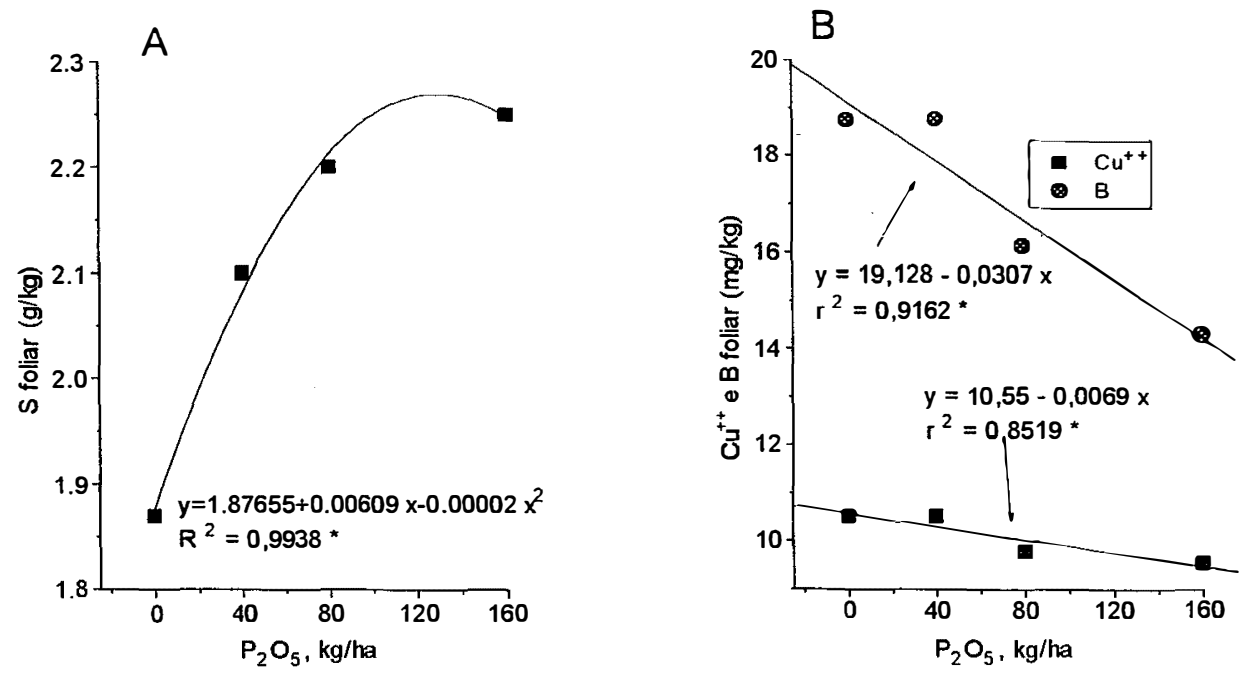

Figura 7. Efeito da adubação fosfatada na concentração de enxofre nas folhas da seringueira com oito anos de idade (A); e na concentração de cobre e boro nas folhas da seringueira com nove anos de idade (B). 
Bataglia et al. (1988), analisando folhas de seringueiras, coletadas no verão, detectaram teores $\mathrm{N}$ foliar em torno de $20,5-29,8 \mathrm{~g} \mathrm{~kg}^{-1}$ para todos os seringais em produção selecionados. Esses valores situam-se abaixo da faixa considerada adequada por Pushparajah \& Tan (1972).

A aplicação do nitrogênio provocou um decréscimo significativo no teor de $P$ nas folhas das plantas com onze anos de idade (Figura 6b). Os teores médios obtidos, 2,37 g $\mathrm{kg}^{-1}$ para o nivel 0 , e $2,05 \mathrm{~g} \mathrm{~kg}^{-1}$ para o nivel $3\left(320 \mathrm{~kg} \mathrm{ha}^{-1} \mathrm{de}\right.$ $\mathrm{N})$ estão dentro da faixa considerada adequada por Bataglia \& Cardoso (1987) e Malavolta et al. (1989). Berniz (1987) encontrou valores mais elevados de $P$ nas folhas para o tratamento que não recebeu adubação nitrogenada no segundo ano de avaliação das plantas. Autores como Watson (1989) e Viegas \& Haag (1985) não encontraram qualquer influência da adubação nitrogenada no teor de $P$ foliar.

Bataglia et al. (1988) encontraram teores médios de $P$ na faixa de $1,52-3,88 \mathrm{~g} \mathrm{~kg}^{-1}$ nos seringais cultivados sobre diferentes tipos de solos do estado de São Paulo.

$\mathrm{Na}$ figura $7 \mathrm{a}$ verifica-se que a aplicação do superfosfato simples causou um aumento significativo na concentração de $S$ nas folhas das plantas com oito anos de idade, provavelmente devido a fonte utilizada. Viegas \& Haag (1985) observaram que a adubação com superfofasfato triplo reduziu a concentração de $\mathrm{K}, \mathrm{S}, \mathrm{Cu}, \mathrm{B}$ e $\mathrm{Zn}$ nas folhas. Watson (1989) relatou que a adubação fosfatada aumentou os niveis de $\mathrm{P}$ e $\mathrm{Ca}$ e diminuiu a relação $\mathrm{Mg} / \mathrm{P}$ foliar. Pushparajah (1977) constatou que a aplicação de fosfato de rocha aumentou a concentração de $P$ e Ca nas folhas.

Os teores médios de $1,87 \mathrm{~g} \mathrm{~kg}^{-1}$ de $S$ foliar encontrados para o nível 0 e $2,25 \mathrm{~g} \mathrm{~kg}^{-1}$ para o nível 3 (160 $\mathrm{kg} \mathrm{ha}{ }^{-1}$ de $\mathrm{P}_{2} \mathrm{O}_{5}$ ) de adubação fosfatada, estão contidos dentro da faixa considerada adequada da tabela 18. 
A concentração de $P$ nas folhas das plantas, com oito anos de idade, aumentou com aplicação das doses de superfosfato simples porém, estatisticamente não significativo (Tabela 19).

Dos micronutrientes determinados, somente o $\mathrm{Cu}$ e - B foram afetados de forma negativa e significativa pela aplicação das doses crescentes de superfosfato simples (Figura 7b). Os teores médios de $\mathrm{Cu}$, determinados nas plantas com nove anos de idade ficaram na faixa de $10,5 \mathrm{mg}$ $\mathrm{kg}^{-1}$ para o nivel 0 e $9,50 \mathrm{mg} \mathrm{kg}^{-1}$ para o nível $3\left(160 \mathrm{~kg} \mathrm{ha}^{-1}\right.$ de $\mathrm{P}_{2} \mathrm{O}_{5}$ ). Comparando os resultados obtidos no presente estudo com a faixa estabelecida por Shorrocks (1965), apresentada na tabela 17 , pode-se considerar que existe possibilidade da planta apresentar deficiencia, desse micronutriente, caso não se proceda nos próximos anos uma adubação visando elevar o teor desse nutriente.

Os teores médios de $B$ nas folhas das plantas com nove anos de idade variaram de $18,75 \mathrm{mg} \mathrm{kg}^{-1}$ para a ausência de $P$ e $14,75 \mathrm{mg} \mathrm{kg}^{-1}$ para o nível 3 de adubo fosfatado (160 $\mathrm{kg} \mathrm{ha-1}$ de $\mathrm{P}_{2} \mathrm{O}_{5}$ ); acentuando mais a sua deficiência. Shorrocks (1965), estudando a concentração de macronutrientes e micronutrientes nas diferentes partes da seringueira encontrou concentração de boro nas folhas na faixa de 20-52 $\mathrm{mg} \mathrm{kg}^{-1}$. Berniz (1987) observou uma redução no teor de $\mathrm{Cu}$ nas folhas das seringueiras no segundo ano de experimentação no campo. Viegas \& Haag (1985) também encontraram uma redução na concentração de $\mathrm{Cu}$ e $\mathrm{B}$ nas folhas das seringueiras com 220 dias de idade com aplicação de superfosfato triplo.

Bataglia et al. (1988) encontraram teores médios de $B$ variando entre 27 e $49 \mathrm{mg} \mathrm{kg}^{-1}$ para seringais em produção. Somente um grupo de seringais instalados sobre um Podzólico Vermelho-Amarelo eutrófico, com cascalho (PVc) apresentou teores médios muito alto $\left(84 \mathrm{mg} \mathrm{kg}^{-1}\right)$. 
Sintomas foliares de amarelecimento internerval são ticios como excesso de B nas folhas. Haag et al. (1986) estudando toxidez de $B$, observaram que $0,5 \mathrm{mg}$ de $B$ por $\mathrm{kg}^{-1}$ de substrato pode levar a uma toxidez desse elemento nas plantas. Esses mesmos autores mencionaram que concentrações de $B$ acima de $100 \mathrm{mg} \mathrm{kg}^{-1}$ nas folhas podem indicar condições de toxidez.

Nas figuras $8 a$ e $8 b$ pode-se constatar os efeitos lineares e altamente significativos das doses de potássio nos teores de $K$ foliar. Este resultado concorda com os encontrados por Shorrocks (1962), Watson (1989), Viegas \& Haag (1985), Kitamura (1992), Pushparajah \& Tan (1972).

A análise foliar realizada nas plantas com oito anos de idade revelou concentrações de $\mathrm{K}$ de $3,80 \mathrm{~g} \mathrm{~kg}^{-1}$ para o nível 0 e $8,30 \mathrm{~g} \mathrm{~kg}^{-1}$ para o nivel 3 (320 kg ha-1 de $\mathrm{K}_{2} \mathrm{O}$ ). Por outro lado, a análise foliar efetuada nas plantas no ano seguinte, apresentou teores de $\mathrm{K}$ de $12,40 \mathrm{~g} \mathrm{~kg}^{-1}$ para o nivel 0 e $17,67 \mathrm{~g} \mathrm{~kg}^{-1}$ para o nivel 3 (320 kg ha-1 de $\mathrm{K}_{2} \mathrm{O}$ ).

Comparando os resultados obtidos no presente estudo (Tabela 19), com a faixa estabelecida na tabela 18 , observa-se que, as plantas com oito anos de idade apresentaram teores de $\mathrm{K}$ foliar baixos para todas as doses de $\mathrm{K}_{2} \mathrm{O}$ testadas. Os teores de $\mathrm{K}$ foliar encontrado nas seringueiras com nove e onze anos de idades apresentaram niveis adequados.

É importante ressaltar que a análise química do solo efetuada em fevereiro de 1995 (Tabela 7), revelaram teores baixos de $\mathrm{K}$ trocável em mais de $70 \%$ dos tratamentos, variando em torno de 0,6-3,0 $\mathrm{mmol}_{\mathrm{c}} \mathrm{dm}^{-3}$. Esses valores de $\mathrm{K}$ trocável no solo permitem inferir que naquela época, fevereiro de 1995, o solo apresentava reserva baixa de $K$, sendo insuficiente para suprir as necessidades das seringueiras. 

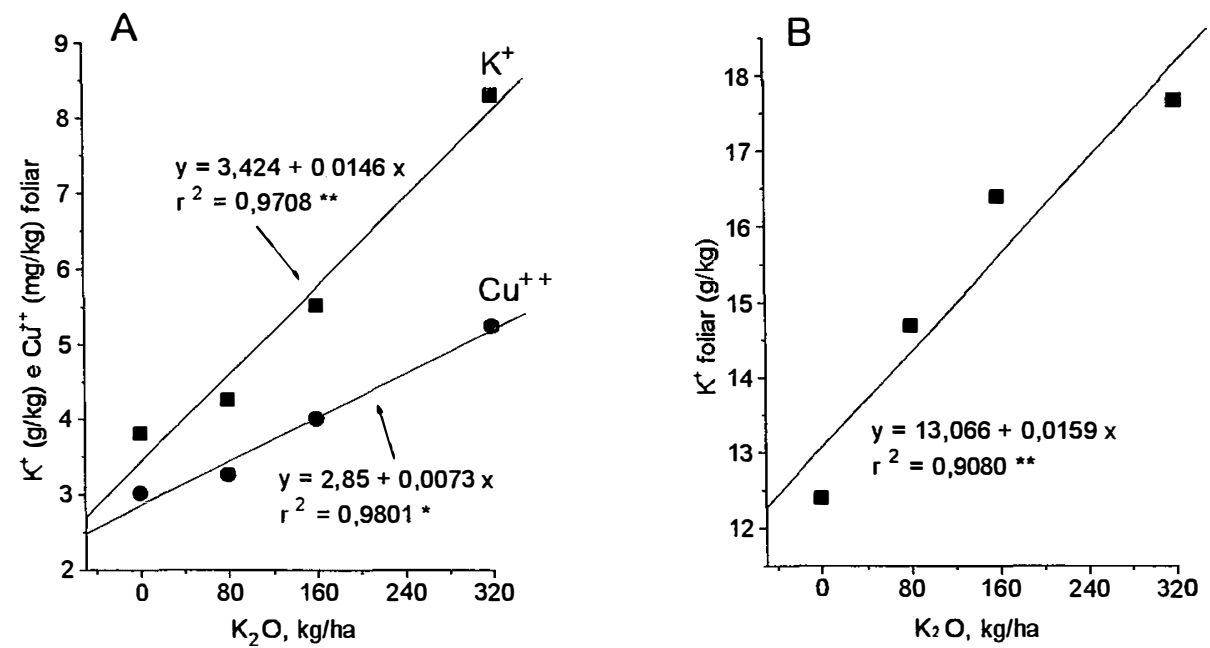

Figura 8. Influência da adubação potássica nas concentrações de potássio e cobre nas folhas da seringueira com oito anos de idade $(A)$; e na concentração de potássio nas folhas da seringueira com nove anos de idade (B).
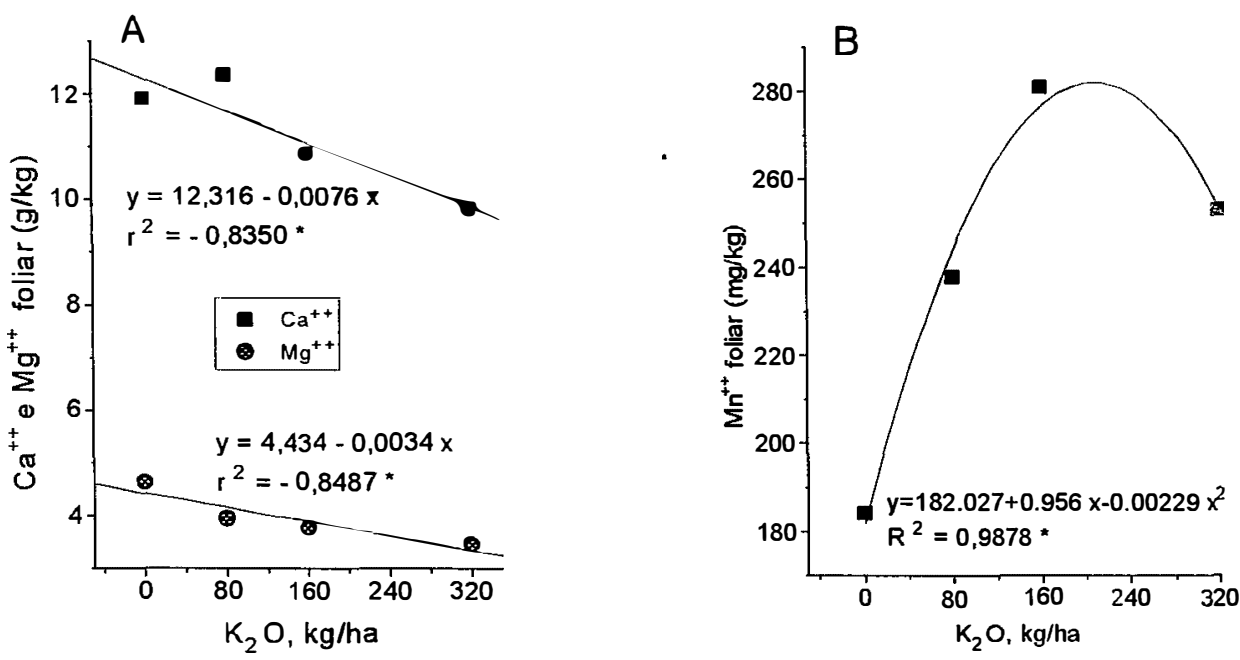

Figura 9. Efeito da adubação potássica nas concentrações de cálcio e magnésio nas folhas da seringueira com onze anos de idade $(A)$; e na concentração de manganês na folhas da seringueira com nove anos de idade (B). 
Ainda na figura 8 a pode-se constatar que a concentração de $\mathrm{Cu}$ nas folhas das plantas com vito anos de idade também foi afetado pelas doses crescentes de potássio. Apesar da resposta significativa, a variação ocorrida de 3,00 $\mathrm{mg} \mathrm{kg}^{-1}$ para o nível 0 e $5,25 \mathrm{mg} \mathrm{kg}^{-1}$ para o nivel $3(320 \mathrm{~kg} \mathrm{ha}$ 1 de $\mathrm{K}_{2} \mathrm{O}$ ) foi muito pequena, podendo não interferir o desempenho das plantas. Shorrocks (1965) encontrou concentração de $\mathrm{Cu}$ nas folhas em torno de $9-19 \mathrm{mg} \mathrm{kg}^{-1}$. Bataglia et al. (1988) detectou teores de $\mathrm{Cu}$ foliar variando de

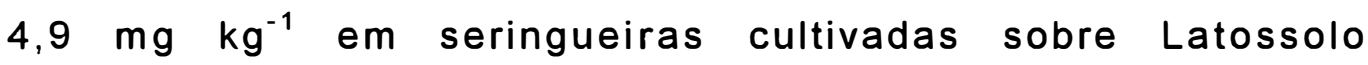
Vermelho-Escuro distrófico, textura argilosa (Led) até $11,4 \mathrm{mg}$ $\mathrm{kg}^{-1}$ em seringais instalados em Latossolo Roxo eutrófico, textura argilosa (Lre) ambos localizados no planalto paulista.

Berniz (1987) observou uma variação de 5,89 $\mathrm{mgkg}^{-1}$ para o nível 0 e $8,33 \mathrm{mg} \mathrm{kg}^{-1}$ para o nível $3\left(50 \mathrm{~kg} \mathrm{ha}^{-1}\right.$ de nitrogênio), em plantas com dois anos de idade. Por outro lado, Viegas \& Haag (1985) observaram um decréscimo na concentração de $\mathrm{Cu}$ nas folhas, com o aumento das doses de nitrogênio aplicadas.

Na figura 9a, observa-se que as doses crescentes de potássio reduziram as concentrações de $\mathrm{Ca}$ e $\mathrm{Mg}$ contidas nas folhas das seringueiras com onze anos de idade. O teor médio de $\mathrm{Ca}$ de $12,37 \mathrm{~g} \mathrm{~kg}^{-1}$ detectado no nível 1 (80 $\mathrm{kg} \mathrm{ha}^{-1}$ de $\mathrm{K}_{2} \mathrm{O}$ ) e $9,82 \mathrm{~g} \mathrm{~kg}^{-1}$ para o nivel 3 (320 $\mathrm{kg} \mathrm{ha}^{-1}$ de $\mathrm{K}_{2} \mathrm{O}$ ), estão dentro da faixa considerada adequada. Berniz (1987) observou que não houve redução nos teores de $\mathrm{Ca}$ e $\mathrm{Mg}$ foliar com aplicação de doses crescentes de potássio.

O antagonismo entre potássio e magnésio, na cultura da seringueira, tem sido mencionado por diversos pesquisadores, enfatizando a redução do $\mathrm{Mg}$ nas folhas, principalmente nos maiores niveis de K (Viegas \& Haag, 1985). Entretanto, quando a cultura responde a aplicação do fertilizante potássico, a concentração de magnésio nas folhas pode diminuir, chegando à valores levemente abaixo do 
exigido para o desenvolvimento adequado das plantas, fato este comprovado através das respostas lineares obtidas.

Os teores médios de magnésio de 4,65 $\mathrm{g} \mathrm{kg}^{-1}$ encontrados nas folhas das plantas na ausência do $\mathrm{K}$ e $3,45 \mathrm{~g}$ $\mathrm{kg}^{-1}$ determinado nas folhas das plantas que receberam o nivel 3 (320 kg ha-1 de $\mathrm{K}_{2} \mathrm{O}$ ), podem ser considerados adequados, quando comparados com os dados da tabela 18.

A análise do solo realizada no experimento com oito anos de idade, revelou a relação $\mathrm{K}^{+} / \mathrm{Mg}^{++}$no solo de $3,4 / 5,2 \mathrm{mmol}_{\mathrm{c}} \mathrm{dm}^{-3}$ no tratamento que recebeu o nivel 3 (320 $\mathrm{kg} \mathrm{ha}{ }^{-1}$ de $\mathrm{K}_{2} \mathrm{O}$ ). O tratamento $80 \mathrm{~kg} \mathrm{ha}^{-1}$ de $\mathrm{K}_{2} \mathrm{O}$, apresentou uma relação $\mathrm{K}^{+} / \mathrm{Mg}^{++}$de $1,6 / 4,7 \mathrm{mmol}_{\mathrm{c}} \mathrm{dm}^{-3}$ (Tabela 7). Com base nos níveis adequados desses nutrientes, observa-se que o aumento no teor de $\mathrm{Mg}^{++}$trocável de 5,2 para $8,0 \mathrm{mmol}_{\mathrm{c}} \mathrm{dm}^{-}$ ${ }^{3}$, alcançaria uma relação ideal no tratamento que recebeu o nivel 3 de $\mathrm{K}_{2} \mathrm{O}$.

No que diz respeito a relação $\mathrm{Ca}^{++} / \mathrm{Mg}^{++}$, verificase que essa relação variou de $11,0 / 5,8 \mathrm{mmol}_{\mathrm{c}} \mathrm{dm}^{-3}$ no tratamento que recebeu o nível 0 de $\mathrm{K}_{2} \mathrm{O}$. Neste caso, observase que todas as doses de potássio utilizadas levaram a um desbalanço do $\mathrm{Ca}^{++} / \mathrm{Mg}^{++}$no solo.

Uma possivel explicação para esse desbalanço apresentado nas relações $\mathrm{K}^{+} / \mathrm{Mg}^{++}$e $\mathrm{Ca}^{++} / \mathrm{Mg}^{++}$no solo pode ser explicado pelo efeito residual do calcário dolomítico aplicado, conduzindo a uma elevada absorção desses cátions divalentes pelas plantas, em um período muito curto de tempo.

Sabe-se também que o potássio presente na solução do solo pode deslocar o $\mathrm{Ca}$ e o $\mathrm{Mg}$ do complexo de troca, possibilitando uma maior lixiviação desses cátions divalentes, ao longo do perfil.

$\mathrm{Na}$ figura $9 \mathrm{~b}$ observa-se que a concentração de $\mathrm{Mn}$ nas folhas das plantas com nove anos de idade aumentou de forma linear até o nível 2 , seguido de uma queda causada pela dose 3 , apresentando uma resposta quadrática com as doses 
de potássio aplicadas. Na tabela 8 pode-se constatar que os tratamentos cue receberam as doses crescentes de potássio apresentaram indices de $\mathrm{pH}$ de 4,52-4,76, valores esses extremamente favoráveis à disponibilidade de $\mathrm{Mn}$ na solução do solo, e consequentemente, à absorção pelas plantas. Pushparajah \& Tan (1972) observaram que a concentração de $\mathrm{Mn}$ nas folhas variou de $45-150 \mathrm{mg} \mathrm{kg}^{-1}$. Shorrocks (1965) encontrou um intervalo bem maior, variando de $45-1034 \mathrm{mg} \mathrm{kg}$ 1 em folhas de diferentes estádios de desenvolvimento. Trabalhos desenvolvidos no Rubber Research Institute of Malaya (1982) estabelece valores de $101-150 \mathrm{mg} / \mathrm{kg}$ como faixa considerada média. Berniz (1987), porém, não observou variação no teor foliar de $\mathrm{Mn}$ com as doses crescentes de potássio aplicadas.

Os teores de $M n$ foliares encontrados no T6 equivalente a $753,70 \mathrm{mg} \mathrm{kg}^{-1}$ e no T16 de $1156,20 \mathrm{mg} \mathrm{kg}^{-1}$ (Tabela 20), são considerados altos, porém, estão dentro da faixa estabelecida por Shorrocks (1965).

Da tabela 19 à 24 encontram-se as comparações das médias efetuadas pelo teste de Tukey, ao nível de $5 \%$ de probabilidade, dos resultados analíticos das amostras foliares coletadas nas plantas com oito, nove e onze anos de idade.

O efeito dos tratamentos na concentração de macro e micronutrientes nas folhas com oito anos de idade, foi significativo para o N, P, K, Cu e B (tabelas 19 e 20). Apesar das diferenças estatísticas significativas, as concentrações do $\mathrm{N}$, em torno de 17,97-24,0 $\mathrm{g} \mathrm{kg}^{-1}$; do $\mathrm{P}$ variando de 0,87-1,27 $\mathrm{g}$ $\mathrm{kg}^{-1}$ e o $\mathrm{K}$ em torno de $3,8-8,3 \mathrm{~g} \mathrm{~kg}^{-1}$ ficaram abaixo dos niveis considerados adequados por outros autores (Tabela 18). No caso do micronutriente $\mathrm{Cu}$, variando de $3,00-6,5 \mathrm{mg} \mathrm{kg}^{-1}$ e $B$ em torno de $10,5-30,75 \mathrm{mg} \mathrm{kg}^{-1}$, ambos ficaram abaixo dos niveis encontrados por Shorrocks (1965), (Tabela 18).

Nas folhas das plantas com nove anos de idade, as diferenças foram significativas para as concentrações de $N, K$, 
$\mathrm{Cu}, \mathrm{Mn}$ e B (Tabelas 21 e 22). As faixas de concentrações dos nutrientes encontrados foram: $30,47-36,05 \mathrm{~g} \mathrm{~kg}^{-1}$ para o $\mathrm{N}$; $12,40-17,67 \mathrm{~g} \mathrm{~kg}^{-1}$ para $\circ \mathrm{K} ; 9,25-11,25 \mathrm{mg} \mathrm{kg}^{-1}$ para $\circ \mathrm{Cu}$; 184-304 $\mathrm{mg} \mathrm{kg}^{-1}$ para o $\mathrm{Mn} ; 13,45-21,35 \mathrm{mg} \mathrm{kg}^{-1}$ para o $B$, revelando que o $\mathrm{N}$ e $\circ \mathrm{K}$ alcançaram niveis considerados adequados conforme tabela 18. O B encontra-se abaixo da faixa observada, por Shorrocks (1965); o Cu, dentro da faixa observada por Shorrocks (1965), enquanto que o $\mathrm{Mn}$, extremamente elevado e acima da faixa estabelecida por Pushparajah \& Tan (1972). 


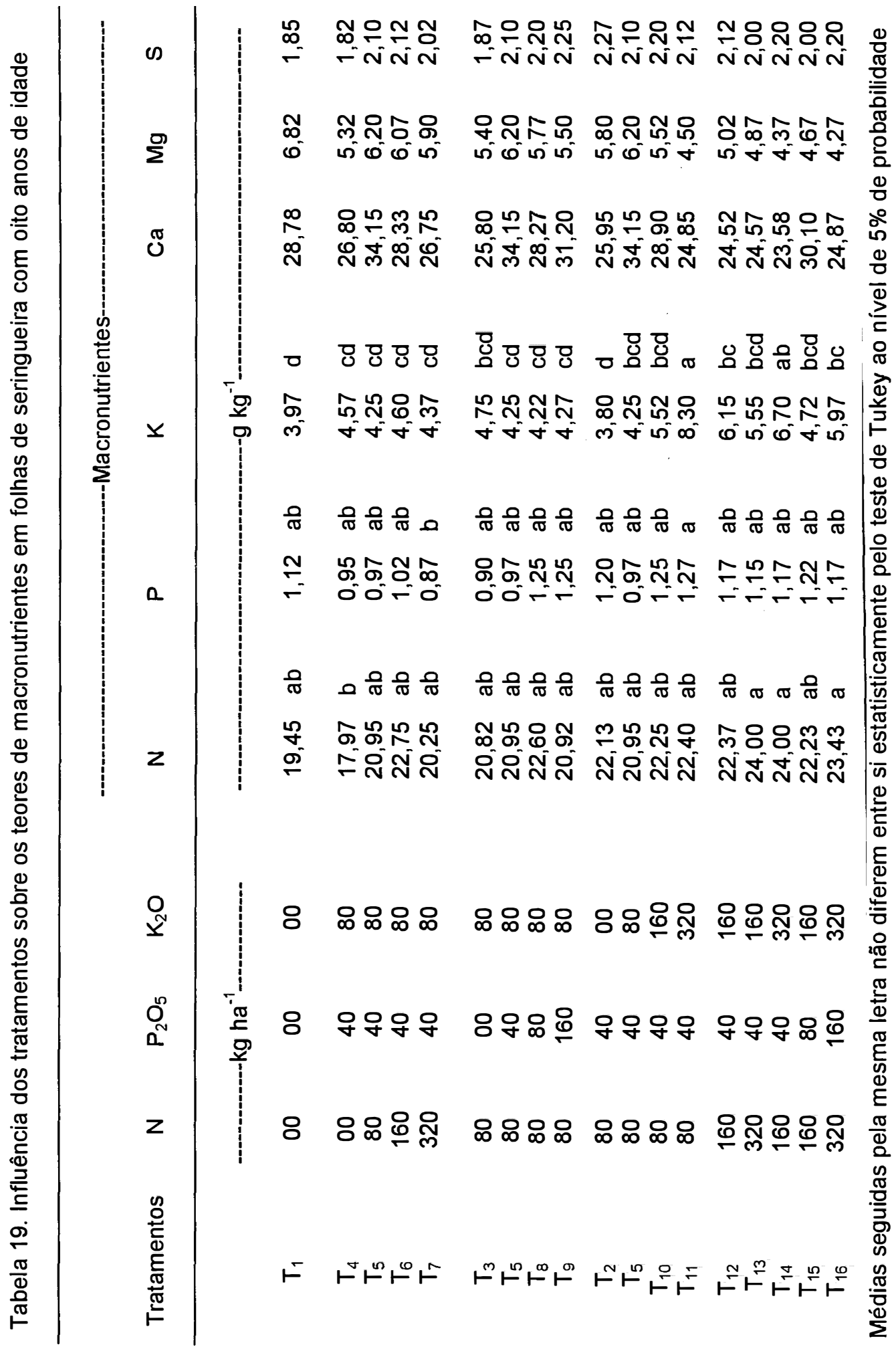




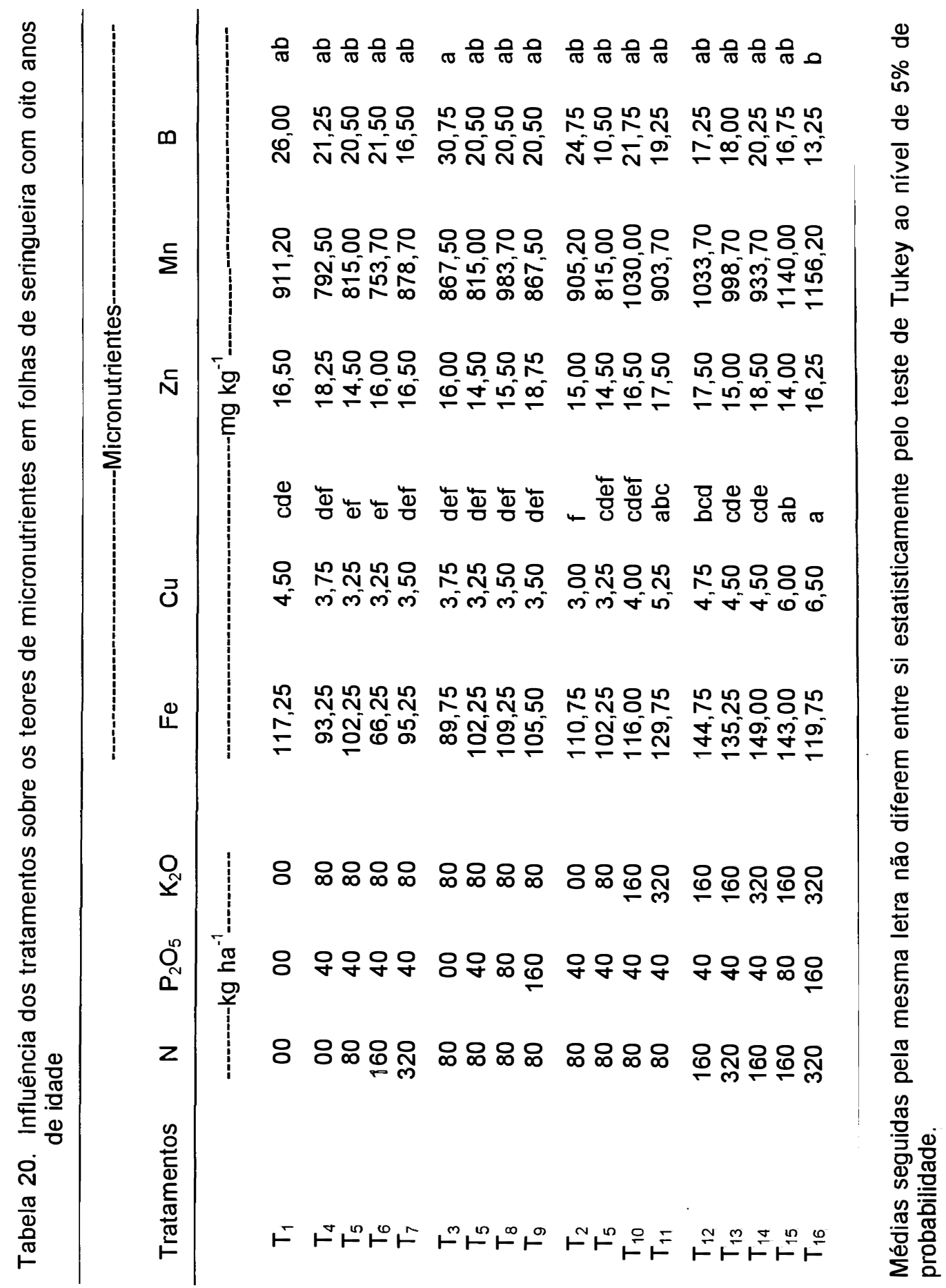




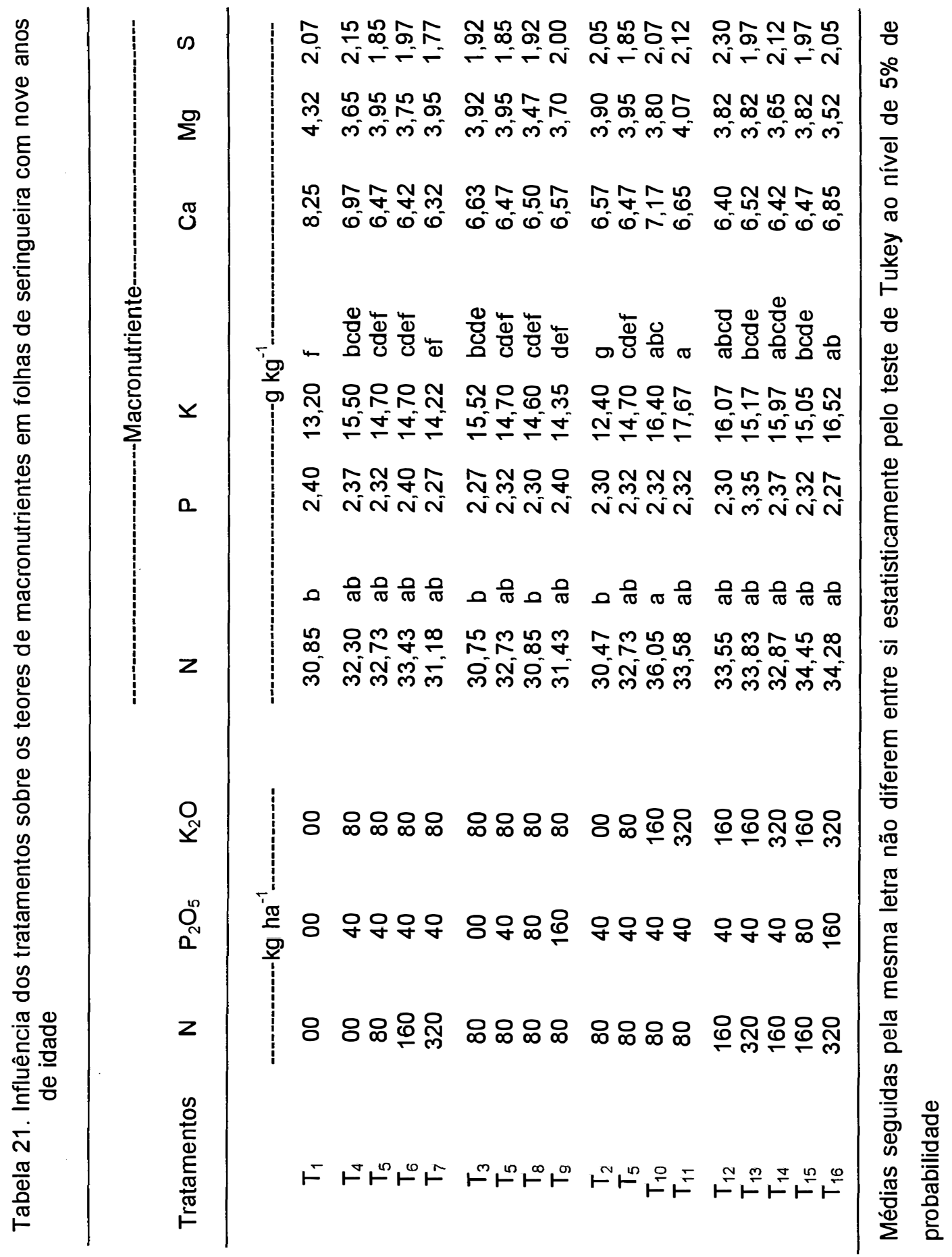




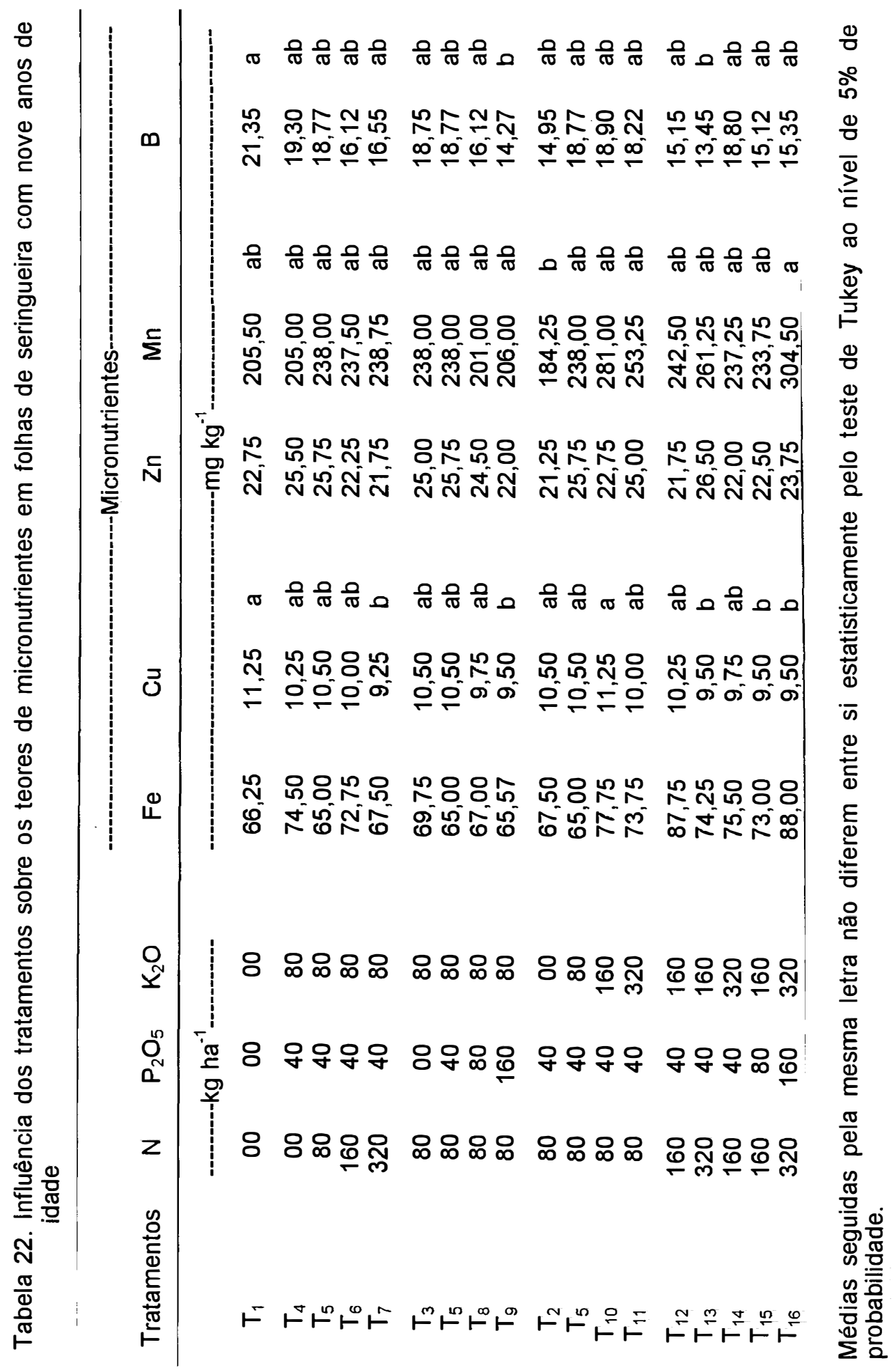


A concentração dos demais nutrientes $\mathrm{P}, \mathrm{Ca}, \mathrm{Mg}$, $S$, Fe e $Z_{r_{1}}$, determinados nas folhas das seringueiras com nove anos de idade, não apresentaram diferenças estatísticas signifciativas, com os diferentes tratamentos utilizados. Porém, vale salientar que, a concentração de $P$ nas folhas com nove anos de idade, foram bem mais altas do que nas folhas das plantas com oito anos de idade, para todos os tratamentos testados.

A concentração de $C$ a nas folhas com oito anos de idade apresentou faixas de concentrações entre $23,58-34,15 \mathrm{~g}$ $\mathrm{kg}^{-1}$, enquanto que a análise foliar efetuada nas plantas com nove anos de idade apresentou intervalos de 6,3-7,2 $\mathrm{g} \mathrm{kg}^{-1}$, para todos os tratamentos testados. A concentração dos demais nutrientes, $\mathrm{Mg}, \mathrm{S}, \mathrm{Fe}$ e $\mathrm{Zn}$ não mostraram grandes variações da primeira para a segunda análise.

Aos onze anos de idade, (tabelas 23 e 24) observa-se que os tratamentos afetaram significativamente os teores de $\mathrm{K}, \mathrm{Ca}, \mathrm{Mg}, \mathrm{Cu}$ e $\mathrm{B}$. Nota-se que a concentração de $\mathrm{K}$, em torno de $10,3-18,6 \mathrm{~g} \mathrm{~kg}^{-1}$, ficou semelhante ao intervalo encontrado no ano anterior; a concentração de $C a$, entre 9,8$13,5 \mathrm{~g} \mathrm{~kg}^{-1}$ mostrou um ligeiro aumento; a faixa de $\mathrm{Mg}$, de 3,3$4,7 \mathrm{~g} \mathrm{~kg}^{-1}$, praticamente não se alterou, o mesmo acontecendo com o $\mathrm{Cu}$ e o $\mathrm{B}$.

Shorrocks (1965) observou que o Ca é absorvido em grande quantidade quando comparado com os demais nutrientes, ficando abaixo somente do $\mathrm{N}$. Cerca de $30-50 \%$ do $\mathrm{Ca}^{++}$contido na planta é depositado no tronco e na casca dos galhos.

Watson (1989) relatou que o uso excessivo de calcário deve ser evitado, uma vez que elevados teores de cálcio pode acumular na casca da seringueira, na forma de cristais de oxalato de cálcio, provocando efeitos deletérios na formação e no fluxo do látex. 


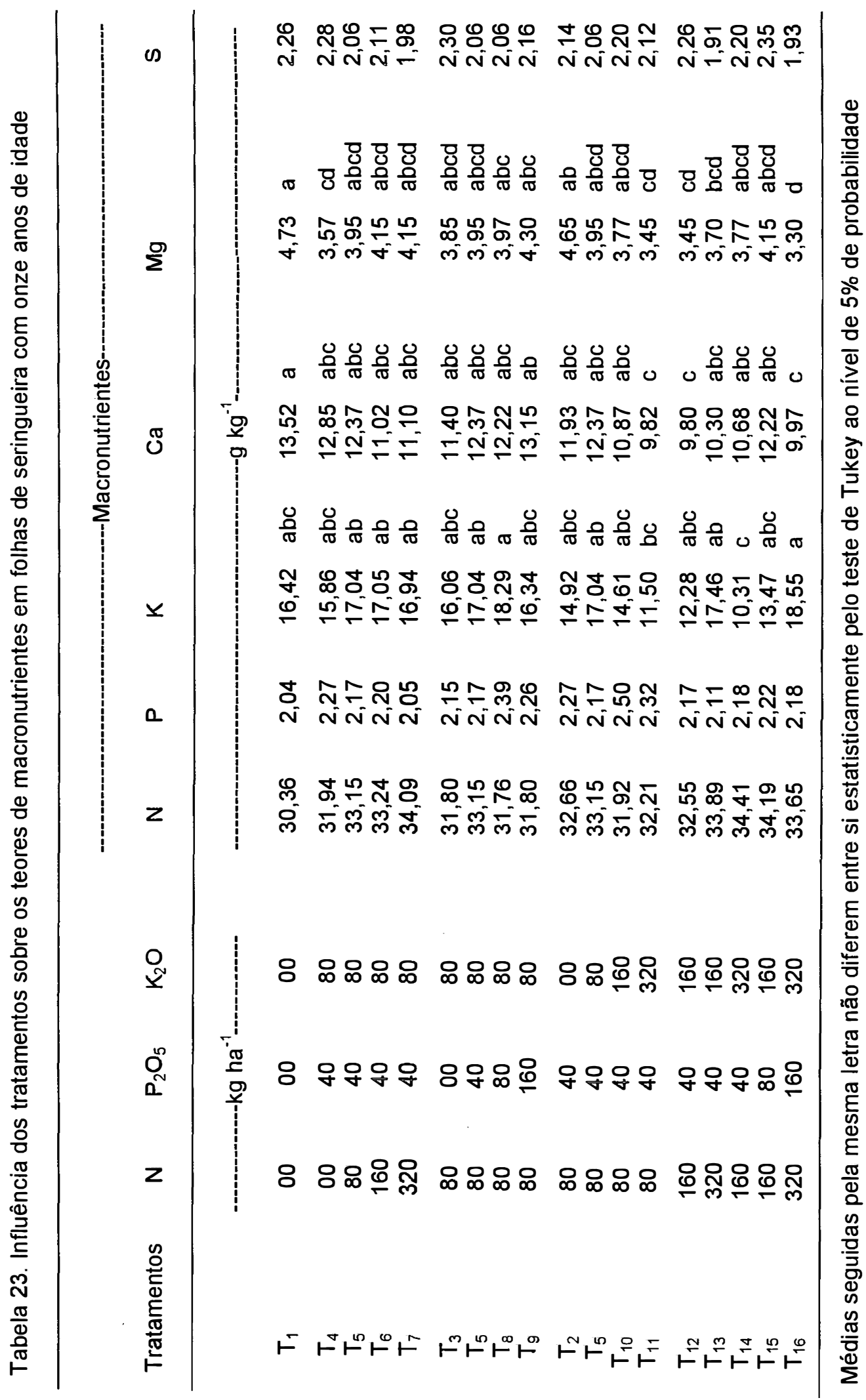




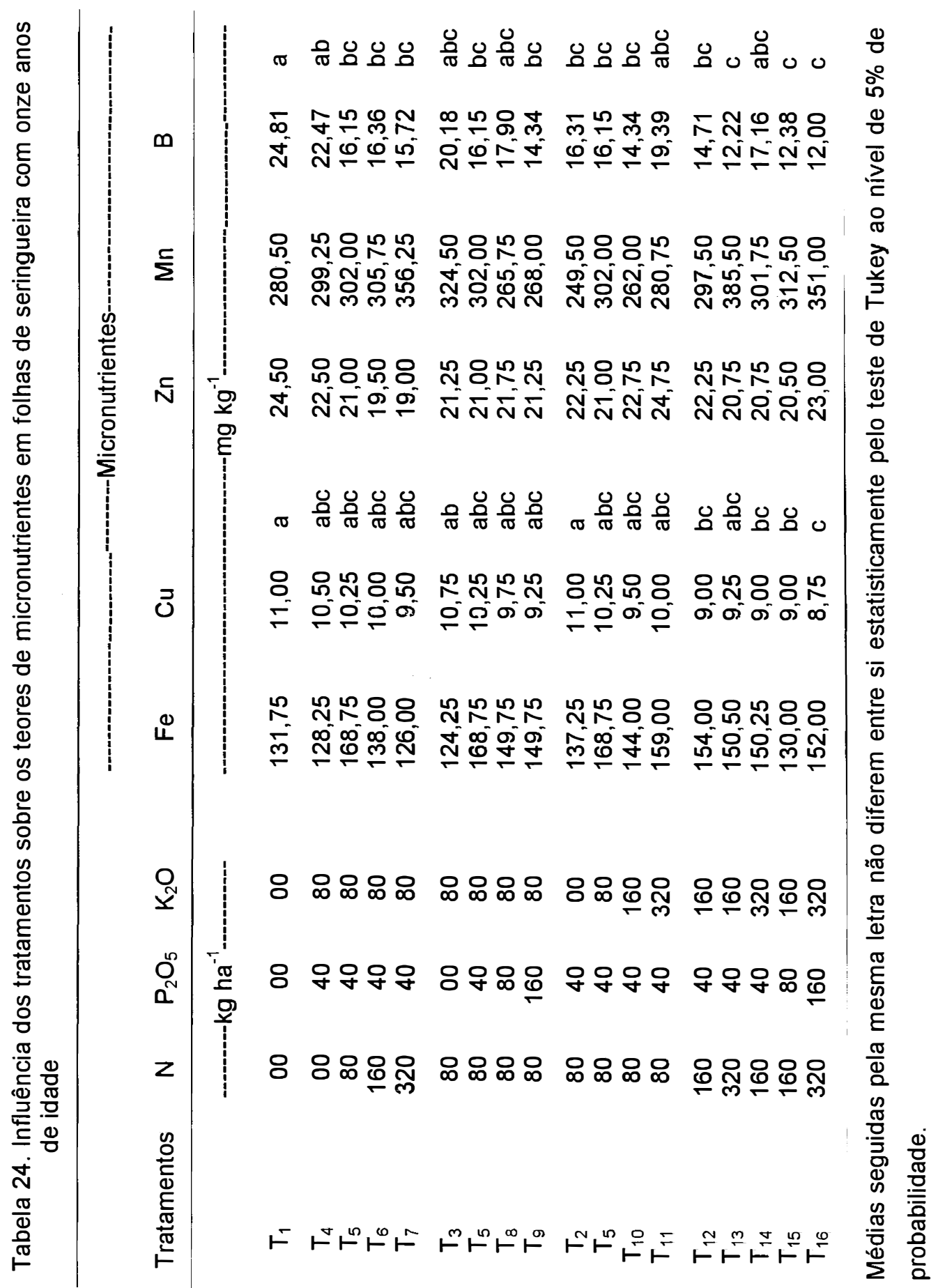




\subsection{Efeito da Adubação Nitrogenada, Fosfatada e} Potássica no Perímetro do Caule e na Espessura da Casca do Caule da Seringueira

Nas tabelas 25,26 e 27 encontram-se os valores do teste $F$, médias gerais e coeficientes de variação do perímetro do caule, medidas semestralmente, no período de quatro a doze anos.

Os valores de perímetro do caule apresentaram diferenças estatísticas significativas com a aplicação do potássio entre 6,0 e 7,5 anos de idades. As doses de nitrogênio e fósforo não influenciaram no perímetro do caule. Esses resultados diferem daqueles encontrados por Ananth et al. (1966), Kalan (1970), Pannoje \& Potty (1975), Reis et al. (1985), Kitamura (1992).

Considerando que, para a classe de teores médios corresponde uma faixa de 90 a $100 \%$ de produção relativa, a falta de resposta a adubação nitrogenada e fosfatada no incremento da circunferência do tronco e espessura da casca, que será discutida posteriormente, pode estar relacionada com esses teores de $\mathrm{N}$ e $\mathrm{P}$ disponível encontrado no solo.

Por outro lado, Pushparajah et al. observaram que a adubação nitrogenada aplicada sem adubação potássica reduziu o desenvolvimento e a produção.

Syvanadian et al. (1975) observaram que a carência de potássio na fase de desenvolvimento pode limitar a área foliar e reduzir a atividade fotossintética das folhas, resultando em um incremento mais lento da circunferência do caule.

Na figura 10a pode-se constatar o efeito linear das doses de potássio sobre a circunferência do caule da seringueira no período de 6,5 a 8,0 anos. 
O inicio da exploração ocorreu em 1991, com plantas com sete anos de idade e através da figura 10a e também das tabelas 28,29 e 30 percebe-se que a taxa de incremento do perímetro do caule tende a diminuir substancialmente, à medida que as plantas entram na fase de produção. 
Tabela 25. Valores de $F$ das regressões, médias gerais e coeficientes de variação da circunferência do tronco da seringueira $(\mathrm{cm}) \mathrm{em}$ diferentes fases de desenvolvimento

-Funções

Idade (anos)

\begin{tabular}{lcccccc} 
& 4,0 & 4,5 & 5,0 & 5,5 & 6,0 & \multicolumn{1}{c}{6,5} \\
\hline Efeito Linear & 1,45 & 1,93 & 2,61 & 2,36 & $5,78^{\star *}$ & $5,58^{\star *}$ \\
Efeito Quadrático & 0,23 & 0,33 & 0,52 & 0,22 & 0,25 & 0,07 \\
Interação & 0,60 & 0,02 & 0,25 & 0,87 & 0,03 & 0,08 \\
Efeito do $\mathrm{N}^{(1)}$ & 0,41 & 0,23 & 0,50 & 0,53 & 0,18 & 0,07 \\
${\text { Efeito do } \mathrm{P}_{2} \mathrm{O}_{5}{ }^{(1)}}^{\text {Efeito do } \mathrm{K}_{2} \mathrm{O}^{(1)}}$ & 0,07 & 0,04 & 0,36 & 0,82 & 0,19 & 0,19 \\
\hline Média Final & 0,63 & 0,97 & 1,12 & 1,13 & $2,31^{*}$ & $2,60^{\star}$ \\
C.V. (\%) & 15,87 & 21,16 & 24,05 & 30,37 & 33,85 & 38,99 \\
& 6,52 & 7,4 & 6,48 & 5,59 & 5,73 & 5,16
\end{tabular}

${ }^{\star} e^{\star \star}=$ niveis de significância de $5 \%$ e $1 \%$, respectivamente

$(1)=$ segundo 0 modelo de superficie de resposta de $2^{\underline{a}}$ ordem nos nutrientes $N_{1} P_{2} O_{5}$ e $K_{2} O$

Tabela 26. Valores de $F$ das regressões, médias gerais e coeficientes de variação da circunferência do tronco da seringueira $(\mathrm{cm})$ em diferentes fases de desenvolvimento

\begin{tabular}{llll}
\hline & & & \\
& 7,0 & 7,5 & \\
\hline & $6,73^{\star \star}$ & $7,31^{\star \star}$ & 8,0 \\
\hline Efeito Linear & 0,06 & 0,04 & 5,86 \\
Efeito Quadrático & 0,10 & 0,16 & 0,04 \\
Interação & 0,24 & 0,46 & 0,06 \\
Efeito do $\mathrm{N}^{(1)}$ & 0,18 & 0,25 & 0,48 \\
Efeito do $\mathrm{P}_{2} \mathrm{O}_{5}^{(1)}$ & $2,45^{\star}$ & $2,28^{*}$ & 0,11 \\
Efeito do $\mathrm{K}_{2} \mathrm{O}^{(1)}$ & 42,60 & 47,37 & 1,63 \\
\hline Média Final & 5,17 & 4,76 & 49,89 \\
C.V. (\%) & & 4,88 \\
\hline
\end{tabular}

(1) Segundo o modelo de superfície de resposta de $2^{\mathrm{a}}$ ordem nos nutrientes $\mathrm{N}, \mathrm{P}_{2} \mathrm{O}_{5}$ e $\mathrm{K}_{2} \mathrm{O}$ 
Tabela 27. Valores de $F$ das regressões, médias gerais e coeficientes de variação da circunferência do tronco da seringueira $(\mathrm{cm})$ em diferentes fases de desenvolvimento

\begin{tabular}{lccccc}
\hline \multirow{2}{*}{ Funções } & \multicolumn{5}{c}{ Idade (anos) } \\
\cline { 2 - 6 } & 8,5 & 9,0 & 9,5 & 10,0 & 12,0 \\
\hline Efeito Linear & 6,72 & 5,95 & 2,42 & 3,65 & 3,76 \\
Efeito Quadrático & 0,04 & 0,03 & 0,28 & 0,09 & 0,17 \\
Interação & 0,13 & 0,16 & 0,03 & 0,02 & 0,22 \\
Efeito do $\mathrm{N}^{(1)}$ & 0,63 & 0,60 & 0,13 & 0,36 & 0,73 \\
Efeito do $\mathrm{P}_{2} \mathrm{O}_{5}{ }^{(1)}$ & 0,15 & 0,18 & 0,05 & 0,10 & 0,14 \\
Efeito do $\mathrm{K}_{2} \mathrm{O}^{(1)}$ & 1,82 & 1,57 & 0,87 & 0,86 & 1,11 \\
\hline Média Final & 50,93 & 52,18 & 54,21 & 56,22 & 60,05 \\
C.V. (\%) & 4,51 & 4,60 & 4,88 & 4,51 & 4,08 \\
\hline
\end{tabular}

(1) Segundo o modelo de superfície de resposta de segunda ordem nos nutrientes $\mathrm{N}, \mathrm{P}_{2} \mathrm{O}_{5}$ e $\mathrm{K}_{2} \mathrm{O}$ 
Tomando como exemplo o $T-11$, o qual proporcionou o maior desenvolvimento do tronco das seringueiras aos sete anos de idade, visualiza-se que a taxa de incremento do quinto para o sexto ano foi de $10,58 \mathrm{~cm}$, enquanto que no período de nove a dez anos esse incremento foi de apenas $3,8 \mathrm{~cm}$. Esses resultados são semelhantes aos encontrados por Bolton (1964), e Reis \& Rosand (1988) onde encontraram resposta as doses de fosfato aplicadas.

Considerando que os 16 tratamentos constituem 16 formulações diferentes, e visando obter-se maiores informações agronômicas, procedeu-se o teste de Tukey a $5 \%$ de probabilidade, onde se verificou que não houveram diferenças estatísticas significativas nos valores de perimetro do caule da seringueira, nas diferentes épocas de amostragens, em relação aos diferentes tratamentos estudados (tabelas 28, 29 e 30).

Por outro lado, a análise de regressão realizada para as doses crescentes de nitrogênio, fósforo e potássio mostraram que as doses de nitrogênio e fósforo não influenciaram de forma significativa o perimetro do caule das plantas. Entretanto, as doses crescentes de potássio afetaram significativamente, a circunferência do caule das seringueiras no período 6,5 a 8,0 anos (Figura 10a).

O efeito linear das doses crescentes de potássio na espessura da casca do caule da seringueira pode ser visualizado na tabela 31. Na tabela 32 estão contidos os dados de espessura da casca medidas no quarto, quinto e décimo primeiro anos de desenvolvimento. Nota-se que somente no quinto ano as doses crescentes de potássio afetaram significativamente esse parâmetro de crescimento. O tratamento que recebeu o nivel 0 apresentou $4,02 \mathrm{~cm}$ de espessura da casca, enquanto que o tratamento que recebeu o nivel 3 apresentou $4,49 \mathrm{~cm}$ de espessura da casca do caule. 


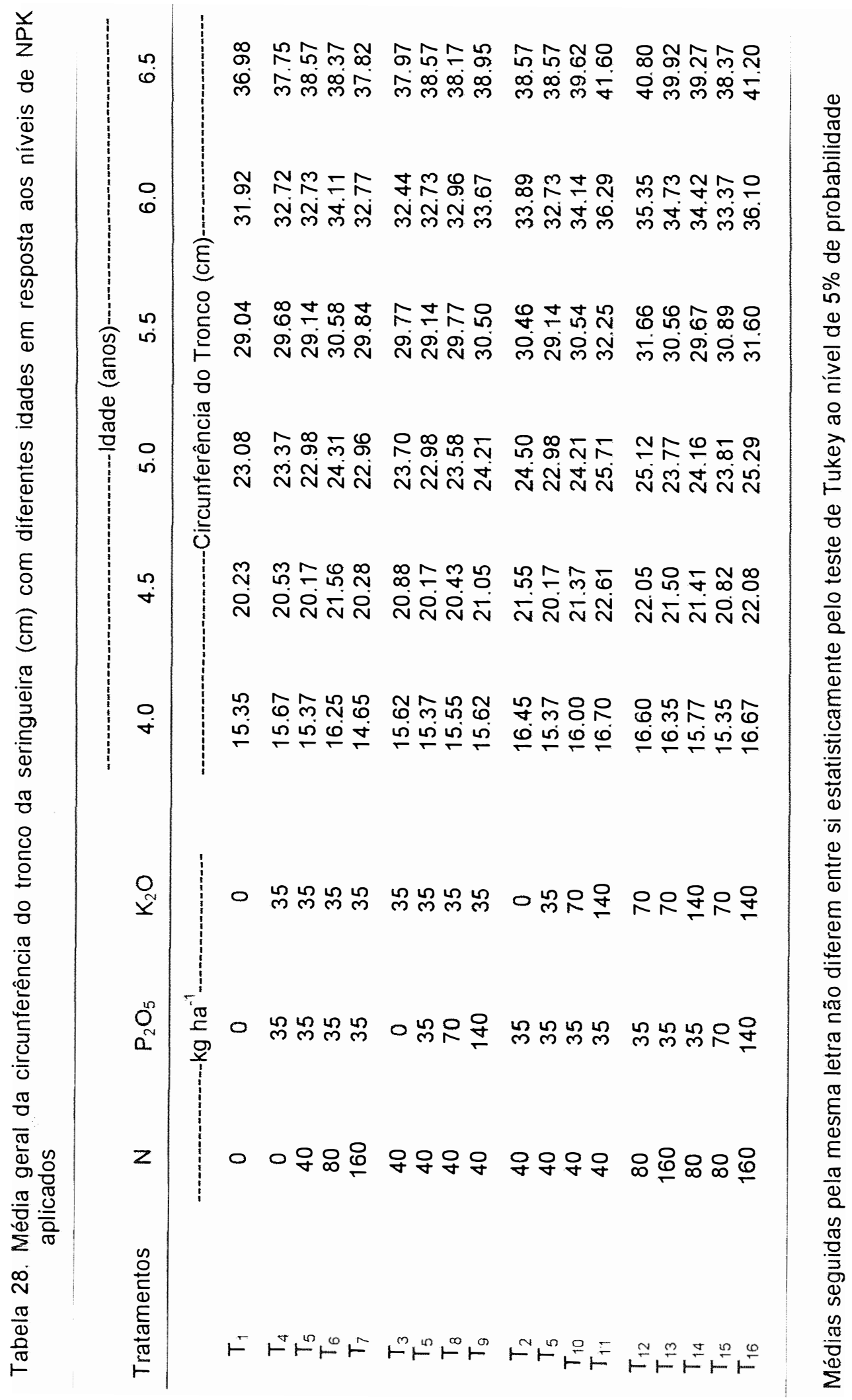




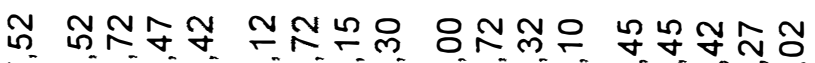

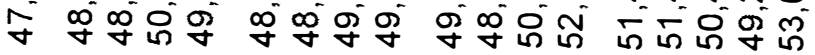

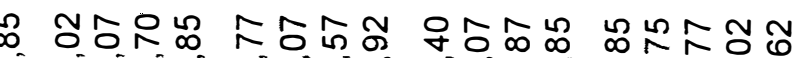

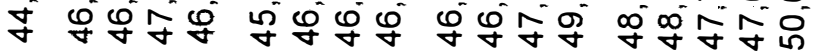

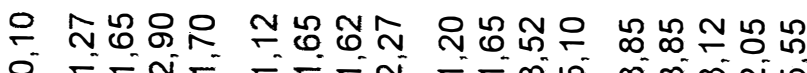

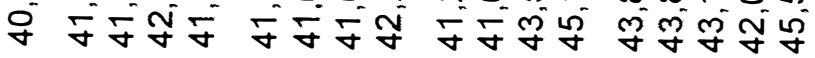

- m

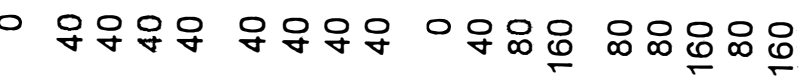

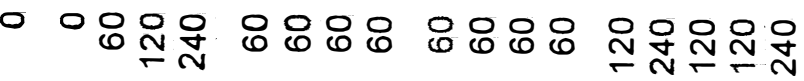

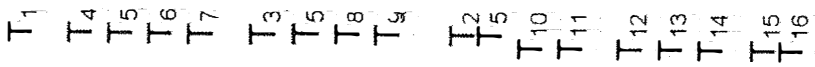




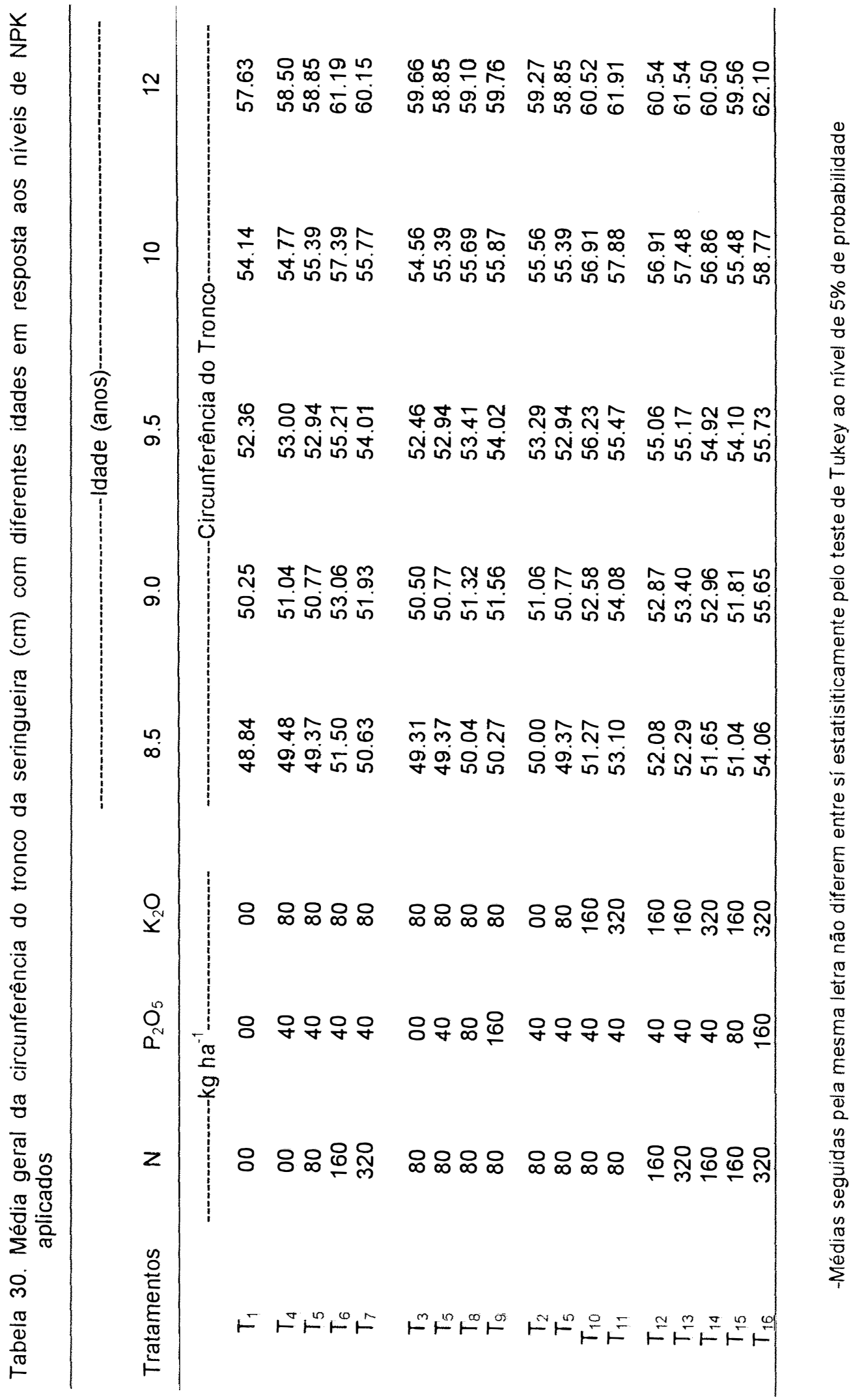


O desenvolvimento da espessura da casca do caule da seringueira tem uma relação direta com o aumento do número e do tamanho nos vasos laticíferos, além da reserva de amido, fatores esses que influenciam o potencial produtivo das plantas.

Syvanadian et al. (1975) relatam a importância da adubação da seringueira, ressaltando que embora as plantas adubadas e não adubadas acusaram o mesmo diâmetro do tronco, tiveram produções diferentes. Tal fenômeno foi justificado pelo fato das mesmas apresentarem o tamanho e número de vasos laticíferos, além da reserva de amido contido na casca totalmente diferentes. Na figura $10 \mathrm{~b}$ pode-se contatar o efeito quadrático das doses crescentes de potássio na espessura da casca do caule das plantas aos cinco anos de idade. Nota-se que o efeito foi mais pronunciado do nivel 2 (70 kg ha-1 de $\mathrm{K}_{2} \mathrm{O}$ ) para o nível $3\left(140 \mathrm{~kg} \mathrm{ha}^{-1}\right.$ de $\mathrm{K}_{2} \mathrm{O}$ ) com um incremento de $0,43 \mathrm{~cm}$. 
Tabela 31. Valores de $F$ das regressões, médias gerais e coeficientes de variação da espessura da casca do tronco da seringueira $(\mathrm{mm})$, durante as fases de présangria e pós-sangria

\begin{tabular}{|c|c|c|c|}
\hline & 4,0 & 5,0 & 11,0 \\
\hline Efeito Linear & 2,17 & $4,19^{\star \star}$ & 1,27 \\
\hline Efeito Quadrático & 0,62 & 0,30 & 0,32 \\
\hline Interação & 0,18 & 0,58 & 0,52 \\
\hline Efeito do $\mathrm{N}^{(1)}$ & 0,95 & 0,63 & 0,28 \\
\hline Efeito do $\mathrm{P}_{2} \mathrm{O}_{5}{ }^{(1)}$ & 0,15 & 0,20 & 0,43 \\
\hline Efeito do $\mathrm{K}_{2} \mathrm{O}^{(1)}$ & 0,23 & $3,50^{*}$ & 1,37 \\
\hline Média Final & 3,30 & 4,06 & 7,93 \\
\hline C.V. (\%) & 6,70 & 6,36 & 6,04 \\
\hline
\end{tabular}

${ }^{*} e^{\star \star}$ - niveis de significância de 5 e $1 \%$, respectivamente

(1) Segundo o modelo de superficie de resposta de $2^{\mathrm{a}}$ ordem nos nutrientes $\mathrm{N}, \mathrm{P}_{2} \mathrm{O}_{5}$ e $\mathrm{K}_{2} \mathrm{O}$ 


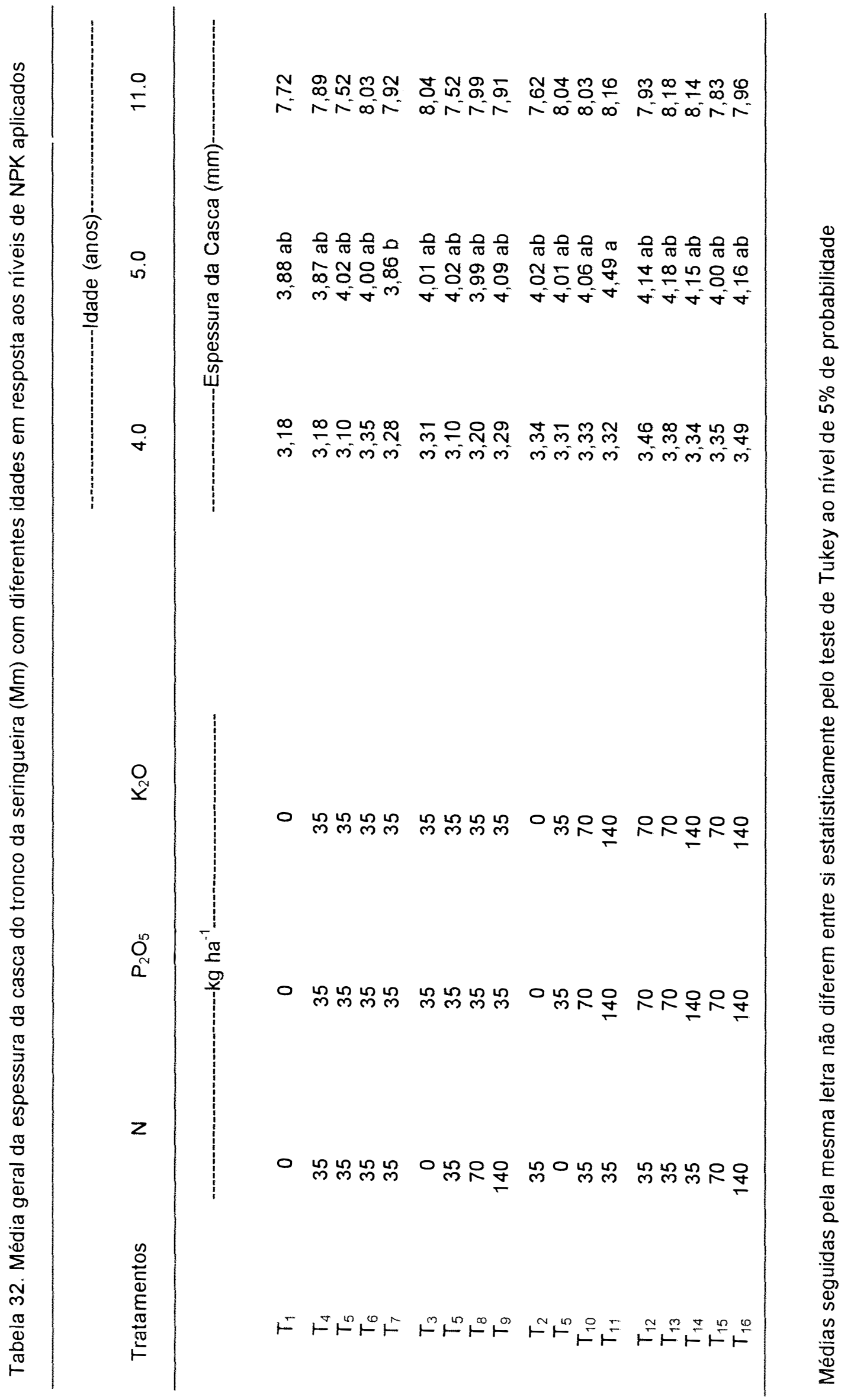


Uma outra forma de discutir a resposta ao aumento da circunferência do caule, às doses de potássio aplicadas, pode ser visualizado nas figuras 11 a e $11 \mathrm{~b}$.

Considerando que o diâmetro ideal para início da sangria é de $45 \mathrm{~cm}$, nota-se que aos sete anos de idade as plantas que receberam o nivel 3 (160 $\mathrm{kg} \mathrm{ha}^{-1}$ de $\left.\mathrm{K}_{2} \mathrm{O}\right)$, alcançaram o diâmetro de explotação. Por outro lado, como na prática o início da explotação e a intensidade de sangria durante o ano está muito em função do aspecto econômico, verifica-se que as plantas que receberam o nivel $2\left(80 \mathrm{~kg} \mathrm{ha}^{-1}\right.$ de $\mathrm{K}_{2} \mathrm{O}$ ) alcançaram o tamanho adequado para exploração 3 a 4 meses mais tarde.

Outro fator que deve ser considerado é que, em geral, os seringais do continente asiático são eficientemente manejados em termos de fertilização e introdução de leguminosas de cobertura, principalmente na fase de desenvolvimento. Este manejo, certamente, antecipa o início da exploração comercial desses seringais. 


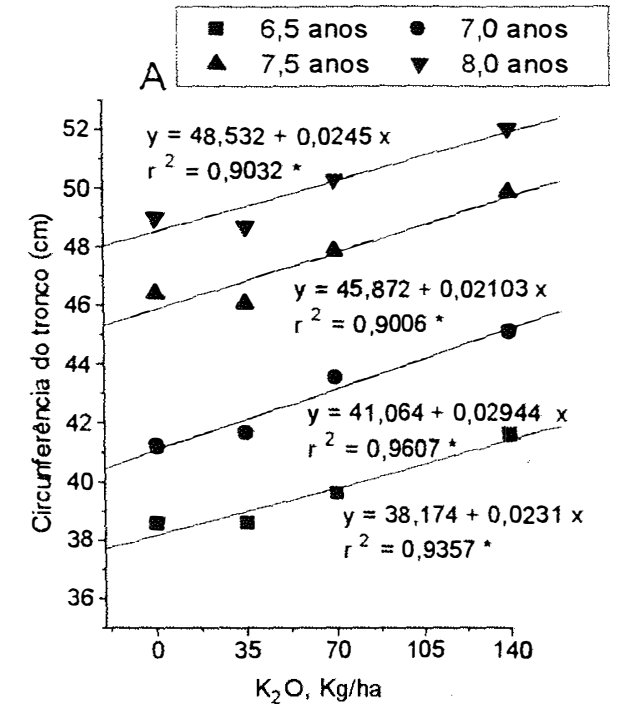

B

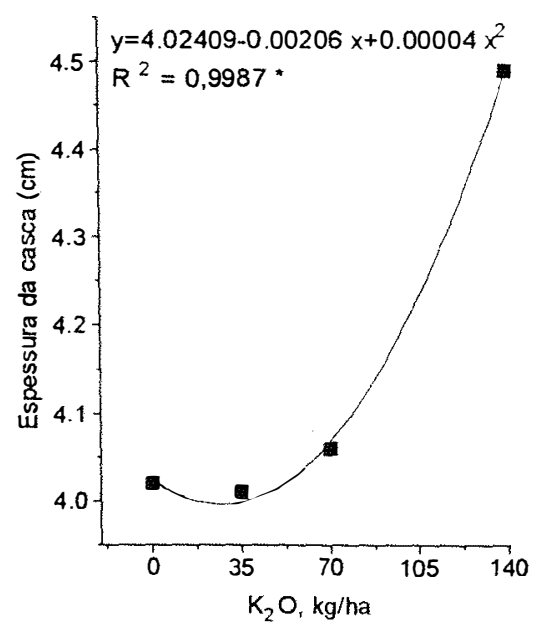

Figura 10. Influência da adubação potássica na circunferência do caule da seringueira em diferentes épocas de amostragens (A); e na espessura da casca da seringueira com cinco anos de idade $(B)$.
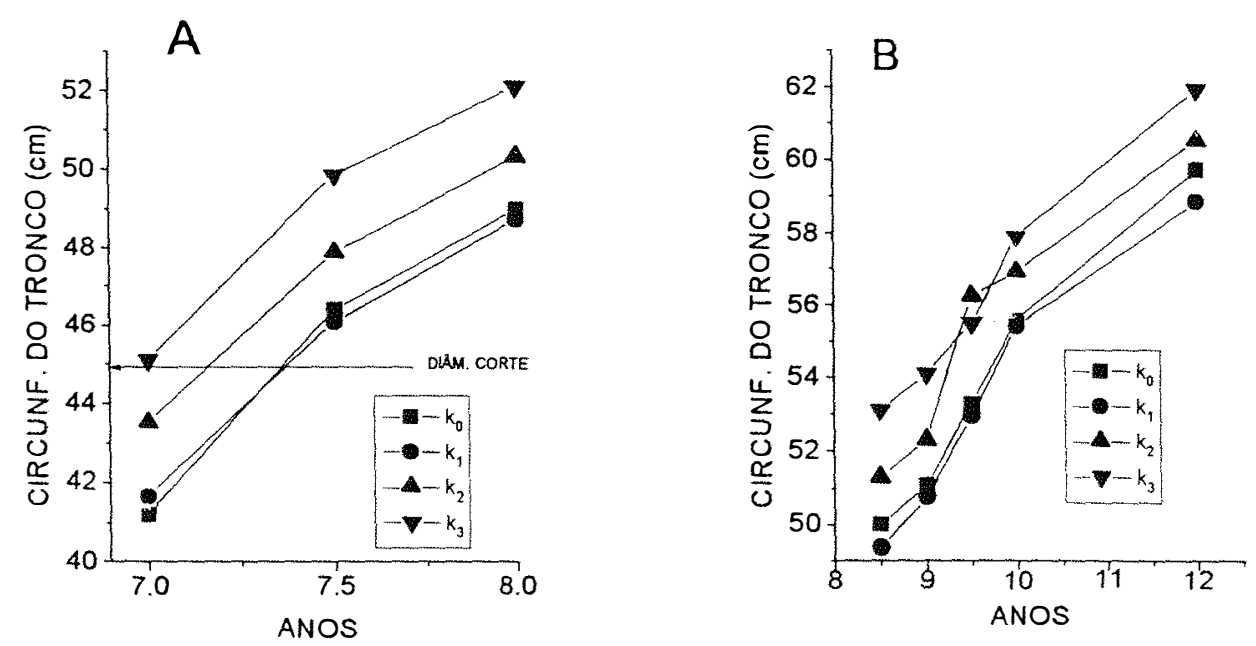

Figura 11. Efeito da adubação potássica na circunferência do tronco da seringueira no período de 7 - 8,0 anos (A); e de 8,0-12 anos (B). 


\subsection{Efeito da Adubação Nitrogenada, Fosfatada e Potássica em Alguns Parâmetros Fisiológicos do Látex}

Nas tabelas 33,34 e 35 são apresentados os valores de $F$ das regressões, médias gerais e coeficientes de variação dos resultados analíticos de alguns parâmetros fisiológicos, determinados em amostras do látex coletada na quarta semana de julho de 1995, e da produção bimestral referente aos meses de junho e julho de 1995.

Verifica-se que adubação nitrogenada afetou de forma linear o conteúdo de $\mathrm{Pi}$, as relações $\mathrm{Mg}^{++} / \mathrm{Pi}$ e $\mathrm{K}^{+} / \mathrm{Pi}$. Por outro lado, a adubação potássica causou efeito linear nas relações $\mathrm{Mg}^{++} / \mathrm{Pi} ; \mathrm{Ca}^{++} / \mathrm{Pi} ; \mathrm{Mg}^{++} / \mathrm{Ca}^{++} ; \mathrm{Mg}^{++} / \mathrm{K}^{+}$; nos teores de $\mathrm{Ca}^{++}$e $\mathrm{K}^{+}$e na produção bimestral, enquanto que a adubação fosfatada não afetou estatisticamente os parâmetros fisiológicos analisados.

$\mathrm{Na}$ figura $12 \mathrm{a}$, observa-se que as doses crescentes de nitrogênio aplicadas no solo provocaram um aumento significativo na produção e um decréscimo no teor de fósforo inorgânico contido no látex. O nitrogênio absorvido pelas raizes na forma de amônio $\left(\mathrm{NH}_{4}{ }^{+}\right)$ou nitrato $\left(\mathrm{NO}_{3}{ }^{-}\right)$, dará origem à compostos orgânicos de importância vital para as plantas tais como: proteinas, ácidos nucleicos e outros compostos constituintes das membranas celulares, além de fazer parte da estrutura molecular da clorofila (Marschner, 1986).

Embora no xilema a maior proporção de fósforo é encontrada na forma inorgânica existem também outros compostos complexos como o fosforil colina. A maior parte do fosfato inorgânico das células, parece estar armazenado no vacúolo de onde não sai com muita facilidade. Ainda assim ocorre transporte dos órgãos mais velhos para os mais novos (Malavolta 1976). 
Por outro lado o fósforo, em geral, absorvido na forma de ions fosfato $\left(\mathrm{H}_{2} \mathrm{PO}_{4}{ }^{-}\right)$pode ser translocado na forma iônica, ou ainda ser transformado em açúcares fosfatados (éster fosfatados) ou também ser utilizado na fase fotoquímica da fotossintese para a produção de trifosfato de adenosina (ATP) e difosfato de adenina nucleotideos (NADPH), os quais serão utilizados para a fixação do $\mathrm{CO}_{2}$ e posteriormente produção de sacarose através do ciclo de Calvin (Marschner, 1986). 


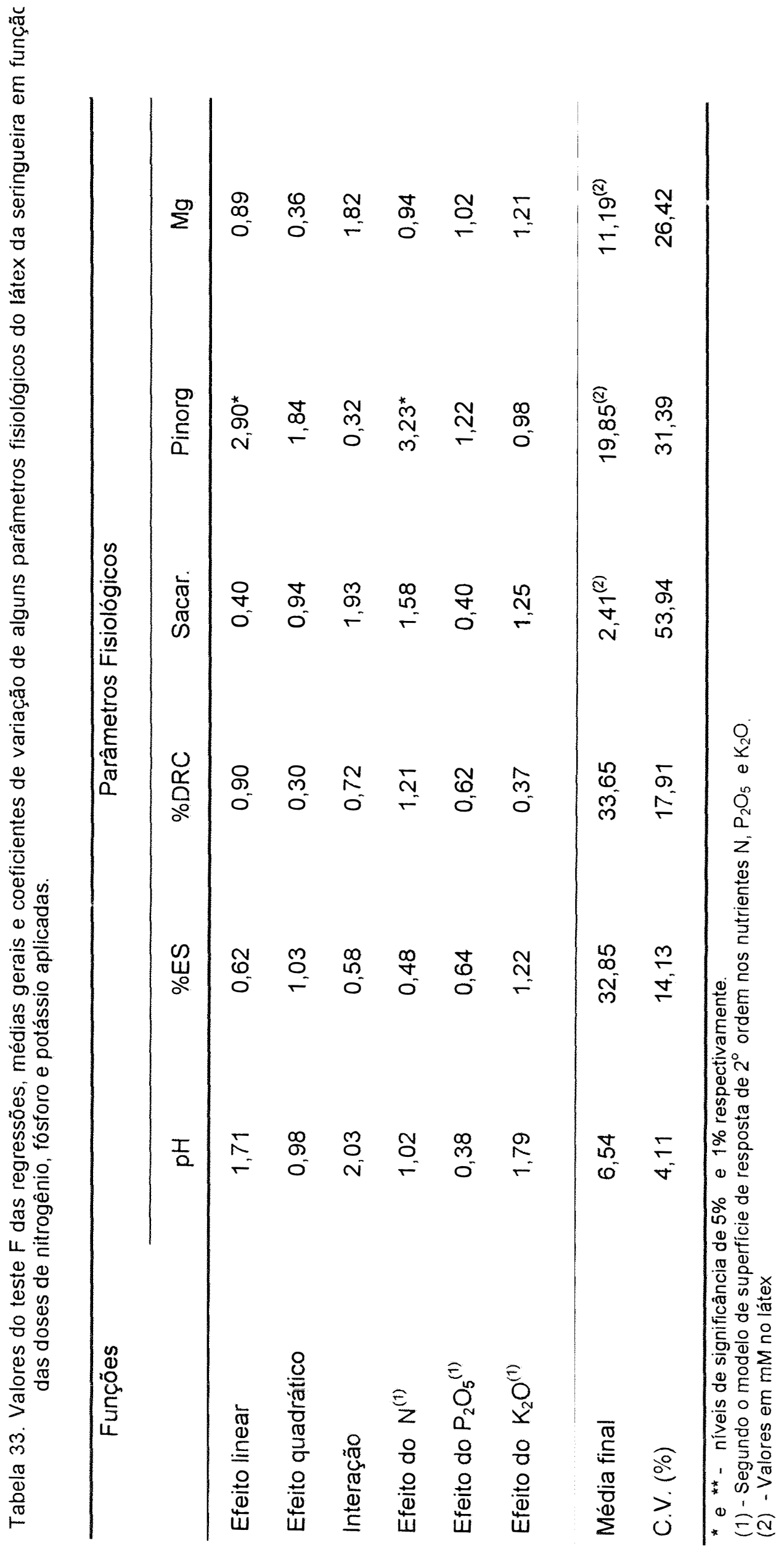




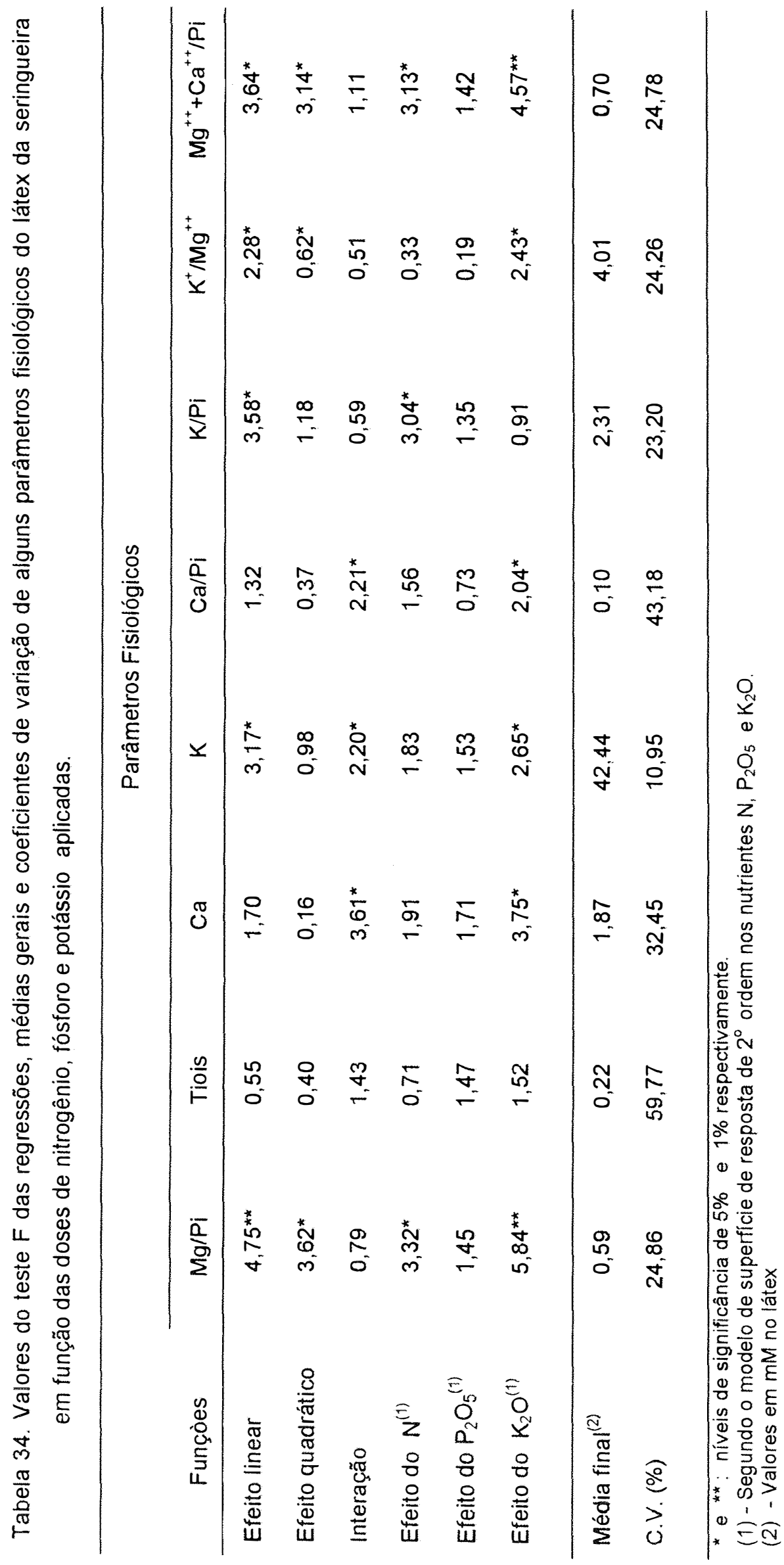


Tabela 35. Valores do teste $F$ das regressões, médias gerais e coeficientes de variação de alguns parâmetros fisiológicos do látex da seringueira e da produção, em função das doses de nitrogênio, fósforo e potássio aplicadas.

\begin{tabular}{lcccc}
\hline & Parâmetros Fisiológicos & & Produção \\
\hline Funções & $\mathrm{Mg}^{++} / \mathrm{Ca}^{++}$ & $\mathrm{Mg}^{++} / \mathrm{K}^{+}$ & $\mathrm{Ca}^{++} / \mathrm{K}^{+}$ & Bimestral $^{(2)}$ \\
\hline Efeito Linear & $2,39^{*}$ & $2,72^{\star}$ & 0,55 & 0,63 \\
Efeito Quadrático & 0,33 & 0,98 & 0,05 & $3,05^{\star}$ \\
Interação & 1,80 & 1,01 & 1,95 & 3,08 \\
Efeito do ${ }^{(1)}$ & 0,94 & 0,59 & 0,98 & 1,64 \\
Efeito do $\mathrm{P}_{2} \mathrm{O}_{5}{ }^{(1)}$ & 0,65 & 0,47 & 0,72 & 1,99 \\
Efeito do $\mathrm{K}_{2} \mathrm{O}^{(1)}$ & $2,50^{*}$ & $3,07^{*}$ & 1,82 & $3,67^{*}$ \\
& & & & \\
\hline Média Final & $6,43^{(3)}$ & $0,26^{(3)}$ & $0,04^{(3)}$ & 90,32 \\
C.V. (\%) & 35,35 & 24,11 & 31,70 & 16,36 \\
\hline
\end{tabular}

${ }^{\star} \mathrm{e}^{\star \star}$ - níveis de significância de $5 \%$ e $1 \%$ respectivamente

(1) - Segundo o modelo de superfície de resposta de $2^{\text {a }}$ ordem dos nutrientes $\mathrm{N}$, $\mathrm{P}_{2} \mathrm{O}_{5}, \mathrm{~K}_{2} \mathrm{O}$

(2) - Correspondente aos meses de junho e julho em $\mathrm{kg} /$ tratamento

(3) - Valores em mM no látex 

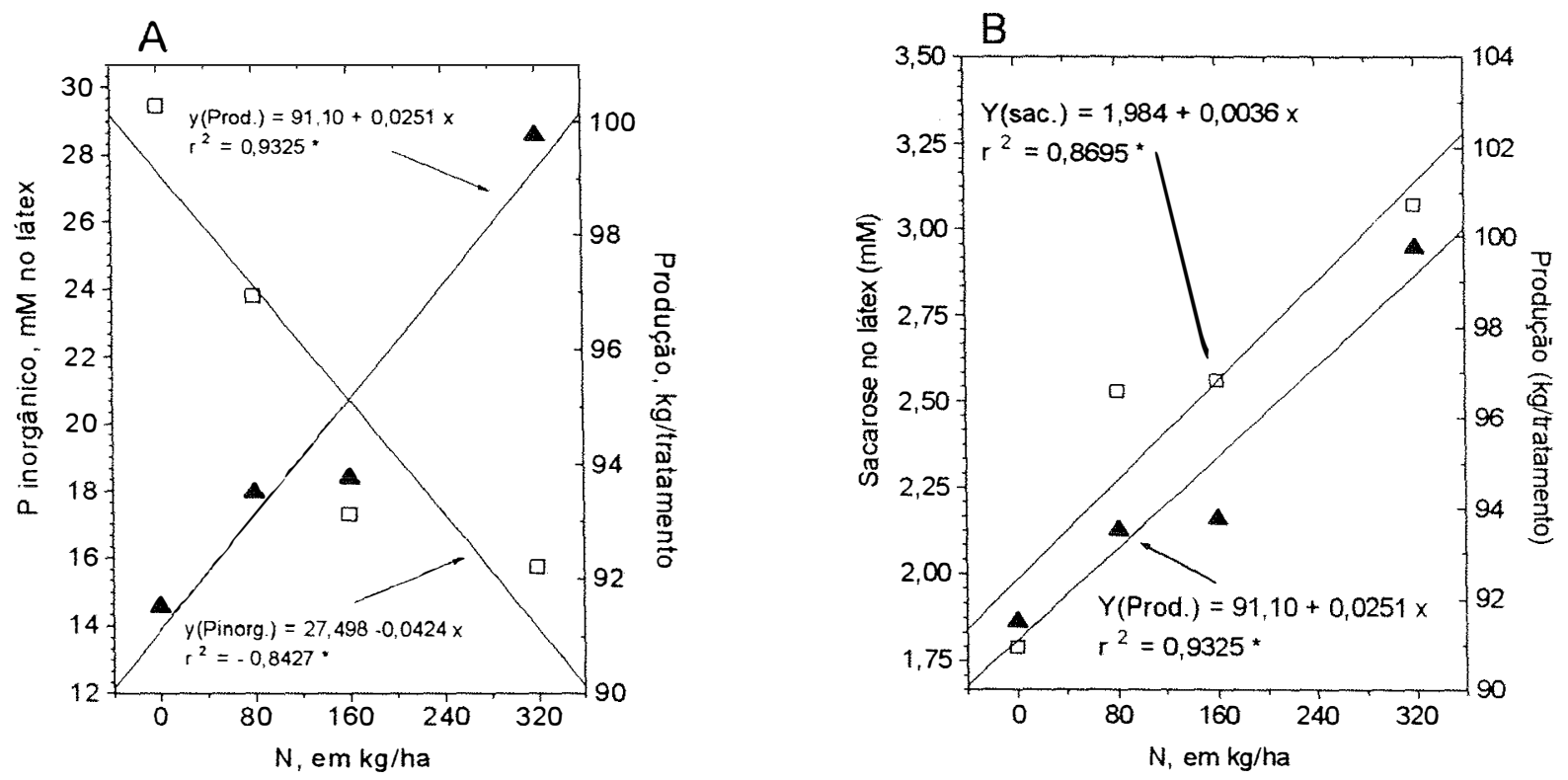

Figura 12. Efeito da adubação nitrogenada nos teores de fósforo inorgânico no látex e na produção bimestral (A); teor de sacarose e produção bimestral (B)
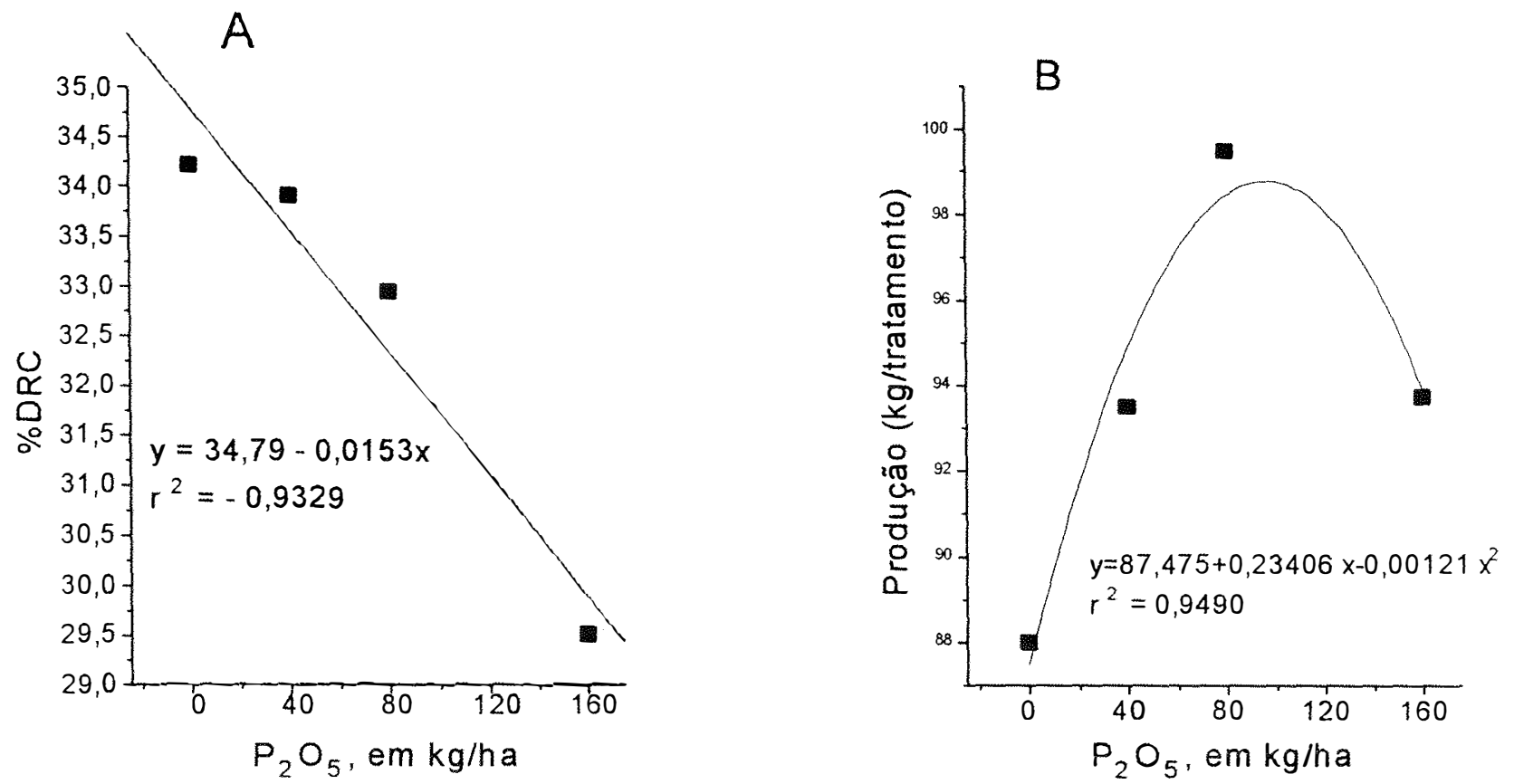

Figura 13. Efeito da adubação fosfatada no conteúdo de borracha seca (A); e na produção bimestral (B) 
O decréscimo no teor de fósforo inorgânico e o acréscimo da produção, observadas na figura $12 \mathrm{a}$, podem ser atribuidas à fatores como: as doses crescentes de nitrogênio causaram um maior desenvolvimento vegetativo das plantas, aumentando a demanda pelo fósforo para atender suas exigências metabólicas; o aumento da produção também exigiu maiores quantidades de fósforo inorgânico para a sintese isoprênica. Isto pode justificar a queda no teor desse nutriente mineral nos vasos laticíferos.

Observações visuais do seringal, no momento da coleta das amostras de látex, mostraram que naquela época, julho de 1995, o seringal apresentava aproximadamente 70 a $80 \%$ de sua copa com folhas adultas em plena atividade fotossintética. Verificou-se também que a mudança de folhas estava ocorrendo de forma gradativa.

Comparando o seringal do presente estudo com um seringal implantado no Campus da ESALQ, notou-se que este apresentou, naquela mesma época, uma mudança brusca das folhas, ou seja, derrubando rapidamente todas as folhas senescentes e iniciando o processo de reenfolhamento.

Essa diferença de comportamento, nos diferentes locais, permite inferir que as seringueiras do experimento estavam utilizando o fósforo inorgânico tanto para a produção de borracha, como para outras atividades metabólicas, justificando a queda no teor desse nutriente à nivel de látex.

Embora o teor de fósforo inorgânico tenha apresentado um decréscimo, esse intervalo de $15,72 \mathrm{mM}$ encontrado nas plantas que não receberam adubação nitrogenada e de $29,45 \mathrm{mM}$ encontrado nas plantas que receberam as maiores doses de nitrogênio são considerados valores altos.

Sá (1991), analisando amostras de látex do clone PB 235, coletado no inverno, encontrou valores variando de 12 
a $20 \mathrm{mM}$, valores esses também considerados altos, os quais concordam com os dados observados no presente estudo.

Jacob et al. (1989b) mencionaram que o conteúdo de fósforo inorgânico no látex tende a diminuir no inverno. A queda de folhas e o reenfolhamento conduz o metabolismo das árvores, essencialmente, para a reposição dos sistemas fotossintéticos, provavelmente retardando outras atividades de sintese.

Por outro lado, verifica-se na literatura, valores relativamente mais elevados do conteúdo de fósforo inorgânico no látex, nos meses em que em a radiação solar, a precipitação pluviométrica e a temperatura são mais baixas.

A sacarose é a principal forma de carboidrato translocada por todas as partes da planta através do floema. A concentração de sacarose na seiva é muito alta, podendo apresentar valores em torno de 100 - $200 \mathrm{mM}$ (Marschner, 1986). Em todas as plantas superiores, a sacarose produzida na fotossintese, é a molécula básica em todas as síntese, seja do amido, da celulose, dos lipídeos armazenados, etc.

$\mathrm{Na}$ seringueira, o metabólito secundário polisopreno deriva diretamente ou indiretamente da sacarose. Sob condições em que a sacarose pode ser um fator limitante, correlações positivas podem ocorrer entre o conteúdo de sacarose no látex e a produção em grama/planta (Jacob et al. $1989 b)$.

Tais correlações podem ser observadas através da figura $12 b$, onde as doses crescentes de nitrogênio aplicadas no solo aumentaram de forma linear o conteúdo de sacarose e a produção. Como o nitrogênio faz parte da estrutura molecular da clorofila, é provável que o aumento na absorção desse nutriente pela planta, possibilitou um acréscimo na taxa fotossintética, incrementando com isso a produção de sacarose e consequentemente, uma maior produção de látex. 
Apesar do aumento observado, os valores determinados de $1,79 \mathrm{mM}\left(\mathrm{N}_{0}\right)$ e $3,07 \mathrm{mM}\left(\mathrm{N}_{3}\right)$ são considerados muito baixos. Esses dados discordam dos encontrados por Sá (1991) que encontrou valores extremamente elevados (18,98 $30,84 \mathrm{mM})$ de sacarose no látex coletado no inverno no clone PB 235.

Comparando os valores encontrados para o fósforo inorgânico com os valores limitantes da tabela 1, propostos para os parâmetros fisiológicos do látex pré-estabelecidos para o clone GT-1 (Jacob et al. 1989b), verifica-se que os tratamentos 00 e $80 \mathrm{~kg} \mathrm{ha-1}$ de nitrogênio apresentaram valores de fósforo inorgânico acima do limite mínimo $(>20,00 \mathrm{mM})$ considerado quando as plantas começam apresentar os primeiros sintomas de super-exploração. Já os tratamentos 160 e $320 \mathrm{~kg} / \mathrm{ha}$ de nitrogênio apresentaram valores acima do limite $(<10 \mathrm{mM})$ considerado quando as plantas apresentam-se sub-exploradas e abaixo do limite ( $>20 \mathrm{mM}$ ) que caracteriza o sintoma de super-exploração.

Da mesma forma, os valores de sacarose determinados em função das doses crescentes de nitrogênio sendo (1,79mM para o nível zero e $3,07 \mathrm{mM}$ para o nível três), ficaram muito abaixo do limite máximo $(<5,00 \mathrm{mM})$ considerado para caracterizar os primeiros sintomas de super-exploração da seringueira.

O conteúdo de borracha seca (DRC) pode se tornar fator limitante da produção quando ocorre déficit hídrico na planta, e, consequentemente, quando ocorre impedimento da transferência de água do tecido parenquimático para os laticiferos (Jacob et al., 1989b).

Deve-se considerar também que o déficit hídrico nas plantas acarretado pela baixa disponibilidade de água no solo, pode levar a uma diminuição da absorção de determinados nutrientes, principalmente daqueles absorvidos através do fluxo de massa, como no caso do cálcio e do 
magnésio, podendo induzir a um desequilibrio cátiônico no tecido foliar ou nos laticiferos.

Através da figura $13 a$ pode-se constatar que a adubação fosfatada diminuiu o conteúdo de borracha seca $(D R C)$. Considerando que existe uma relação direta entre o DRC e a viscosidade do látex, a diminuição observada poderá aumentar a intensidade ou duração do fluxo, com reflexos positivos na produção.

A figura 13 b comprova a relação inversa existente entre o conteúdo de borracha seca (\%DRC) e a produção, em função da adubação fosfatada. Quanto menor o valor de \%DRC menor será a viscosidade do látex, possibilitando um aumento na intensidade de fluxo durante a sangria $e$, consequentemente, aumentando a produção. Pode-se observar que o efeito foi linear até a dose de $160 \mathrm{~kg} \mathrm{ha}^{-1}$ de $\mathrm{P}_{2} \mathrm{O}_{5}$; acima dessa dose a adubação passa a apresentar um efeito depressivo na produção.

Conduru Neto (1987) menciona que a adubação fosfatada pode reduzir a produção e também diminuir o tempo de fluxo do látex. Por outro lado, o mesmo autor relata que o fósforo inorgânico é constituinte da membrana dos lutóides e das particulas de borracha. Portanto, um teor elevado desse nutriente pode ser considerado favorável à produção de látex.

lons como $\mathrm{Mg}^{++}$e $\mathrm{PO}_{4}^{-3}$ e os grupos-SH (tióis) desempenham importante papel na atividade de certas enzimas chaves no metabolismo do isopreno, como exemplo pode-se citar a invertase, piruvato quinase, fosfoenolpiruvato carboxilase (Jacob et al., 1989b).

Com respeito ao fluxo, D'Auzac \& Jacob (1989) mencionaram que quando amostra de látex foi coletada e separada a fração amarelada (lutóide), esta fração amarelada floculou espontaneamente em poucos dias, enquanto que o restante permaneceu estável por várias semanas, mostrando, portanto, que os lutóides atuam como coagulantes pela 
formação de microflocos consistindo de particulas de borracha e lutóides.

O soro $B$, que contém os lutóides, é um soro ácido enriquecido de proteinas cationicas e cátions divalentes como $\mathrm{Ca}^{++}$e $\mathrm{Mg}^{++}$, com poder de provocar a formação de microflocos e uma suspensão diluida cremosa de borracha. Vários autores têm demonstrado que o soro C (citosol) contém proteinas aniônicas, enquanto que aquelas contidas nos lutóides são cationnicas. O contato entre essas proteinas com cargas opostas resultam em uma neutralização das cargas superficiais e uma desestabilização da solução coloidal do látex (D'Auzac \& Jacob, 1989)

Na figura 14a, nota-se que as doses crescentes de nitrogênio aplicadas no solo na forma de uréia, contribuiram para o aumento da relação $\mathrm{Mg}^{++} / \mathrm{Pi}$ contido no látex. Experimentos desenvolvidos na Malásia mostraram que a aplicação de sulfato de amônio também aumentou a relação $\mathrm{Mg}^{++} / \mathrm{Pi}$ no látex. O balanço entre $\mathrm{Mg}^{++} / \mathrm{Pi}$ no látex é tido como de importância e foi sugerido a faixa de 0,7 - 0,13 como a relação ótima desses nutrientes no látex (Watson, 1989; Shorrocks, 1979).

Considerando que as análises foram realizadas no soro TCA, ou seja, conteúdo total desses nutrientes contido no látex, excluindo somente a fase borracha, torna-se dificil concluir se essa relação, de acordo com os valores encontrados, afetará de alguma forma a estabilidade coloidal do látex e consequentemente a intensidade do fluxo.

Entretanto, comparando a relação $\mathrm{Mg}^{++} / \mathrm{Pi}$ encontrada no presente estudo com os valores da tabela 1 mencionadas por Jacob et al., 1989b, pode-se inferir que a relação $\mathrm{Mg}^{++} / \mathrm{Pi}$ de $0,41 \mathrm{mM}$ encontrado nas parcelas que não receberam adubação nitrogenada, ficou abaixo do limite $(<0,50 \mathrm{mM})$ considerado quando as plantas apresentam os primeiros sintomas de super-exploração (Figura 14a). 
A

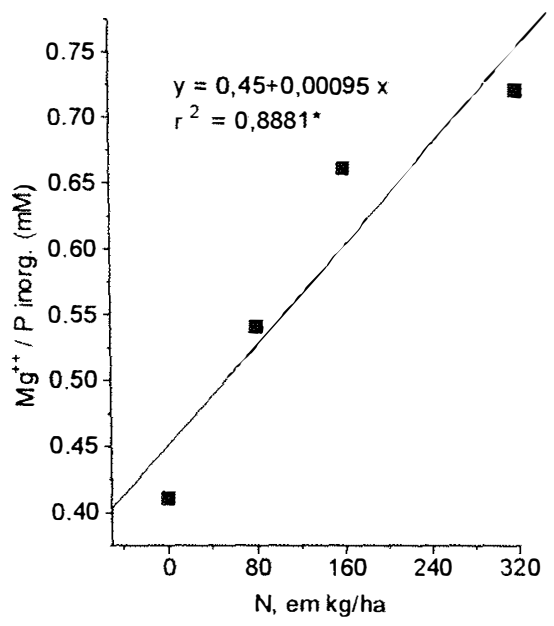

C

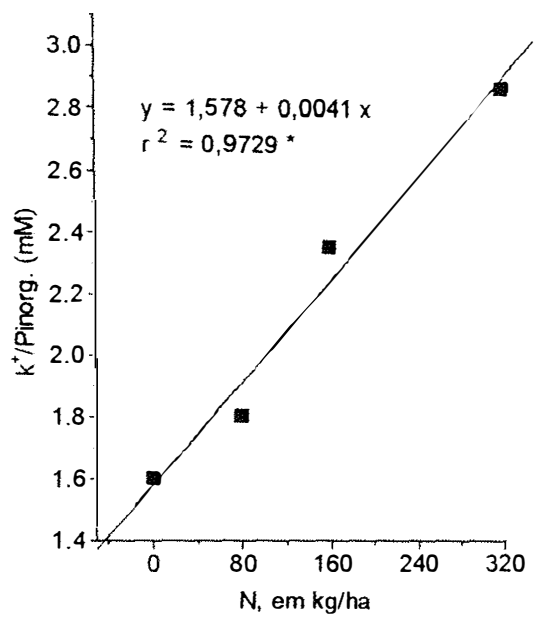

$B$
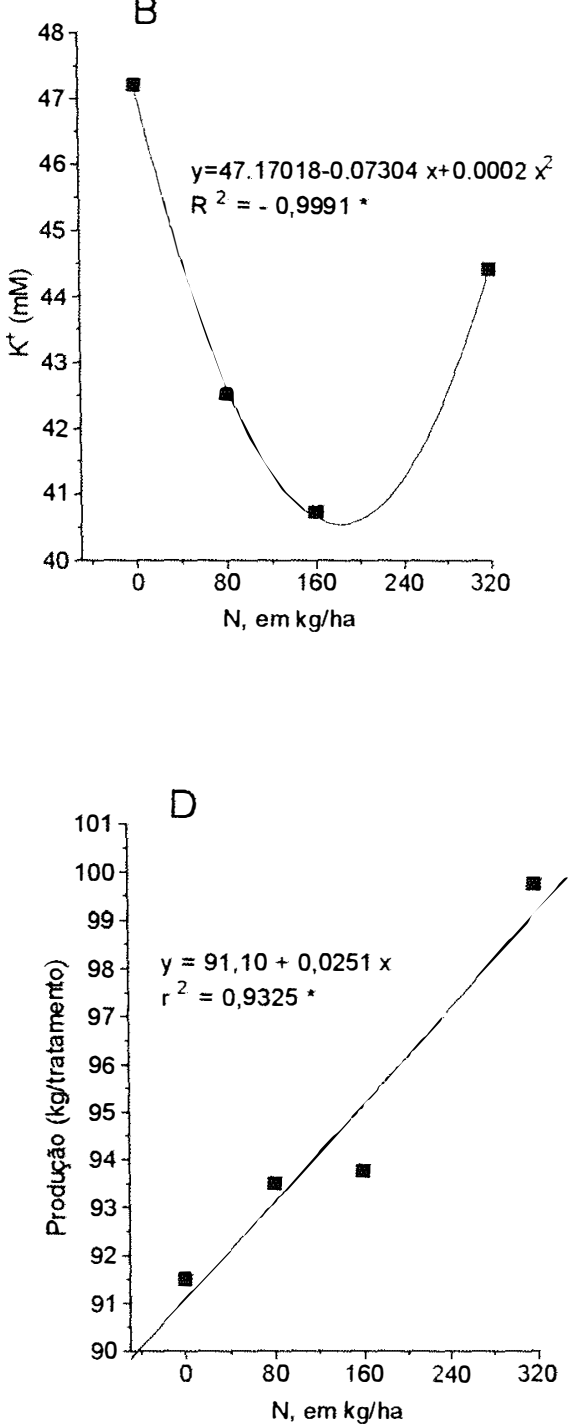

Figura 14. Efeito da adubação nitrogenada na relação de concentração do magnésio/fósforo inorgânico $(A)$; teor de potássio $(B)$; na relação de concentração do potássio/ fósforo inorgânico ( $C$ ) contido no látex e na produção bimestral (D). 
Por outro lado, o valor de $0,72 \mathrm{mM}$ encontrado nas parcelas que receberam $320 \mathrm{~kg} \mathrm{ha}^{-1}$ de nitrogênio, ficou acima do limite que caracteriza uma super-exploração e abaixo do limite que define a sub-exploração das plantas.

Da mesma forma, verifica-se que o conteúdo de borracha seca de $33,64 \%$ encontrado nas parcelas que não receberam adubação nitrogenada e $35,34 \%$ determinados nas parcelas que receberam a dose mais alta de nitrogênio, confirmam valores acima do limite que define os primeiros sintomas de super-exploração e acima do limite característico de plantas sub-exploradas respectivamente (tabela 36).

Observa-se também (Figura $14 \mathrm{c}$ ) que a relação $\mathrm{K}^{+} / \mathrm{Pi}$ apresentou coeficiente de correlação linear positivo e significativo com as doses crescentes de uréia aplicadas. Apesar de ambos os elementos terem diminuidos com 0 aumento das doses de uréia aplicadas, o fato do Pi ter apresentado um decréscimo mais acentuado, possibilitou uma resposta linear crescente nessa relação.

A influência da adubação nitrogenada no conteúdo de $\mathrm{K}^{+}$no látex pode ser visualizado através da figura $14 \mathrm{~b}$. Os valores encontrados numa faixa de $40,72 \mathrm{mM}$ a $47,21 \mathrm{mM}$ podem ser interpretados de diferentes formas: a) apesar do efeito ter sido negativo e estatisticamente significativo, esse decréscimo pouco influenciou na atividade metabólica da planta, uma vez que o teor de potássio somente no citosol pode variar de 30 a $80 \mathrm{mM}$; b) como a análise foi realizada no conteúdo total do látex, excluindo-se somente a fase borracha, pode-se concluir, com razoável segurança, que o conteúdo máximo determinado de $47,21 \mathrm{mM}$ é baixo e pode posteriormente trazer problemas fisiológicos às plantas. 
As elevadas concentrações de $\mathrm{K}^{+}$no citoplasma $(100-200 \mathrm{mM})$ e nos cloroplastos $(20-200 \mathrm{mM})$ são necessárias para neutralizar as macromoléculas aniônicas solúveis (ácidos orgânicos e inorgânicos aniônicos) e insolúveis, como também para estabilizar o pH entre 7 e 8 nesses compartimentos, adequados para a maioria das reações enzimáticas (Marschner, 1986).

Comparando as figuras $14 \mathrm{~b}$ e $14 \mathrm{~d}$, observa-se que a produção apresentou uma correlação positiva e significativa, enquanto que $0 \mathrm{~K}^{+}$no látex apresentou uma correlação negativa e significativa. Uma provável explicação para essa relação inversa pode ser atribuido ao aumento da atividade fotossintética das plantas, provocado pela eficiencia da adubação nitrogenada, possibilitando uma maior produção de fotos sintetizados.

O potássio é um nutriente responsável pela ativação de inúmeras enzimas como no desdobramento dos carboidratos, evitando o acúmulo de carboidratos solúveis, a queda no teor de amido, o acúmulo de compostos nitrogenados solúveis e também na regulação estomática (Marschner, 1986).

Assim, é de se esperar que ocorra um alto consumo desse nutriente não somente para suprir as necessidades fisiológicas de manutenção e desenvolvimento das plantas, como também sua utilização nas células laticiferas, uma vez que, a atividade da enzima piruvato quinase no metabolismo da sacarose é máxima em altas concentrações de $\mathrm{K}^{+}$, acarretando, consequentemente, uma queda no teor nos vasos laticiferos.

A adubação potássica aumentou significativamente o teor de $\mathrm{K}^{+}$no látex, discordando dos resultados relatados por Watson (1989), enquanto que a relação $\mathrm{Mg}^{++} / \mathrm{Pi}$ apresentou um decréscimo com as doses crescentes de potássio, coincidindo com o resultado mencionado por Watson (1989). Da mesma forma, a relação $\mathrm{Mg}^{++} / \mathrm{K}^{+}$no látex 
apresentou um relação linear negativa e significativa com as doses crescentes de potássio aplicadas.

A análise do conteúdo total de minerais do látex fresco expresso em $\mathrm{mM}$ de $\mathrm{N}, \mathrm{P}, \mathrm{K}, \mathrm{Ca}^{++}$e $\mathrm{Mg}^{++}$apresentou valores de $185 ; 16 ; 43 ; 1,5$ e $42 \mathrm{mM}$, respectivamente. $O \mathrm{~K}^{+}$ está distribuido em proporções aproximadamente iguais entre o citosol e o compartimento dos lutóides (D'Auzac \& Jacob, 1989).

As concentrações de $\mathrm{Mg}^{++}$e $\mathrm{Pi}$ são oito a nove vezes maiores nos lutóides; a concentração do $\mathrm{Ca}^{++}$no citosol varia de 0,08 a $0,23 \mathrm{mM}$; e $\circ \mathrm{K}^{+}$no citosol varia entre 30 e $80 \mathrm{mM}$ de acordo com o tipo de clone. O $\mathrm{K}^{+}$é o principal nutriente responsável pela pressão osmótica do látex (D’Auzac \& Jacob, 1989).

Observa-se através da figura $15 a$ que as doses crescentes de cloreto de potássio aplicadas no solo, proporcionaram um aumento no teor de cálcio no látex, o que difere das observações de Watson (1989) que encontrou um decréscimo no teor de cálcio no látex com a aplicação de cloreto de potássio.

Por outro lado, nota-se que ocorreu um incremento no teor de $\mathrm{K}^{+}$no látex, embora não estatisticamente significativo, visto que a relação $\mathrm{Mg}^{++} / \mathrm{K}^{+}$apresentou-se linear negativa e estatisticamente significativa (figura $15 \mathrm{c}$ ). Observa-se ainda na figura $15 \mathrm{~b}$ que, a adubação potássica diminuiu a relação $\mathrm{Mg}^{++} / \mathrm{Pi}$ até a dose de $160 \mathrm{~kg} \mathrm{ha}^{-1}$ de $\mathrm{K}_{2} \mathrm{O}$. Resultados similares foram mencionados por Watson (1989) em experimentos desenvolvidos na Malásia. 

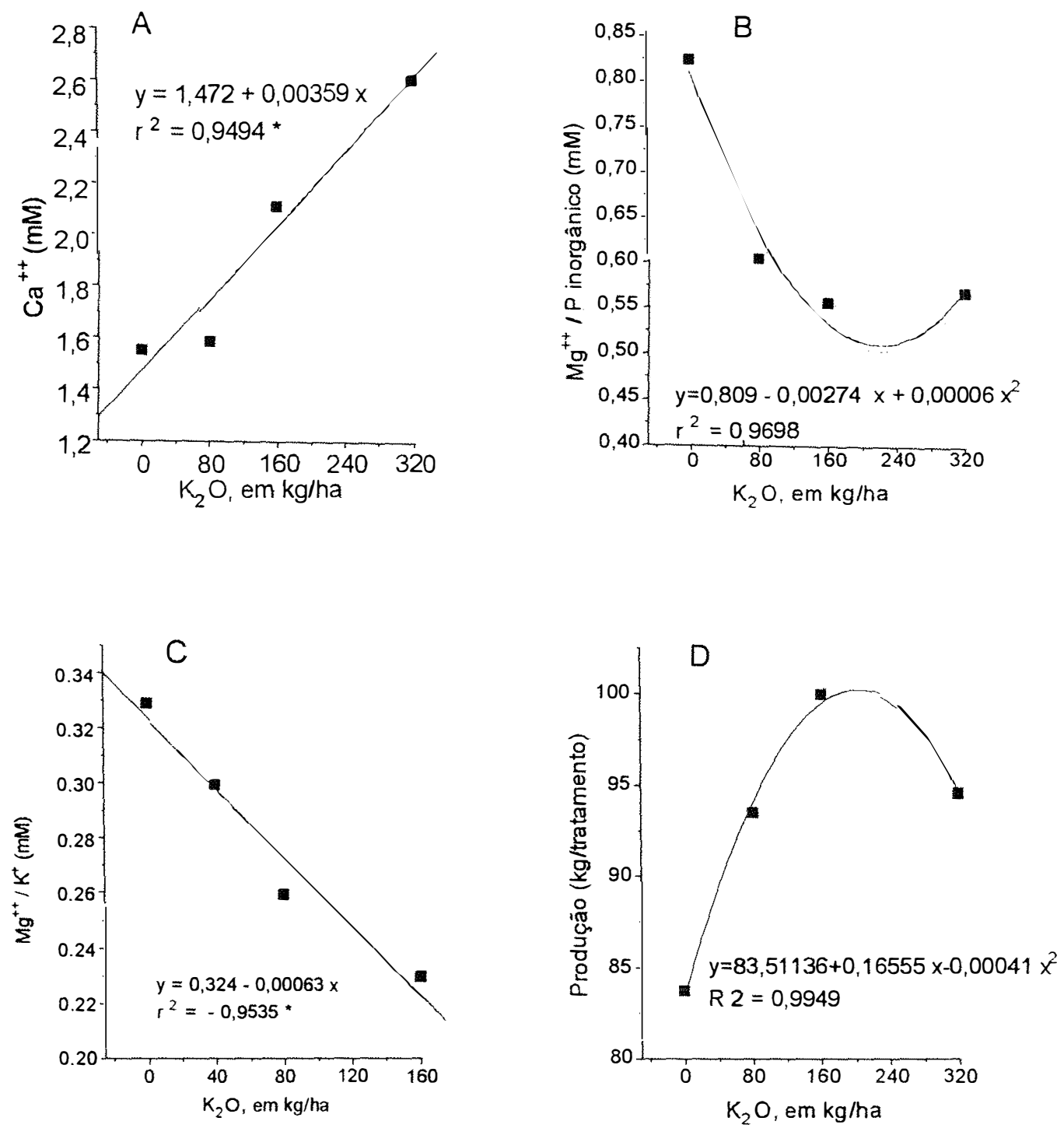

Figura 15. Efeito da adubação potássica no teor de cálcio $(A)$; na relação de concentração de magnésio/fósforo inorgânico (B); na relação de concentração de magnésio/ potássio contido no látex $(C)$ e na produção bimestral (D). 
Comparando-se as figuras $15 b$ e $15 d$, nota-se que a medida que a relação $\mathrm{Mg}^{++} / \mathrm{Pi}$ diminui, a produção aumenta alcançando uma produção máxima exatamente na dose de 160 $\mathrm{kg} \mathrm{ha}^{-1}$ de $\mathrm{K}_{2} \mathrm{O}$. Esse comportamento provavelmente se deva a baixa relação $\mathrm{Mg}^{++} / \mathrm{Pi}$ e $\mathrm{Mg}^{++}+\mathrm{Ca}^{++} / \mathrm{Pi}$ que apresentam relação direta com a estabilidade do látex e consequentemente maior intensidade de fluxo durante a sangria (Beaufils, 1957; Yip \& Gomez, 1980).

Ainda com relação aos efeitos da adubação potássica, a relação de concentração de $\mathrm{Mg}^{++} / \mathrm{Pi}$ contido no látex ficou em torno de 0,55 a $0,82 \mathrm{mM}$. Shorrocks (1979) relata que o balanço entre $\mathrm{Mg}^{++} / \mathrm{Pi}$ no látex é tido como de importância e foi sugerido 0,7-0,13 como a relação ótima no látex. Entretanto, deve-se observar que tanto fatores inerentes a própria planta (clones diferentes) como também fatores ambientais (temperatura, precipitação pluviométrica e tipo de solo) podem modificar essa relação, não permitindo, portanto, concluir que os valores encontrados no presente estudo encontram-se baixos ou adequados.

As figuras 16 a e $16 \mathrm{~b}$ demonstram as significativas elevações das relações $\mathrm{Ca}^{++} / \mathrm{K}^{+}$e $\mathrm{Mg}^{++}+\mathrm{Ca}^{++} / \mathrm{Pi}$ contidas no látex com as doses crescentes de uréia aplicadas. Tais resultados ocorreram devido a pequena variação determinada nos teores de $\mathrm{Ca}^{++}$e $\mathrm{Mg}^{++}$no látex.

Alto conteúdo de $\mathrm{Pi}$ e baixa relação $\mathrm{Mg}^{++} / \mathrm{Pi}$ e $\mathrm{Mg}^{++}$ $+\mathrm{Ca}^{++} / \mathrm{Pi}$ estão associados com boa estabilidade do látex (Watson, 1989). Comparando as figuras 17b e 16b observa-se que a adubação potássica contribuiu para a estabilidade do látex, diminuindo a relação $\mathrm{Mg}^{++}+\mathrm{Ca}^{++} / \mathrm{Pi}^{\text {, ao }}$ passo que a adubação nitrogenada afetou de forma linear e positiva essa relação. É dificil explicar as razões para esse comportamento. Provavelmente alterações metabólicas a nível de vasos laticiferos estejam envolvidos. 
A

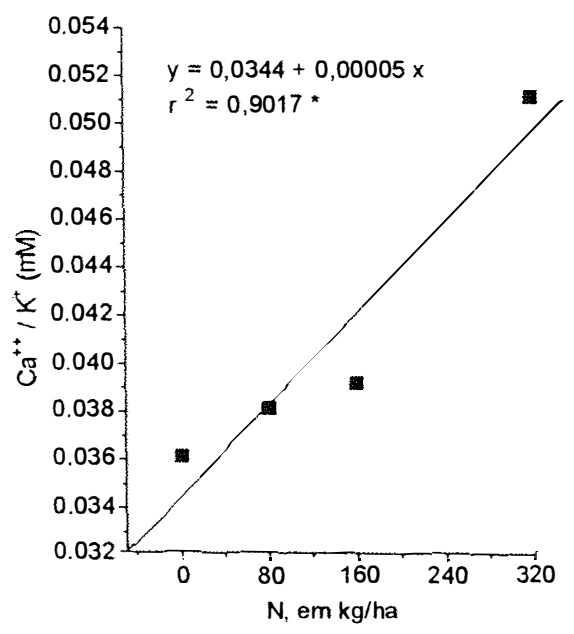

$B$

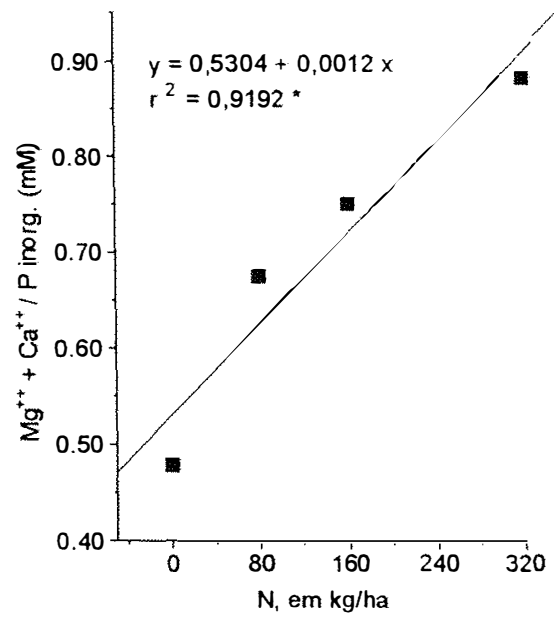

Figura 16. Efeito da adubação nitrogenada nas relações de concentração do $\mathrm{Ca}^{++} / \mathrm{K}^{+}(\mathrm{A})$; e do $\mathrm{Mg}^{++}+\mathrm{Ca}^{++} / \mathrm{P}$ inorgânico $(\mathrm{B})$, contido no látex
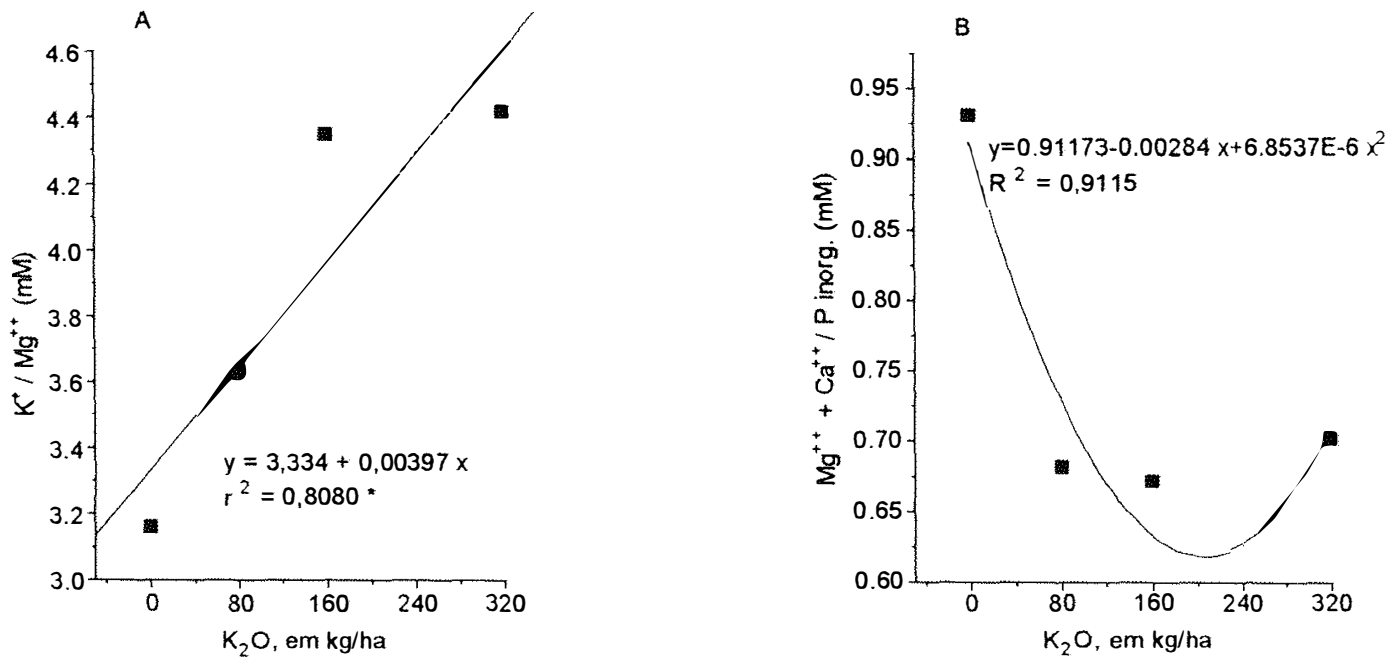

Figura 17. Efeito da adubação potassica nas relações de concentração do $\mathrm{K}^{+} / \mathrm{Mg}^{++}(\mathrm{A})$; e no $\mathrm{Mg}^{++}+\mathrm{Ca}^{++} / \mathrm{P}$ inorgânico $(\mathrm{B})$, contidos no látex 
Na figura 15a observa-se que o aumento no teor de $\mathrm{K}^{+}$e o decréscimo no teor de $\mathrm{Mg}^{++}$contribuiu para o aumento da relação $\mathrm{K}^{+} / \mathrm{Mg}^{++}$contido no látex com as doses crescentes de potássio aplicados. Watson (1989) relata que adubação com fertilizantes contendo magnésio aumenta o conteúdo de $\mathrm{Mg}^{++}$no látex e diminui o conteúdo de $\mathrm{K}^{+}$levando a um decréscimo na relação $\mathrm{K}^{+} / \mathrm{Mg}^{++}$e acréscimo na relação $\mathrm{Mg}^{++} / \mathrm{P}$ inorgânico a nivel de látex. O incremento na relação $\mathrm{Mg}^{++} / \mathrm{P}$ inorgânico torna-se mais elevado quando o fertilizante magnesiano é aplicado juntamente com fertilizante nitrogenado.

$\mathrm{Na}$ tabela 36 nota-se que todos os parâmetros fisiológicos analisados não apresentaram diferenças estatisticamente significativas, o mesmo acontecendo para os demais parâmetros apresentados nas tabelas 37 e 38 , exceto para a relação $\mathrm{Mg}^{+\cdots} / \mathrm{Pi}$ que apresentou diferença significativa.

A diagnose do látex à nivel industrial consiste na determinação dos teores de sacarose, $P$ inorgânico, tióis e conteúdo de sólidos totais (TSC); no qual a \% DRC contribui com mais de $90 \%$ do TSC contido no látex (Jacob et al., $1989 b)$. 


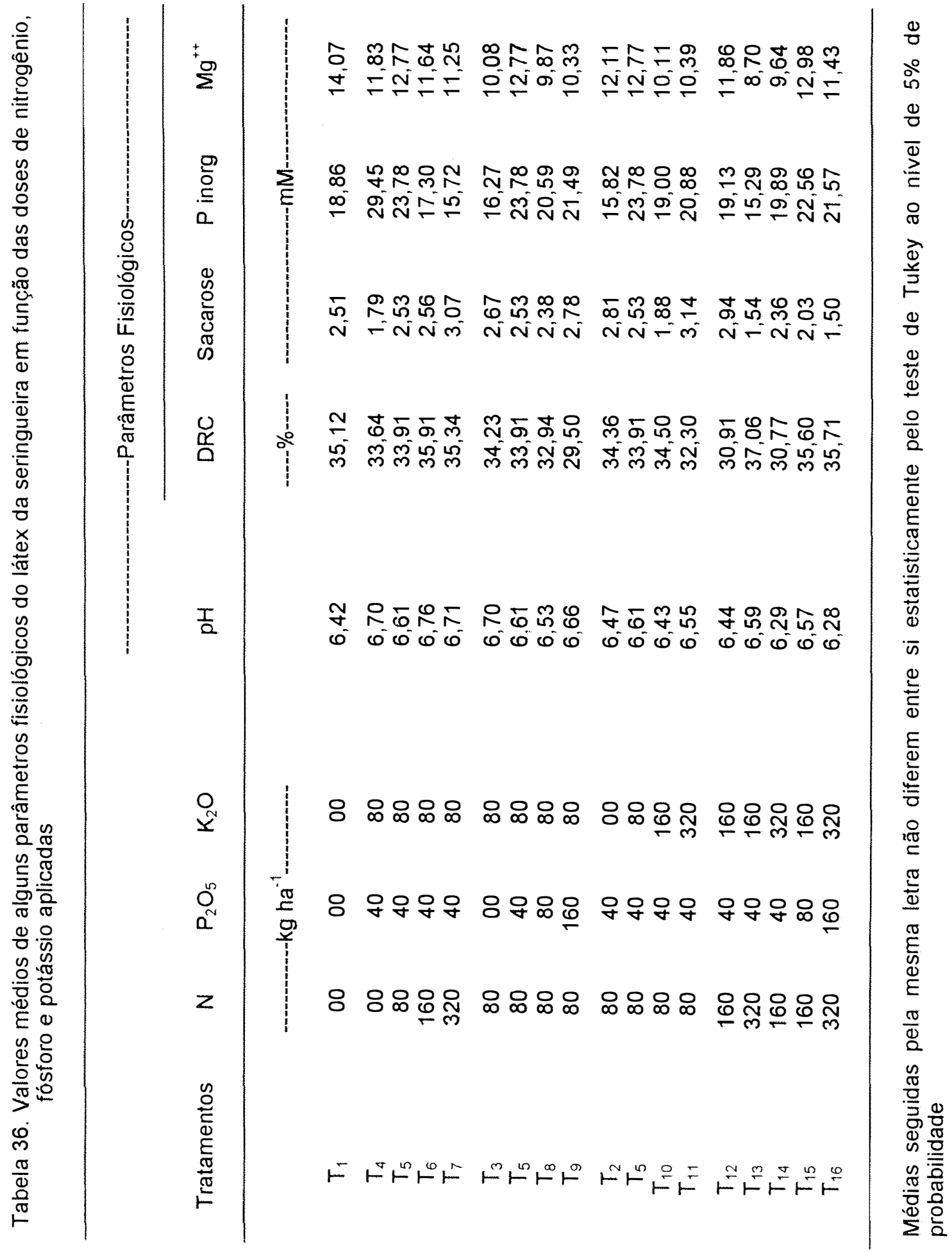




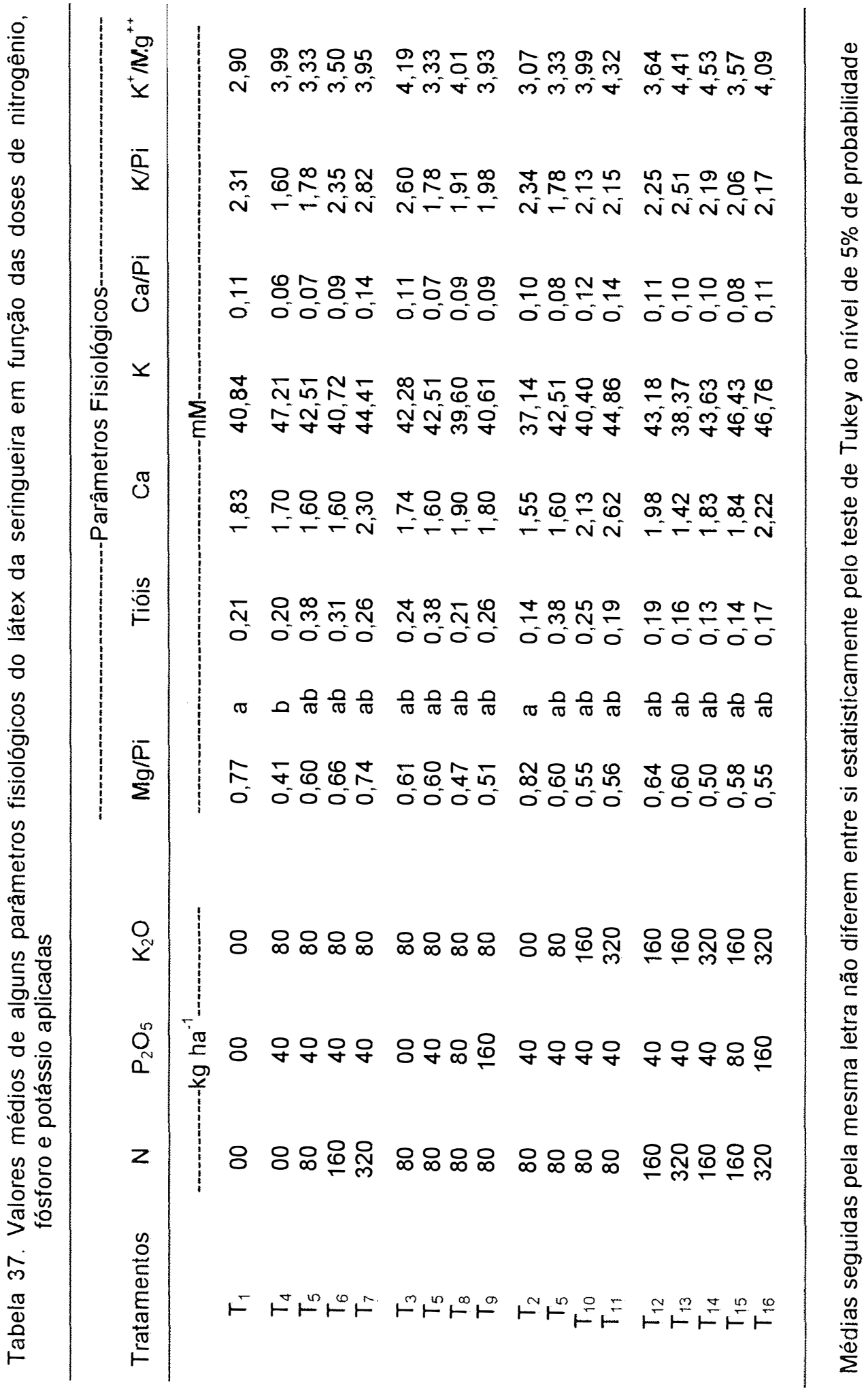




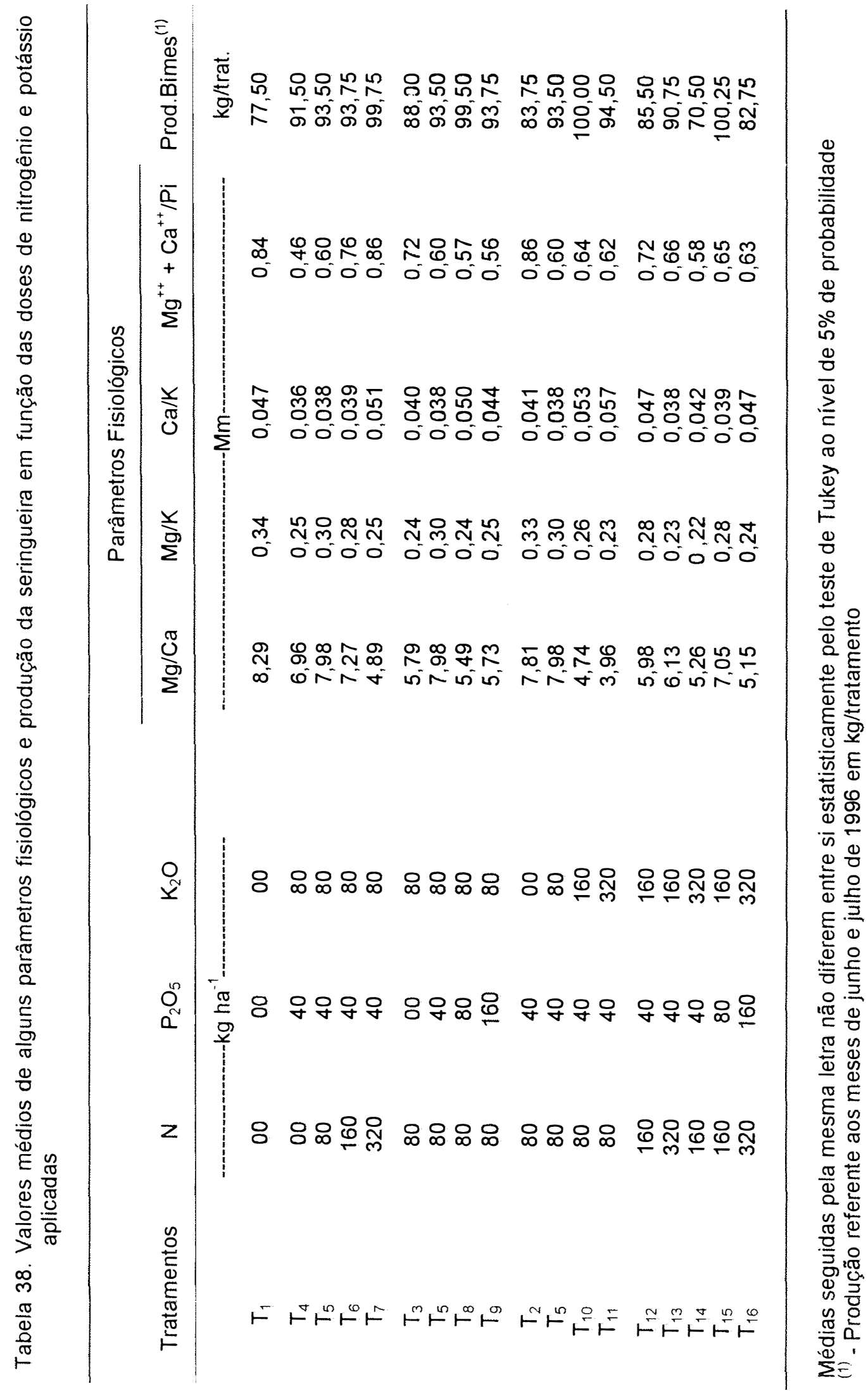


Na tabela 39 encontram-se os resultados analíticos da diagnose do látex determinados no presente estudo. De maneira geral, para demonstrar as bases sólidas da diagnose do látex, é necessário examinar as relações interparamétricas, se possivel, juntas, ligando esse critério com a produção (Jacob et al., 1989b).

Na tabela 39 observa-se que, o tratamento 8 (80160-80) foi o único tratamento que apresentou valores de parâmetros fisiológicos caracterizando um estado de superexploração das plantas. Nota-se também que grande parte dos tratamentos que receberam os niveis mais baixos de nitrogênio mostraram uma tendência de super-exploração das seringueiras.

O conteúdo de sacarose foi baixo, provavelmente como resultado do fornecimento limitado, ou seja, esgotamento do estoque elou fenômeno de translocação ativa. A fase final da super-exploração é acompanhada por um aumento do teor de sacarose, indicando a paralisação do metabolismo nos laticíferos esgotados (Jacob et al., 1989b).

Em relação aos teores baixos de tióis encontrados (0,13-0,38mM), uma provável explicação para tais resultados, pode ser devido ao processo de degeneração oxidativa, uma vez que, os tióis ou grupo R-SH desempenham importante papel na proteção das membranas das organelas do látex retendo as formas tóxicas de oxigênio (Jacob et al., 1989b).

Niveis adequados de tióis controlam a estabilidade coloidal do látex e consequentemente o fluxo, equilibrando a intensidade metabólica e portanto a regeneração do látex. No caso de super-exploração, o fenômeno de secamento de painel que se desenvolve é a prova da existência de mecanismo que degradam os sistemas laticíferos, quando os teores de tióis não encontram-se em níveis adequados.

Os valores de fósforo inorgânico encontrados no presente estudo, caracterizados como valores adequados $(>10$ 


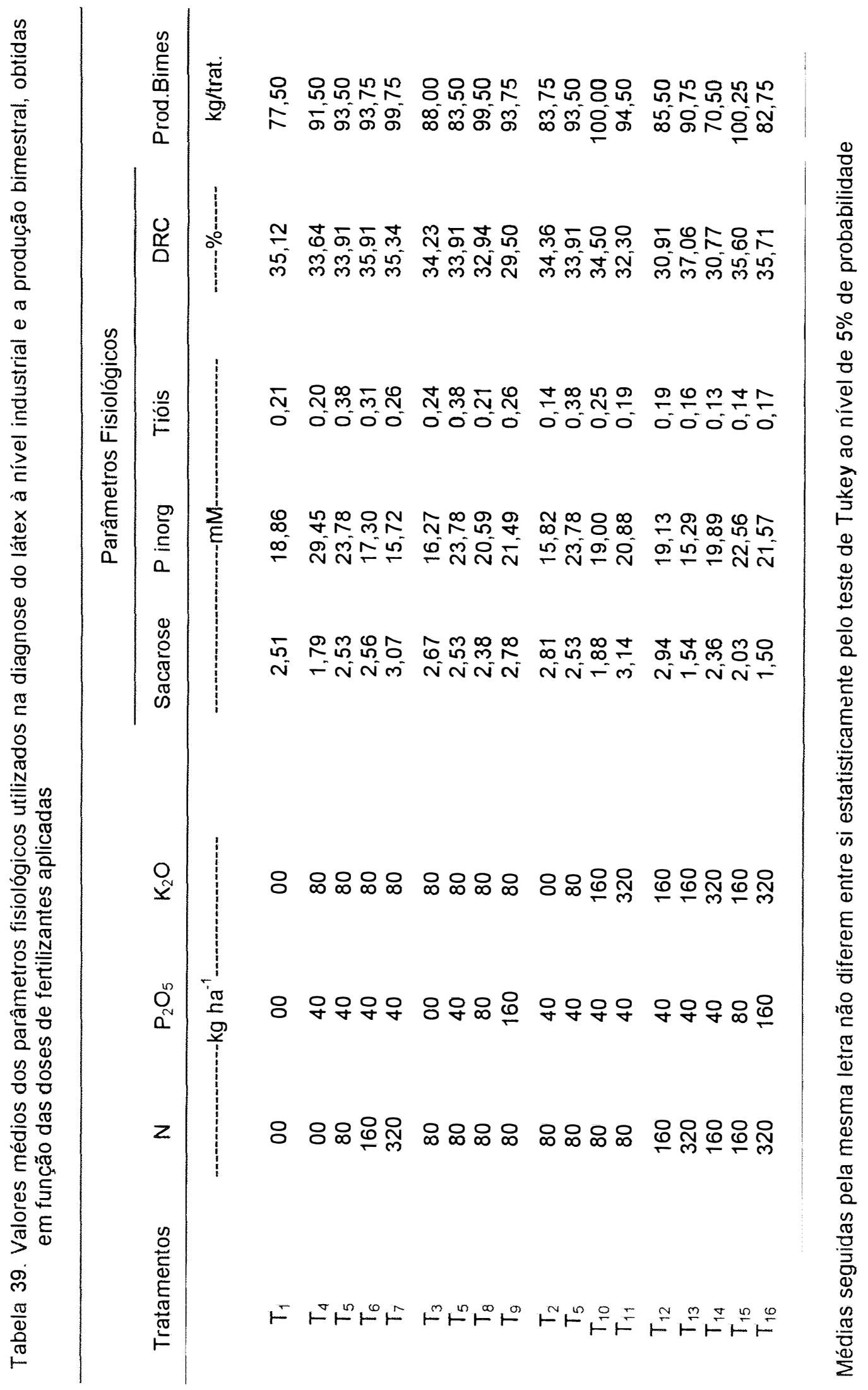


Os valores de fósforo inorgânico encontrados no presente estudo, caracterizados como valores adequados ( $>10$ e $<20 \mathrm{mM}$ ) ou, quando acima de $20 \mathrm{mM}$, como sendo indicação de super-exploração das seringueiras, provavelmente indicam uma hidrólise ativa da fosfatase inorgânica, produzida pela transferase da borracha, responsável pelo alongamento da cadeia de polisopreno e, podendo indicar também uma ineficiente utilização desse ânion no metabolismo, na fase final da super-exploração (Jacob et al., 1989b).

O mau funcionamento dos laticíferos conduz a um ligeiro aumento no conteúdo de sólidos totais, resultando em um sério problema de translocação de água. A variação observada na tabela 39 em torno de 29,50 a 37,06 permite inferir que alguns tratamentos poderão, posteriormente, apresentar problemas de fluxo e consequentemente, de produçáo. 


\section{CONCLUSÕES}

O solo continuou ácido, com baixos teores de $\mathrm{Ca}$ e Mg trocáveis, necessitando, portanto, de uma calagem com calcário dolomitico. O $\mathrm{K}$ trocável encontrava-se baixo para a maioria dos tratamentos, requerendo a aplicação de dose mais alta $\left(320 \mathrm{~kg} \mathrm{ha}^{-1}\right)$.

As concentrações de nitrogênio, fósforo e enxofre nas folhas, e o teor de fósforo no solo encontravam-se em niveis adequados, portanto, recomenda-se adubação de manutenção.

A análise foliar efetuada em amostras coletadas fevereiro de 1995 revelou baixos teores de $\mathrm{Cu}$ e $\mathrm{B}$, mostrando a necessidade de adubação para elevar a concentração desses micronutrientes nas seringueiras.

O potássio proporcionou maior desenvolvimento da seringueira e apresentou resposta de natureza linear.

Entre os niveis estudados, o nivel $N_{1} P_{1} K_{3}$ foi quem possibilitou que a seringueira atingisse o diâmetro adequado para o inicio de exploração aos sete anos de idade.

As doses de $\mathrm{N}$ diminuiram o teor de $\mathrm{Pi}$ de 29,45 para $15,72 \mathrm{mM}$; aumentaram o teor de sacarose de 1,79 para $3,07 \mathrm{mM}$ e aumentaram a relação $\mathrm{Mg}^{++} / \mathrm{Pi}$ de 0,41 para 0,72 $\mathrm{mM}$.

As doses crescentes de fósforo diminuiram a percentagem de borracha seca ( $\% D R C$ ) de $34,23 \%$ para $29,50 \%$. 
As plantas que receberam os tratamentos 80-16080 apresentaram valores dos parâmetros fisiológicos indicando uma situação de super-exploração. As plantas dos tratamentos que receberam as menores doses de nitrogênio $(00$ e $80 \mathrm{~kg}$ ha ${ }^{-1}$ ) também mostraram uma tendência de super-exploração. 


\section{REFERÊNCIAS BIBLIOGRÁFICAS}

ANANTH, K.C.; GEORGE, C.M.; MATHEW, M. \& UNNI, R.G. The report of the results of fertilizer experiments with young rubber in South india. Rubber Board Bulletin, v. 9, n. 1, p. 30-42. 1966.

ASSOCIAÇÃO PAULISTA DE PRODUTORES E BENEFICIADORES DE BORRACHA-APABOR. A borracha na Asia. Informe Técnico $N^{0}$ 22/94. São José do Rio Preto. 2p., 1994

BATAGLIA, O.C. \& CARDOSO, M. Situação nutricional dos seringais de São Paulo. In: SIMPÓSIO DA CULTURA DA SERINGUEIRA, 2, Piracicaba.Anais... Piracicaba, USP/ESALQ, p.89-97, 1987.

BATAGLIA, O.C.; CARDOSO, M.; CARRETERO, M.V. Situação nutricional de seringais produtivos no Estado de São Paulo. Bragantia, v. 47, n.1, p.109-123, 1988.

BATAGLIA, O.C.; CARDOSO, M.; IGUE, T. \& RAIJ, B.V. Desenvolvimento da seringueira em solos do Estado de São Paulo. Pesquisa Agropecuária Brasileira, Brasilia, v. 22, n. 4 , p. 419-24, 1987b.

BEAUFILS, E.R. Research for rational explotation of Hevea using a physiological diagnosis based on the mineral analysis of various parts of the plants. Fertilite, v. 3, p. 227-28, 1957. 
BERNIZ, J.M.J. Influência de N,P,K, em seringueira jovem (Hevea brasiliensis Muell. Arg.). Viçosa-UFV. 1987. 59p.(Tese) Universidade Federal de Viçosa.

BOLTON, J. \& SHORROCKS, V.M. The effect of magnesium limestone and other fertilizers on mature plantings of Hevea brasiliensis. Journal of the Rubber Research Institute of Malaya. V. 17, n. 2, p. 31-39, 1960.

BOLTON, J.C. The response of imature Hevea brasiliensis to fertilizers in Malaya. I. Experiments in Shale-derived soils. Journal of the Rubber Research Institute Malaya, Kuala, Lumpur, v. 18, n. 2, p. 67-79, 1964.

BOX, G.E.P.; HUNTER, W.G. Jr.; HUNTER, J.S. Statistics for experimenters: An introdution to design, data analysis and model building. New York: Wiley-Interscience, 653p. 1973.

BRASIL. Superintendência da Borracha. O genero Hevea Descrição das Espécies e Distribuição Geográfica. In.: Plano Nacional da Borracha. 64p. 1971.

BREMNER, J.M. Inorganic forms of nitrogen. In: BLACK, C,A, ed. Methods of soil analysis. Part. 2. Madison. America Society of Agronomy, 1965. P.1179-1237.

CARDOSO, M. Instruções para a cultura da seringueira. 2.ed. Rev. Atual. Campinas, Instituto Agronômico. 42p. (Boletim, 196), 1980.

CASTRO, P.R.C. Bases fisiológicas da produção e da estimulação de Hevea brasiliensis Muell Arg. In: BERNARDES, M.S. Sangria da seringueira, Piracicaba, ESALQ/USP - FEALQ, 1-25, 1990. 
CHAN, H. Y. \& PUSHPARAJAH, E. Produtivity potentials of Hevea on West Malaysian soils. A preliminary assessment, in Proc. Rubber Res. Inst. Malays. Plant. Conf. Rubber Research Institute Malaysia, Kuala Lumpur, p.97, 1972.

CHAN, H. Y.; WONG, C.B.; SIVANADYAN, K.; PUSHPARAJAH, E. Influence of soil morphology and physiography and leaf nutrient content and performance of Hevea, In: Proc. Rubber Res. Inst. Malaysia, Plant. Conf., Rubber Research Institute Malaysia, Kuala Lumpur, p.115, 1974.

CHAPMAN, G.W. Leaf analysis and plant nutrition. Soil Science, Baltimore, v.52, p. 63-66, 1941.

COELHO, L.C.; BARROS, N.F.; NEVES, J.C.L.; ALVAREZ, V.; MAGALHÃES, A.B. \& GUERRA, C.C. Necessidade de calagem, adubação potássica e relações cálcio, magnésio e potássio para a produção de porta-enxertos de seringueira. In: ANAIS DA XX REUNIÃO BRASILEIRA DE FERTILIDADE DE SOLOS E NUTRIÇÃO DE PLANTAS, Piracicaba, S.P. p.366-367, 1992.

CONDURÚ NETO, J.M.H. Fatores limitantes e parâmetros fisiológicos da produção da seringueira. Belém, FCAP, 20p. (Informe Técnico, 10), 1987.

CONSTABLE, D.H. \& hODNETT, G.E. The response of Hevea brasiliensis to fertilizers in Ceylon. Empire Journal of Experimental Agriculture, v.27, n.106, p.150-15, 1959.

CORTEZ, J.V. Histórico e expansão da cultura da seringueira no Estado de São Paulo. In: SIMPÓsIo SOBRE A CULTURA DA SERINGUEIRA NO ESTADO DE SÃO PAULO, 1, Piracicaba, Anais. Piracicaba, ESALQ. 1-10, 1986. 
D'AUZAC, J. \& JACOB, J.L. The composition of latex from Hevea brasiliensis as a lacticiferous cytoplasm. In: D'AUZAC, J.; JACOB, J.L. \& CHRESTIN, H. Physiology of rubber tree latex. Boca Raton, CRC. Press Inc., Florida, p. 59-96. 1989.

D'AUZAC, J. Factores envolved in the stopping of flow after tapping. In: D'AUZAC, J.; JACOB, J.L. \& CHRESTIN, H. Physiology of rubber tree latex. Boca Raton, CRC. Press Inc., Florida, p. 257-85. 1988b.

DEAN, W. A luta da borracha no Brasil. Um estudo de história ecológica. São Paulo, Nobel, 286p. 1989.

DUCKE, A. Novas contribuições para o conhecimento das seringueiras da Amazônia Brasileira. Il. jan. 1946. (Boletim técnico).

FALLOWS, J.C. The major elements in the foliage of Hevea brasiliensis and their inter-relations. Proceedings of the Natural Rubber research Conference, 1960, Kuala Lumpur, Malaysia, p. 142-153, 1961.

GOMES, F. P. Curso de Estatística Experimental, $8^{\underline{a}}$ ed. São Paulo. ESALQ/USP. Editora Nobel, 430p. 1979.

GONÇALVES, P.S. Melhoramento genético da seringueira (Hevea spp.) In: SIMPÓSIO SOBRE A CULTURA DA SERINGUEIRA NO ESTADO DE SÃO PAULO, 1. Piracicaba, 1986. Anais. Piracicaba, ESALQ, p.95-123, 1986. 
GONÇALVES, P.S.; CARDOSO, M.; MENTE, E.M.; MARTINS, A.L.M.; GOTTARDI, M.V.C.; ORTOLANI, A.A. Desempenho preliminar de clones de seringueira na região de São José do Rio Preto, Planalto do Estado de São Paulo. Bragantia, v. 52, n.2, p.119-130, 1993.

GONÇALVES, P.S.; VASCONCELLOS, M.E.; SILVA, E.B. Desenvolvimento vegetativo de clones de seringueira. Pesquisa Agropecuária Brasileira, v. 14, n. 4, p.365-375, 1979.

GUHA, M.M. ; NARAYANAN, R. Variations in leaf nutrient status in relation to soil type. Journal of Rubber Research Institute of Malaya, v. 21, p. 225, 1969.

HAAG, H. P.; BUENO, N.; PEREIRA, J.P. Exigências minerais em uma cultura de seringueira. In. SIMPÓSIO SOBRE A CULTURA DA SERINGUEIRA NO ESTADO DE SÃO PAULO, 1., Piracicaba, 1986. Anais. Piracicaba, ESALQ, 1986. p.33-82.

HAINES, W.B. ; CROWTHER, E. M. Manuring Hevea. III. Results on young buddings in British Malaya. Empire Journal Experimental Agriculture, v. 8, p. 170-84, 1940.

INTERNATIONAL RUBBER DIGEST. Brasil: Rubber tree beeing planted; natural rubber consumption, production and stocks, $v$. 49, n. 1, p. 15-16, Julho 1995.

IRCA. Métodos para determinação de parâmetros fisiológicos do látex utilizados pelo Institut de Recherches sur le Caoutchouc (IRCA). 1985. s.n.t.

JACOB, J.L.; PREVOT, J.C.; LACROTTE, R.; ESCHBACH, J.M. Le diagnostic latex. Platations, Research, Development. V.2, n.2, p. 33-37, 1995a. 
JACOB, J.L.; PREVOT, J.C.; SAINTE BEUVE, J.; BONFILS, F.; deLIVONNIERE, $H$. La filiere latex naturel concentre; de la cellule laticifere au gant du chirurgien. Platations, Research, Development. v.2, n.6, p.31-35, 1995b.

JACOB, J.L.; PREVOT, J.C.; KEKWICK, R.G.O. General metabolism of Hevea brasiliensis latex (with the exception of isoprenic anabolism).In: D'AUZAC, J.; JACOB, J.L. ; CHRESTIN, $H$. Physiology of rubber tree latex. Boca Raton, CRC. Press, 1989a.p.101-41

JACOB, J.L. ; PREVOT, J.C.; ROUSSEL, D.; LACROTTE, R.; SERRES, E.; D'AUZAC, J.; ESCHBACH, J.M. ; OMONT, H. Yield-limiting factores, latex physiological parameters, latex diagnosis, and clonal typology. In: D'AUZAC, J.; JACOB, J.L. ; CHRESTIN, H. Physiology of rubber tree latex. Boca Raton, CRC. Press. 1989b. p.345-82

JACOB, J.L. ; PREVOT, J.C.The metabolism of the laticiferous cells of Hevea brasiliensis. In: D'AUZAC, J.; JACOB, J.L. ; CHRESTIN, H. Physiology of rubber tree latex. Boca Raton, CRC. Press. 1989. p.79-100

JACOB, J.L.; SERRES, E.; PREVOT, J.C.; LACROTTE, R.; VIDAL, A.; ESCHBACH, J.M. ; D'AUZAC, J. Mise au point du diagnostic latex chez l'hevea. Agritrop, v. 12, p. 97-115, 1988a.

JOSEPH, M.; AMMA, M.K. ; MATHEW, M. Distribution of potassium in the major rubber growing soils of South India. Indian Journal of Natural Rubber Research, v. 3, n. 1, p. 29-34, 1990. 
JOSEPH, M.; MATHEW, M.; SETHURAJ, M.R. ; RANGANATHAN, C.R. Diagnosis and recomendation integrated system: 1 . Formulation of DRIS norms for Hevea brasiliensis. Indian Journal of Natural Rubber Research, Bangalore; India, v. 6, n. 1-2, p. 117-122, 1993.

KALAM, M.A. Effect of fertilizer application on growth and leaf nutrient control of some important Hevea brasiliensis clones. Rubber Board Bulletin, v. 16, n. 1, p. 19-29, 1970.

KITAMURA, M.C. Influência dos níveis de nitrogênio, fósforo, potássio e magnésio no desenvolvimento da seringueira jovem (Hevea brasiliensis Muell. Arg.) em um solo sob cerrado de Mato Grosso do Sul. Lavras, 1992. 90p. Dissertação (Mestrado) - Escola Superior de Agricultura de Lavras.

KRISHNAKUMAR, A.K.; THOMAS, E.; NAGESWARA, R.; POTTY, S.N. ; SETHURAJ, M.R. Ecological impact of rubber (Hevea brasiliensis) plantations in North East India. 1. Influence on soil physical properties with special reference to moisture retention. Indian Journal of Natural Rubber Research, v. 3, n. 1, p. 53-63, 1990.

LEMOS FILHO, J.P.; PINTO, H.S.; ROCHA NETO, O.G. Temperaturas de sub-resfriamento e de congelamento em folhas maduras de seringueira. Pesquisa Agropecuária Brasileira,v. 26, n. 7, p. 995-1000, 1991.

MAINSTONE, B.J. Manuring of Hevea VI. Some Long. Term. manuring effects, with special reference to phosphorus, in one of the DUNLOP (Malaysia) experiments. Empire Journal of Experimental Agriculture, v. 31, p. 175-185, 1963. 
MALAVOLTA, E. Manual de química agrícola: nutrição de plantas e fertilidade do solo. São Paulo: Agronômica Ceres, 1976. $528 p$.

MALAVOLTA, E.;. VITTI, G. C; OLIVEIRA, S. A. Avaliação do estado nutricional das plantas: principios e aplicações. Piracicaba: POTAFOS, 1989. $201 \mathrm{p}$.

MARSCHNER, H. Manual nutrition of higher plants. Hohenheim: Institute of Plant Nutrition, University of Hohenheim, 1986. $674 p$.

MARTIN, N.B. ; ARRUDA, S.T. A produção brasileira de borracha natural: situação atual e perspectivas. Informações Econômicas, v. 22, n. 7, p. 37-65, 1993.

MINISTÉRIO DA AGRICULTURA. Levantamento de reconhecimento dos solos do Estado de São Paulo. Contribuição a Carta de Solos do Brasil. Boletim do Serviço Nacional de Pesquisas Agronômicas, n.12, p.198-203, 1960.

MIRANDA, E.R.; ROSAND, P.C.; SANTANA, C.J.L. Requerimentos nutricionais e adubação do cultivo da seringueira. CEPLAC/CEPEC, Ilheus: CEPLAC, CEPEC, 1975. 32p. (Boletim Técnico, 33).

ORTOLANI, A.A. Efeito das temperaturas extremas no desenvolvimento e produção da seringueira. In: SIMPÓSIO DA CULTURA DA SERINGUEIRA. 2, Piracicaba, 1987. Anais, Piracicaba: ESALQ, 1987. p.1-12 
PANNOJE, K.J. ; POTTY, S.N. Responses of Hevea brasiliensis to fertilizer in South India. In: RUBER RESERARCH INSTITUTE OF MALAYSIA PLANTERS' CONFERENCE, Kuala Lumpur, 1975. Proceedings. Kuala Lumpur: R.R.I.M., 1975. p. 84-105.

PUSHPADAS, M.V. ; AHAMMED, M. Nutritional requirements and manurial recommendations. In: PILLAY, P.N.R., ed. Handbook of natural rubber production in India. Kottayan: Rubber Research Institute of India, 1980.

PUSHPARAJAH, E. ; TAN, K.T. Factors influencing leaf nutrient levels in rubber. In: RUBER RESERARCH INSTITUTE OF MALAYSIA PLANTERS' CONFERENCE, Kuala Lumpur, 1975. Proceedings. Kuala Lumpur: R.R.I.M., 1972. p. 140.

PUSHPARAJAH, E. Nutritional status and fertilizer requirements of Malaysia on soil for Hevea brasiliensis. Chent State, 1977. 275p. Thesis (Doctor) - University Ghen Belgium.

PUSHPARAJAH, E. Recent development in the nutrition of Hevea in West Malaysia. Quarterly Journal of the Rubber Research Institute of Sri Lanka, v. 50, n. 1-2, p. 68-83, 1973.

PUSHPARAJAH, E.; CHAN, H. Y. ; SIVANADYAN, K. Recent development for reduced fertilizer applications for Hevea. In: RUBER RESERARCH INSTITUTE OF MALAYSIA PLANTERS' CONFERENCE, Kuala Lumpur, 1975. Proceedings. Kuala Lumpur: R.R.I.M., 1983. p. 313. 
PUSHPARAJAH, E.; SIVANADYAN, K.; P'NG, T.C. ; NG, E.K. Nutritional requirements of Hevea brasiliensis in relation to stimulation. In: In: RUBER RESERARCH INSTITUTE OF MALAYSIA PLANTERS' CONFERENCE, Kuala Lumpur, 1975. Proceedings. Kuala Lumpur: R.R.I.M., 1971. p. 1-11.

RAIJ, B. VAN; QUAGGIO, J. A. Métodos de análises de solos para fins de fertilidade do solo. Campinas, IAC, 1983. 31p. (IAC. Boletim Técino, 81)

RAIJ, B. VAN. Fertilidade do solo e adubação. São Paulo: Agronômica Ceres, 1991. p.90-95.

RAIJ, B. VAN. Recomendações de adubação e calagem para o Estado de São Paulo. (IAC. Boletim Técnico. 100), Campinas: 1985. $107 p$.

REIS, E.L. Fracionamentos e métodos de aplicação de fertilizantes no desenvolvimento da seringueira. In: REUNIÃO BRASILEIRA DE FERTILIDADE DE SOLO E NUTRIÇÃO DE PLANTAS, 20., Piracicaba, 1992. Anais. Piracicaba: SBCS, 1992. P. 294-295.

REIS, E.L.; CABALA-ROSAND, P. Eficiência dos fertilizantes aplicados nas fases pré e pós-sangria da seringueira. Revista Theobroma, v. 18, n. 3, p.189-200, 1988.

REIS, E.L.; SANTANA, C.J. ; ROSAND, P.C. Influência da calagem e adubação na produção da seringueira no Sul da Bahia. Revista Theobroma, v. 14, n. 1, p. 33-44, 1984 a. 
REIS, E.L.; SOUZA, L.F.S. ; MELLO, F.A.F. Influência da aplicação de nitrogênio, fósforo e potássio sobre o desenvolvimento da seringueira Hevea brasiliensis Muell. Arg.) no sul da Bahia. Revista Theobroma, v. 14, n. 1, p. 45-52, $1984 b$.

RUBBER RESEARCH INSTITUTE OF MALAYA. Cycle of nutrients in rubber plantation, Planters Bulletin of the Rubber Research Institute of Malaysia, v.120, n.73, p. 73-81. 1972.

RUBBER RESEARCH INSTITUTE OF MALAYA. Some physical factors of soils, Planters Bulletin of the Rubber Research Institute of Malaysia, v.115, n.220, 1971.

RUBBER RESEARCH INSTITUTE OF MALAYSIA. Manual for diagnosing nutritional requirements for Hevea. Kuala Lumpur: RRIM, 1990.

SÁ, T. D. DE A. Avaliação ecofisiológica de seringueiras (Hevea brasiliensis Muell. Arg.) submetida a diferentes intensidades de sangrias, em ambientes contrastantes do Estado de São Paulo. Campinas, 1991.114p. Tese (Doutorado)-Universidade Estadual de Campinas.

SANTANA, C.J.L. de; CABALA ROSAND, F.P. ; VASCOCELOS FILHO, A.P. 1977. Fertilidade dos solos ocupados com seringueira no sul da Bahia e grau de tolerância dessa cultura ao aluminio. Revista Theobroma, v. 7, n. 4, p. 125-32, 1977.

SARRUGE, J.R. ; HAAG, H.P. Análises químicas em plantas. Piracicaba: ESALQ, Departamento de Química, 1974. 56p. 
SHORROCKS, V.M. Deficiências minerais em Hevea e plantas de cobertura associadas. Brasilia: Superintendência da Borracha, 1979. $76 p$

SHORROCKS, V.M. Leaf analysis as a guide to the nutrition of Hevea brasiliensis. 5. Leaf sampling technique for the nature rubber. Journal of Rubber Research Institute of Malaya, v. 17, p. $167-190,1962$.

SHORROCKS, V.M. Mineral nutrition growth and nutrient cicle of Hevea brasiliensis, I. Growth and nutrient content. Journal of Rubber Research Institute of Malasya, v. 19, n. 1, p. 3248,1965 .

SUPERINTENDENCIA DA BORRACHA. Plano Nacional da Borracha. solos. Brasilia: MIC/SUDHEVEA, 1971b. $147 p$.

SYVANADIAN, K. ; HARIDAS, G.; PUSPARAJAH, E. Reduced imaturity period of Hevea brasiliensis. In: RUBER RESERARCH INSTITUTE OF MALAYSIA PLANTERS' CONFERENCE, Kuala Lumpur, 1975. Proceedings. Kuala Lumpur: R.R.I.M., 1975. p. $147-157$.

WATSON, G.A. Nutrition. In: Webster, C.C. ; Baulkwill, W.J., ed. Hevea. New York: Longman, 1989. p.290-347.

WEBSTER, C.C. ; PAADEKOOPER, E.C. The botany of the rubber tree. In: WEBSTER, C.C. ;BAULKWILL, W. J. Rubber. New York, Longman, 1989. p.57-84.

YIP, E. ; GOMEZ, J.B. Factors influencing the colloidal stability of fresh clonal Hevea latices as determined by the aerosol OT test. Journal of the Rubber Research Institute of Malaysia, v. 28 , p. $86-106,1980$. 